\title{
A client-centered approach to reproductive health: A trainer's manual
}

Population Council

Follow this and additional works at: https://knowledgecommons.popcouncil.org/departments_sbsr-rh How does access to this work benefit you? Let us know!

\section{Recommended Citation}

"A Client-centered Approach to Reproductive Health: A Trainer's Manual." Islamabad: Population Council, 2005. 


\section{A Client-Centered Approach to EPRODUCTIVE HEALTH}

\section{A Trainer's Manual}

February 2005

\section{Population Council}


A Client-C entered Approach to Reproductive $\mathrm{H}$ ealth A Trainer's Manual

February 2005

12 Population Council 


\section{For further inquiries:}

\section{(2) Population Council}

\#7, St. 62, F-6/3, Islamabad, Pakistan. Ph: 92512277439 Fax: 9251821401

Email: info@pcpak.org Web: www.popcouncil.org 


\section{Table of contents}

\section{SECTION I}

1. ABOUT THE MANUAL 3

1.1. The manual's target audience 3

1.2. The manual's adaptability 3

1.3. How to use the manual 4

2. ABOUT THE TRAINING 5

2.1. The trainers 5

2.2. The training environment 6

3. THE TRAINING METHODOLOGIES 7

3.1. Go-around 7

3.2. Brainstorming, briefings, group discussions 8

3.3. Role-play 9

3.4. Case study 10

3.5. Video of client-provider interaction $\quad 10$

3.6. Games and energizers 11

4. TRAINING MATERIALS ANDTOOLS 12

4.1. Writing board 12

4.2. Flipchart, flipchart stand and newsprint 13

4. 4. Charts 13

4.5. Forms, assessment sheets 14

4.6. Zopp cards 14

4.7. Additional tools required 14

4.8. Checklist of materials and tools 15

4.9. Abbreviations used in the training 16

4.10. Schedule for training in client-centered approach 17 


\section{SECTION II}

MOdULE 1: GETTING STARTED

Getting started: Schedule/ overview/ materials/ objectives/ key learning points

Activity 1: Objectives of training

Activity 2: Introductions

Activity 3: Hopes, fears and contributions

Activity 4: Training norms

Activity 5: Setting the training climate

MOdULE 2: SELF-AWARENESS

Self-awareness: Schedule/ overview/ materials/ objectives/ key learning points

Activity 1: Ideal health worker

Activity 2: Self-awareness

Activity 3: J 0-Hari window

Activity 4: Who am I?

MOdULE 3: REFLECTIONS AND GO-AROUND

Reflections and go-around: Schedule/ overview/ objectives 48

Activity 1: Reflections $\quad 50$

Activity 2: Sharing experiences 51

MOdULE 4: VISION OF IDEAL SOCIETY 53

Ideal society: Schedule/ overview/ materials/ objectives/learning points 53

Activity 1: Vision 55

Activity 2: Role of an individual 57

MOdule 5: Gender $\quad 59$

Gender: Schedule/ overview/materials/ objectives/ learning points 61

Activity 1: Sex and gender 63

Activity 2: Roles and attributes of men and women 64

Activity 3: Gender discrimination 66 
$\begin{array}{ll}\text { Activity 4: Attitudes and values } & 69\end{array}$

MOdULE 6: COMMUNICATION 73

Communication: Schedule/ overview/ materials/ obj ectives/ learning points

Activity 1: Definition and elements of communication 77

Activity 2: Barriers to communication 80

Activity 3: Types of communication 82

MODULE 7: TOOLS OF COMMUNICATION 87

Tools of communication:

Schedule/ overview/ materials/ obj ectives/ learning points 84

Activity 1: Communication tools $\quad 91$

Activity 2: Types of questions 94

Activity 3: Listening $\quad 97$

Activity 4: Client-provider interaction $\quad 99$

GAMES/ENERGIZERS/ EXERCISES

$\begin{array}{ll}\text { MODULE 8: BEHAVIOR } & 103\end{array}$

Behavior: Schedule/ overview/ materials/ obj ectives/ learning points 105

Activity 1: Definitions $\quad 100$

Activity 2: Types of behavior $\quad 110$

Activity 3: Demonstration of types of behavior 112

MOdULE 9: POWER 115

Power: Schedule/ overview/ materials/ objectives/ learning points 117

$\begin{array}{ll}\text { Activity 1: Meaning and sources of power } & 119\end{array}$

$\begin{array}{ll}\text { Activity 2: Types of power } & 122\end{array}$

GAMES/ENERGIZERS/ EXERCISES

MODULE 10: SAHR 127

SAHR: Schedule/ overview/ materials/ objectives/ learning points 129

Activity 1: SAHR background: motivation, counseling, and negotiation 132

Activity 2: SAHR components 134

$\begin{array}{ll}\text { Activity 3: Application of SAHR } & 137\end{array}$

Activity 4: SAHR in action 141 
MODULE 11: REFERRAL SYSTEM

Referral system: Schedule/ overview/materials/ obj ectives/ learning points

Activity 1: Referrals

136

Activity 2: Referral system and protocol

173

Module 12: Perception Of Change

Perception of change: Schedule/ overview/materials/ objectives/ learning points

Activity 1: Change

MODULE 13: TEAM BUILDING

Team building: Schedule/ overview/ materials/ objectives/ learning points

Activity 1: Importance of team work

Activity 2: Factors involved in team-building

164

MOdULE 14: EVALUATION AND CONCLUSION OF TRAINING

Evaluation and conclusion:

Schedule/ overview/ materials/ objectives/ learning points

Activity 1: Evaluation

Activity 2: Conclusion 


\section{SECTION III}

TRAINING MATERIAL ${ }^{1}$

Training material 1.1: Objectives of the training 173

Training material 1.2: What is a client-centered approach? 174

Training material 1.3: Reproductive health 175

Training material 1.4: Young-old lady picture 176

Training material 2.1: Self-awareness 178

Training material 2.2: J o-Hari window 179

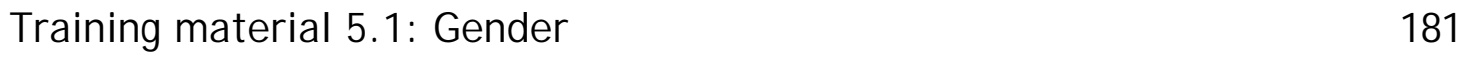

Training material 5.2: Statements to put on Zopp cards 171

Training material 6.1: Communication and components of communication 172

Training material 6.2: Role-play on communication/feedback 174

Training material 6.3: Barriers to commuication: clarification 175

Training material 6.4: Exercise on overcoming communication $\begin{array}{ll}\text { barriers } & 179\end{array}$

Training material 6.5: Role-plays for mixed messages 181

Training material 7.1: Tools of communication 197

Training material 7.2: Statements for Zopp cards 199

Training material 7.3: Types and examples of questions 189

Training material 7.4: Alternate listening exercise 191

Training material 7.5: Listening 192

Training material 7.6: Alternative presentation $\quad 194$

Training material 8.1: Behavior 196

Training material 8.2: Role-plays 201

\footnotetext{
${ }^{1}$ Note: Training materials are numbered by module and the order in which they appear within the module; they are not numbered sequentially. They are indicated in the modules by the letters TM.
} 
Training material 9.1: Power

Training material 9.2: Change and power dynamics

Training material 10.1: Definitions of communication components

Training material 10.2: Introduction to the concept of SAHR

221

Training material 10.3: Posters showing SAHR approach

212

Training material 10.4a: SAHR guidelines at work for static center workers

215

Training material 10.4b: SAHR guidelines at work for community workers

Training material 10.5a: Salutation $\&$ assess: Case studies for static center workers

Training material 10.5b: Salutation $\&$ assess: Case studies for community workers

Training material 10.5c: Help \& reassure: Case studies for static center workers

Training material 10.5d: Help \& reassure: Case studies for community workers

Training material 10.6a: Salutation $\&$ assess: Role-plays for static center workers

Training material 10.6b: Salutation \& assess: Role-plays for community workers

Training material 10.6c: Help \& reassure: Role-plays for static center workers

Training material 10.6d: Help and reassure: Role-plays for community workers

Training material 10.7: Assessment sheet

Training material 10.8: Alternative presentation

Training material 11: New dimension of referral system

Training material 12: Perception of change

Training material 13.1a: Broken squares game: preparation

Training material 13.1b: Broken squares game: instructions for game and players 
Training material 13.1c: Broken squares game: instructions for rapporteur

Training material 13.2: Factors involved in team building 259

Training material 14.1: Training evaluation form 260

Training material 14.2a: Poem (in Urdu) 262

Training material 14.2b: Poem (in English) 254

Training material: Games/ Energizers/ Exercises 256 


\section{ACKNOWLEDGEMENTS}

The concept of SAHR evolved out of profound and often deep arguments about what exactly was required to change the attitude and behaviour of health care providers. The essence of the client centered approach is designed to make health care providers more receptive to the need of clients and responsive to clients' situations beyond just their immediate health problems. The Population Council, Islamabad is extremely proud to be associated with the SAHR training, which has been recognized, by Government and NGOs in Pakistan. We hope that it will have utility internationally, in settings similar to Pakistan, where it can help bring about significant improvements in quality of care and enhance utilization of services in the public and private sectors.

The groundwork that lead up to the formulation of the training benefited from inputs from many professionals. Deep gratitude is due to Dr. Anrudh J ain who brought the concept of quality of care and the importance of improving conditions of reproductive health services in countries like Pakistan. Several others contributed to the early debate and in particular Dr.Safia Ameen, Dr. Albert Henn, Mr. Peter Miller, Ms. Yasmin Zaidi are acknowledged for their intellectual contribution. Dr. Ambreen Ahmed was the person who first introduced the concept of the psychological principles of self awareness which in turn contribute towards behavior change within individuals. ROZAN, an NGO that does such training in the public and private sector, carried out the master training for our trainers.

A core team from the Population Council was involved from the beginning to the end: Drs Gul Rashida and Zakir Hussain have been the heart of this training and development of the manual. Dr. Ali Mir has been a core member at various stages of the course development. Mr. Fayyaz Khan contributed towards the communication part of the training. This team expanded the ROZAN training much further, combined it with examples in reproductive health rooted in the Pakistani context and evolved the six day training course, which is described in this manual. They have been assisted through out by Bushra Bano, Saima Pervez who continue to help them with training 
programs. Lubna Shireen, Zeba Tasneem and Tayyaba Gul were also an essential part of the core team during earlier trainings in Sargodha

The manual was edited earlier by Mary D'Souza. It was later transformed into the shape of a training manual by the very detailed rewriting of Pam Ledbetter. Formatting of the manual was initially done by Khurram Shehzad; and it was finalized in its current form including cover design and lay out by Mehmood Asghar.

This project has been funded initially by Rockefeller Foundation and Population Council central funds. Later the UNFPA sponsored the training of master trainers on the basis of a draft manual. The finalization and printing of this manual has been funded by the European Union.

Finally, we acknowledge the encouragement derived from the faces of several hundred trainees especially community based workers and paramedics, that inspired us to put this manual together. We hope that it will go a long way in improving the quality of care of reproductive health services in Pakistan and elsewhere.

\section{Dr. Zeba A. Sathar}

Country Director

Population Council, Islamabad 


\section{FOREWORD}

This training manual grew out of a project on improving the quality of care rendered by public-sector providers of reproductive health services. This important project was designed and implemented by the Population Council in collaboration with the Ministries of Population Welfare, and Health. I am honored to have been associated with this initiative in Pakistan at a time when the government was thinking about integrating the service delivery components of these two Ministries. For this reason, the scope of this project extended beyond improving the quality of care provided by family planning workers and incorporated health workers providing maternal and child health services.

In our work, we have defined quality of care as: the way the system providing services treats its clients. Hence, the training program placed the client at its center. The success of all efforts made by the service delivery system, in attracting and keeping clients, depends upon the content and quality of interaction when the client comes in contact with the providerwhether the client is visiting a fixed clinic or being visited by a communitybased worker at home.

In order to offer good quality of care, the provider, in addition to being technically competent, should also treat the client with dignity and respect, assess her reproductive health needs by asking questions rather than making assumptions based on her profile, and help her negotiate a solution that is appropriate to her circumstances. Most training programs focus on improving the technical skills of providers; this training manual departs from this usual focus and is oriented to improving providers' inter-personal skills. Emphasis is placed on the client and helping her to meet her own needs rather than on meeting some artificial goals or targets (for example, service goals such as immunization of 50 children or 20 IUD insertions). A client-centered approach pays attention to a client's background, her life, and circumstances and, therefore, this manual emphasizes such topics as equality, gender, and sources of power within the household. Since many providers (especially the community-based workers) have the same background and face similar familial constraints as their clients, this training program is oriented to empower providers so that they in their turn can empower their clients.

I hope the use of this manual in training programs will change providers' orientation such that they are able to treat a client as an individual person rather than as a patient, a case, or a number. However, a sustained change in providers' orientation also requires that their supervisors change their 
orientation from being inspectors and find faults to become supportive supervisors and help workers to overcome obstacles.

This manual is a product of pain-staking efforts of many colleagues. I would particularly like to acknowledge Drs. Zeba Sathar, Gul Rashida, Ali Mir, and Zakir Hussain for their commitment to make it a success.

\section{Anrudh K. J ain}

Acting Vice President and Director

International Programs Division

Population Council, New York

2 February 2005 



\section{Section I Introduction}





\section{INTRODUCTION}

\section{About the manual}

\section{1. The manual's target audience}

This manual is designed for trainers facilitating the learning of trainees in how to offer client-centered reproductive health services. It is intended for people who have prior experience in participatory training using adult learning methods and who have undergone basic training in the clientcentered approach. The trainers should be experienced in encouraging and motivating trainees to participate fully in the training in order to take away the most from the experience, and to then put what they have learned into practice when working with clients. Having said that, the fundamentals of participatory training are repeated and reinforced throughout the manual as a reminder, and to encourage those who may have had less advanced training to provide the needed skills to trainees.

\subsection{The manual's adaptability}

This Trainer's Manual was originally developed for use in Pakistan by the Population Council Pakistan office. One of the benefits of the clientcentered approach is its applicability to any client and any provider in any location. The manual has been revised slightly from its use in Pakistan to enhance its broad appeal and trainers are reminded and encouraged to adopt alternative role-plays, case studies, or personal sharing that may better reflect specific local conditions or group personalities. Material should be modified to address health delivery systems or attitudes that may differ from those presented here. This takes nothing away from the benefit of using this manual as a guide to training in the client-centered approach to reproductive health, because any changes made are likely to be minor. The strength of the training is in the methodologies, the participation, the flow 
of the sessions, the questions, in other words "the process," and this can easily accommodate any changes that better reflect local conditions. Most users will find that the material presented here is directly applicable to their situation and will be glad to use the manual as is. The choice is for the trainer to make.

\subsection{How to use the manual}

This manual provides useful information to help the trainer conduct a training program in the client-centered approach to reproductive health. In addition to the modules covering the step-by-step activities that will help participants master different concepts, the information presented ranges from a practical listing of the tools required to short presentations on topics that the trainer will want to be familiar with during the training. The information is presented in the manual's three sections, as described below.

- Section I. Introduction. Trainers should use the material in the introduction to review the important aspects of the manual itself as well as of the client-centered approach to reproductive health. Practical information is provided here as well, such as a six-day workshop schedule and materials needed, etc.

- Section II. Trainer's guide. The trainer's guide is the heart of the manual. It is here that each session, or module, is presented. Each module covers individual components that together make up a successful client-centered interaction between client and provider. Within each module are specific activities that the trainer will use to facilitate the teaching of each component. Each module provides the following:

- Contents and schedule (timeframe) for the module, an overview of what the module will cover, a list of materials required, the learning objectives, and the key learning points.

- Trainer's notes that alert the trainer to any special preparations required for conducting each activity.

- Step-by-step instructions for each activity within the module.

- Section III. Training material. This section contains the support materials that will help the trainer prepare for the sessions. The training 
materials needed for each section are referred to in the trainer's guide at the point when they are needed

REMINDER: This manual is intended only as a guide and does not seek to provide all of the answers.

\section{ABOUT THE TRAINING}

The strength of this training in the client-centered approach to reproductive health lies primarily in two areas. The first has to do with the strengths the trainer brings to the training. The second has to do with the training environment - an environment largely influenced by the trainer.

REMINDER: Keeping in mind the basic principles, trainers are free to change or create alternative exercises according to local conditions.

\section{1. The trainers}

You, the trainers, are crucial to the quality of the training in the clientcentered approach to reproductive health. You not only facilitate the training but you also model the concepts that are being imparted to the trainees, so that they can, in turn, use these same concepts with their clients. What do you need to bring to the training? You need to provide:

- Preparation. Know the material in advance to facilitate discussion and be prepared to accomplish module goals within the timeframe. Nothing can replace preparation! You make the difference!

- Encouragement. Set the tone for the exchange of ideas and the development of concepts. Participants who contribute learn more and carry that into their work. You make the difference!

- Enthusiasm. Similar to encouragement. Enthusiasm is contagious. You make the difference! 
- Adaptability. Be prepared to adapt to the needs of trainees, to group dynamics and to local conditions. Adaptability strengthens training. You make the difference!

- Leadership. Understand that leadership and participation are not separate. Be a model for the behaviors that are the strength of the client-centered approach. A strong model reinforces success. You make the difference!

REMINDER: As trainer, you should read each module in advance in order to be familiar with the material to be covered, the methodologies to be used and their sequence and timing within each activity, and to prepare whatever materials or set-up will be required.

\subsection{The training environment}

What do we mean by environment? By environment we mean the manner in which the training is conducted, not the physical space because that will vary in every training venue. By manner we include those things that will help the trainees feel supported and accepted during the learning process. The environment will largely be created by the manner in which you, the trainer, conduct the sessions, utilizing the kinds of behavior that you will be encouraging the trainees to use. The environmental factors we are talking about include:

- Atmosphere. The way that the participants are supported and encouraged by the trainer, and through the training itself the opportunities the trainees will have to interact and to encourage and support each other create the best training atmosphere. An atmosphere of shared respect leads to participation. We all respond to respect and encouragement. The trainers and co-trainers work with the participants to provide a solid, supportive learning environment. As indicated above, but well worth repeating: you and your co-trainer(s) own enthusiasm, acceptance, listening skills and participation will set the right atmosphere. 
- Flexibility/adaptability. As indicated above, but also well worth repeating, as the trainer you need to be able to modify the activities to make use of local conditions (language, health delivery structure, etc.) and different group dynamics. When information is to be given to the participants, in the form of a briefing or as part of a discussion, you are provided information that you should become familiar with and then deliver in your own words to best achieve the intent of the message with the group you are training. Some groups may be more familiar with some material than others; you should adapt accordingly. It is important to be flexible in the timing as well; you may decide that some discussions or activities are fruitful and should continue beyond the stated timeframe while in other cases you may find that for your group the time for a particular activity is too long. Do what you need to do to keep the sessions lively and to cover the material. You do not need to be rigid about the timings given in the manual. These are for your guidance in covering the material within a reasonable timeframe.

- Participation. This training is designed to be experiential and participatory, ensuring learning based on shared experiences. The goaround, the discussions following the briefings, the exercises and roleplays are designed to support the participation of each and every trainee.

- Seating arrangement. Seating arrangement is included here because it contributes significantly to creating the right training environment. A unique feature of this training is that the participants and the trainer (and co-trainers) sit on the floor in a circle during the training. This seating

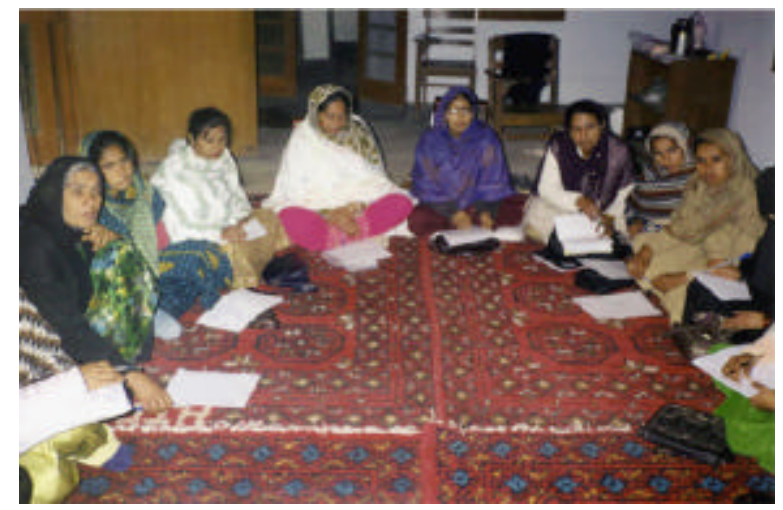
encourages a sense of equality and togetherness among trainers and trainees. Note: to ensure comfort, some type of floor cushion should be provided for each participant. (Exceptions can be made, if required.) 


\section{THE TRAINING METHODOLOGIES}

In addition to the aspects of training described above, methodologies used in this training include: (1) go-around, (2) brainstorming, briefings and group discussions, (3) role-plays, (4) case studies, (5) videos (or an alternative), and (6) games and exercises. These are described in the following pages.

\subsection{Go-around}

The importance of participation has been stressed. A method used to support and encourage participation involves the go-around. During the goaround participants, one after the other around the circle, are asked to share their experiences and thoughts on the topic under discussion. The aim of the go-around approach is to increase each participant's active involvement by giving all trainees the chance to share their personal experiences and to judge their strengths and weaknesses realistically. This format is also used when participants discuss their roles as a member of society and as a service provider.

\subsection{Brainstorming, briefings, group discussions}

All three of these methodologies have the same intent: to share information. Briefings usually involve the trainer defining concepts and giving basic information to the participants. Both brainstorming and group discussions involve participants actively in defining concepts and generating ideas.

Using these three methodologies helps clarify concepts, introduce skills/ topics, and allow the wealth of life and work experiences to be shared. Only brainstorming is described in more detail below as both briefings and group discussions are self-explanatory.

- Description of brainstorming. Brainstorming is the open expression of ideas/ opinions on a given topic by each participant without censorship or interruption whether the ideas/ opinions are practical or not.

Brainstorming should be followed by discussion to refine/ combine/ improve ideas. 
- Benefits of brainstorming. Brainstorming develops creative thinking; produces as many new ideas as possible, provides a good warm-up, and encourages all participants to speak and express their ideas freely.

- Process used for brainstorming. (1) Ask participants to give their ideas/ opinions; (2) encourage each participant to speak; (3) list the ideas on the board/newsprint; (4) allow no interruptions, do not look for ways to combine or improve ideas; (5) have a time limit or stop when enthusiasm wanes; (6) examine each idea and look for ways to combine or improve ideas through discussion after the brainstorming of ideas/ opinions; (7) add any information that may have been missed.

\subsection{Role-play}

\section{REMINDER for ROLE-PLAYS AND CASE STUDIES:}

The case studies and role-plays provided are examples; trainers may choose to prepare other case studies and role-plays incorporating local conditions.

- Description of role-play. Role-plays, which should take less than ten minutes, and are used to develop decision-making, communication and analytical skills and further clarify concepts. Participants are given reallife situations or problems to act out in front of each other; usually there is no set dialogue. Role-plays deal with the feelings and behavior of people. Role-plays are followed by a discussion on the situation or problem presented.

- Benefits of role-plays. Using role-plays helps develop and practice decision-making and analytical skills; develops positive attitudes; demonstrates different approaches to handling a situation; develops communication and negotiation skills;

- Process used for role-plays. (1) Define clearly what the participant will learn; (2) write a brief description of the problem and the characteristics of the individual actors; (3) write down the questions to be discussed after the role-play; (4) explain to each player in private the role they will enact; (5) give players five minutes or so to prepare; (6) brief the 
observers on what to look for; (7) explain that the role-plays should take less than ten minutes; (8) discuss the role-plays: the discussion following each role-play is part of the role-play concept. The discussion should proceed according to the following format: (8a) ask each player how they felt and what problems they faced when enacting their role; (8b) ask the observers about the situation, the attitudes, the interpersonal communication and the solutions to the problem; $(\mathbf{8 c})$ guide the discussion in order to bring out the learning points; (8d) summarize by talking about the lesson learned from the role-play.

REMINDER: Learning takes place mainly through analysis of the situation, not only through observation. Therefore, discussion following role-play is important!

\subsection{Case study}

- Description. A case study is a comprehensive oral or written account of an event, history of an illness, etc. Like role-plays, case studies are used to develop decision-making, communication and analytical skills and further clarify concepts. Case studies allow the participants to discuss real-life situations or problems. The case studies provided are examples; trainers may prepare many more incorporating local conditions.

- Benefits. Improves skills by providing opportunities to practice managerial and analytical skills, such as problem solving and decisionmaking; enhances the ability to think independently and quickly, and to make good judgments.

- Process used for case studies. (1) Divide the participants into groups of five to six each (four groups is preferable); (2) distribute copies of the case study (when there are two case studies and more than two groups, it is okay if some groups have the same study); (3) ask participants to read the situation and ask for clarification from the trainer so they will be prepared to answer questions at the end of the case study; (4) tell every group to select someone to act as rapporteur (the rapporteur's job is to record the group's discussion on newsprint and then present it to all of the participants); (5) answer any questions and remind participants of 
the time limit if it appears that they are spending too much time on one question; (6) promote the discussion according to the guidelines; (7) conclude the discussion with the consensus of the group; (8) ask each group's rapporteur to present the record of their group's discussion; (9) invite views of other participants and group members and encourage discussion; (10) summarize the common points of each presentation and, through discussion, add points that may have been missed.

\title{
3.5. Video of a client-provider interaction
}

\author{
[NOTE: Not everyone who is using this \\ manual will have a copy of the video \\ that the Population Council has \\ prepared. In the activities that call for \\ the use of the video an alternative will \\ be included for those who do not have \\ the video. The alternative presentation \\ should have the same benefits as the \\ video would have had.]
}

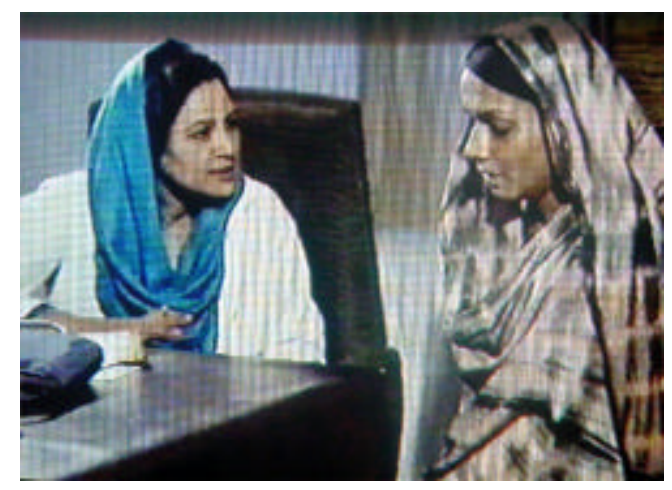

A video has been prepared showing two scenarios of a client-provider interaction (one for static center staff and one for community workers). This is to be used to initiate discussion on strengths and weaknesses in clientprovider interactions, the way the communication process is affected by these strengths and weaknesses, and how to improve communication.

- Description of video. The video is an audiovisual way of showing a reallife situation or a scenario.

- Benefits of using video. Using the video develops analytical and decision-making skills, such as problem solving; it enhances the ability to think independently and quickly. 
- Process used when showing video. (1) Watch the video before showing it to the participants and prepare notes on important points; (2) be sure the equipment/ video works; (3) set video to the start of the segment you will show; (4) before showing the video, give a short explanation about it and tell participants what to observe; (5) after showing the video allow time for

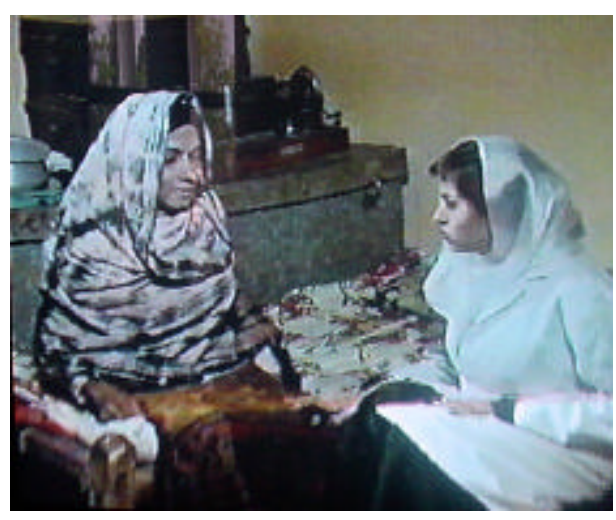
participants to assimilate their thoughts and make notes; (6) answer any questions participants may have; (7) discuss key learning points and questions in light of the objectives of the video; (8) outline exercise objectives at the end of the discussion.

\subsection{Games and energizers}

Games and energizers are used both as training tools and as useful tools to energize and relax participants. They are explained within the module when they are to be used.

\section{TRAINING MATERIALS AND TOOLS}

Training materials are a resource for the trainer when conducting the sessions. Longer training/ resource materials are included in Section III: Training Material, these are identified at the point they are needed by the letters "TM" and are numbered sequentially within each module. Information and resource materials that are shorter are included within the body of the modules. Under the heading for materials at the start of each training module is a list of the training materials and tools that will be needed to conduct the activities in that module. Special mention is also made in the trainer's note at the start of each activity, particularly if you will need an item for that activity that is not commonly being used. Training materials and tools are described in more detail below. 


\subsection{Writing board}

- Description of writing board. A blackboard is the traditional chalkboard used in classrooms. A whiteboard is a plastic white board on which special non-permanent markers can be used. The term "writing board" will be used throughout the document to refer to either type of board. Trainers should use whatever type of writing board is available, being sure to include either chalk or whiteboard markers as appropriate.

- Benefits of using writing board. Easiest means of illustrating a point, erasing it or adding to it; adds variety and contrast to teaching; outlines procedures where precise directions are needed; helps in reinforcing spoken words.

- Process for using writing board. (1) Write with your body sideways to the board so that you are partly facing the participants-this is so you don't lose contact with them and they can see what you are writing: speak to the class, not to the board; (2) write words in bold print, not longhand, drawing letters and symbols on the board large enough to be seen by all participants (a viewing distance of 32 feet requires letters to be at least 2-1/2 inches high); (3) keep the style of the writing simple using short sentences or phrases; (4) use colored chalk or markers, if possible, for writing words that need to be highlighted; (5) write longer material out in advance of the session to save time; (6) clean the board with an eraser or sponge, as appropriate, do not use your fingers.

\subsection{Flipchart, flipchart stand and newsprint}

- Description of flipchart. A flipchart consists of a number of large sheets of paper fixed to a support bar, easel or display board. The paper is clamped along the top so the sheets can be flipped backwards and forwards easily.

- Benefits of using flipchart. Allows the display of a succession of prepared sheets that be shown in order; provides instantly renewable sheets of blank surfaces on which to jot down information during the course of a session, group discussion, brainstorming or other activity.

- Process when using flip chart. (1) Plan the talk that will be assisted by the flipchart; (2) ensure that the charts are properly sequenced before 
the presentation; (3) reveal charts when you are ready to discuss them; (4) talk to the audience not the flipchart; (5) use a pointer instead of your hand to indicate details on the chart so that everyone can see; (6) position the charts in such a way that the participants can see them clearly and comfortably; (7) ensure that the flip chart is securely fastened and the pages can be easily flipped so that there are no long pauses during a presentation.

\subsection{Client profiles for roles-plays and case studies}

Profiles are provided, as needed, for role-plays and case studies; before these are used in a particular activity, the trainer should familiarize him or herself with the material, and copies should be made if required.

\subsection{Charts}

Charts are to be prepared before the start of the session in which they will be used; information to be put on the charts is provided either in the trainer's guide under the activities or in the training materials.

\subsection{Forms, assessment sheets}

Copies of the forms and assessment sheets are to be prepared for all participants; these are found with the training material (Section III).

\subsection{Zopp cards}

Zopp cards are the name used for blank cards of about 6 by 3 inches to be made from colored chart paper. About 200-250 cards should be prepared in advance for the training. The trainer can make Zopp cards using simple colored paper, though slightly heavier paper is best, if it is available. 


\subsection{Additional tools required}

Some additional tools are itemized here; however, refer to the following checklist to be sure that you have everything you will need for the training.

- Cushions or pillows for each participant so that participants will be more comfortable sitting on the floor.

- Newsprint or large sheets of white paper for using as flip charts and preparing presentations (mentioned with flipchart).

- Clamps (or something else) to hold the newsprint on the flipchart stand.

- Colored markers for writing on newsprint and either colored chalk or colored non-permanent markers for the writing board, depending on whether you are using a blackboard or a whiteboard.

- Television and VCR for showing the video (if you have a copy of the video; otherwise you do not need a TV or VCR but will be doing an alternative presentation).

- Ball of string for last exercise. 


\subsection{Checklist of materials and tools}

\section{CHECKLIST OF ALL MATERIALS AND TOOLS REQUIRED FOR TRAINING in addition to THIS MANUAL!}

$\checkmark$ Assessment sheet

Provided

$\checkmark$ Case studies

$\checkmark$ Content for charts

Provided

$\checkmark$ Definitions/ concepts

Provided

$\checkmark$ Forms

$\checkmark$ Games (description/ instructions)

Provided

$\checkmark$ Role-plays (scenarios/ instructions)

Provided

Provided

Provided

- Cards - 200-250 (6"x3" colored card/ paper)

MUST BE PROVIDED

$\checkmark$ Chalk (colored chalk IF using blackboard)

MUST BE PROVIDED

$\checkmark$ Clamps (for holding flip chart)

$\checkmark$ Cushions or pillows*

MUST BE PROVIDED

MUST BE PROVIDED

$\checkmark$ Envelopes (require different sizes)

$\checkmark$ Eraser or sponge (depending on writing board)

MUST BE PROVIDED

$\checkmark$ Flip chart stand (for newsprint and whiteboard)

MUST BE PROVIDED

$\checkmark$ Markers (colored markers for newsprint)

MUST BE PROVIDED

MUST BE PROVIDED

$\checkmark$ Markers (colored dry-erase IF using whiteboard)

MUST BE PROVIDED

$\checkmark$ Newsprint (for flip chart)

MUST BE PROVIDED

$\checkmark$ Notebooks*

$\checkmark$ Pens and pencils*

MUST BE PROVIDED

MUST BE PROVIDED

$\checkmark$ Plain paper

$\checkmark$ Plastercine (or tape/sticky substance)

$\checkmark$ String or yarn (or any equivalent; whole ball)

MUST BE PROVIDED

MUST BE PROVIDED

MUST BE PROVIDED

$\checkmark$ Table, small (used only in module 13)

MUST BE PROVIDED

$\checkmark$ Tape

MUST BE PROVIDED

$\checkmark$ Television and VCR (IF using the video)

MUST BE PROVIDED

$\checkmark$ Video of client-provider interaction

MAY OR MAY NOT BE PROVIDED

$\checkmark$ Writing board (use blackboard OR whiteboard)

MUST BE PROVIDED

* *Must provide enough for all participants. 


\subsection{Abbreviations used in the training}

You may find these abbreviations useful during the training:

$\begin{array}{ll}\text { ANC } & \text { Antenatal Care } \\ \text { BCG } & \text { Bacille Camille Gverin } \\ \text { BHU } & \text { Basic Health Unit } \\ \text { DPT } & \text { Diphtheria Pertusis Tetanus } \\ \text { FWC } & \text { Family Welfare Center } \\ \text { IUCD } & \text { Inter-uterine Contraceptive Device } \\ \text { LHW } & \text { Lady Health Worker } \\ \text { OPD } & \text { Outdoor Patient Department } \\ \text { ORS } & \text { Oral Rehydration Salt } \\ \text { RH } & \text { Reproductive Health } \\ \text { RHC } & \text { Rural Health Center } \\ \text { RTI } & \text { Reproductive Tract Infection } \\ \text { SAHR } & \text { Salutation } \\ & \text { Assessment Including Intentions } \\ & \text { Help } \\ & \text { Reassurance } \\ \text { STD } & \text { Sexually Transmitted Disease } \\ \text { THQ } & \text { Tehsil Headquarters Hospital } \\ \text { TM } & \text { Training Material } \\ \text { TT } & \text { Tetanus Toxide } \\ \text { VBFPW } & \text { Village Based Family Planning Worker }\end{array}$




\section{10. Schedule for training in client-centered approach}

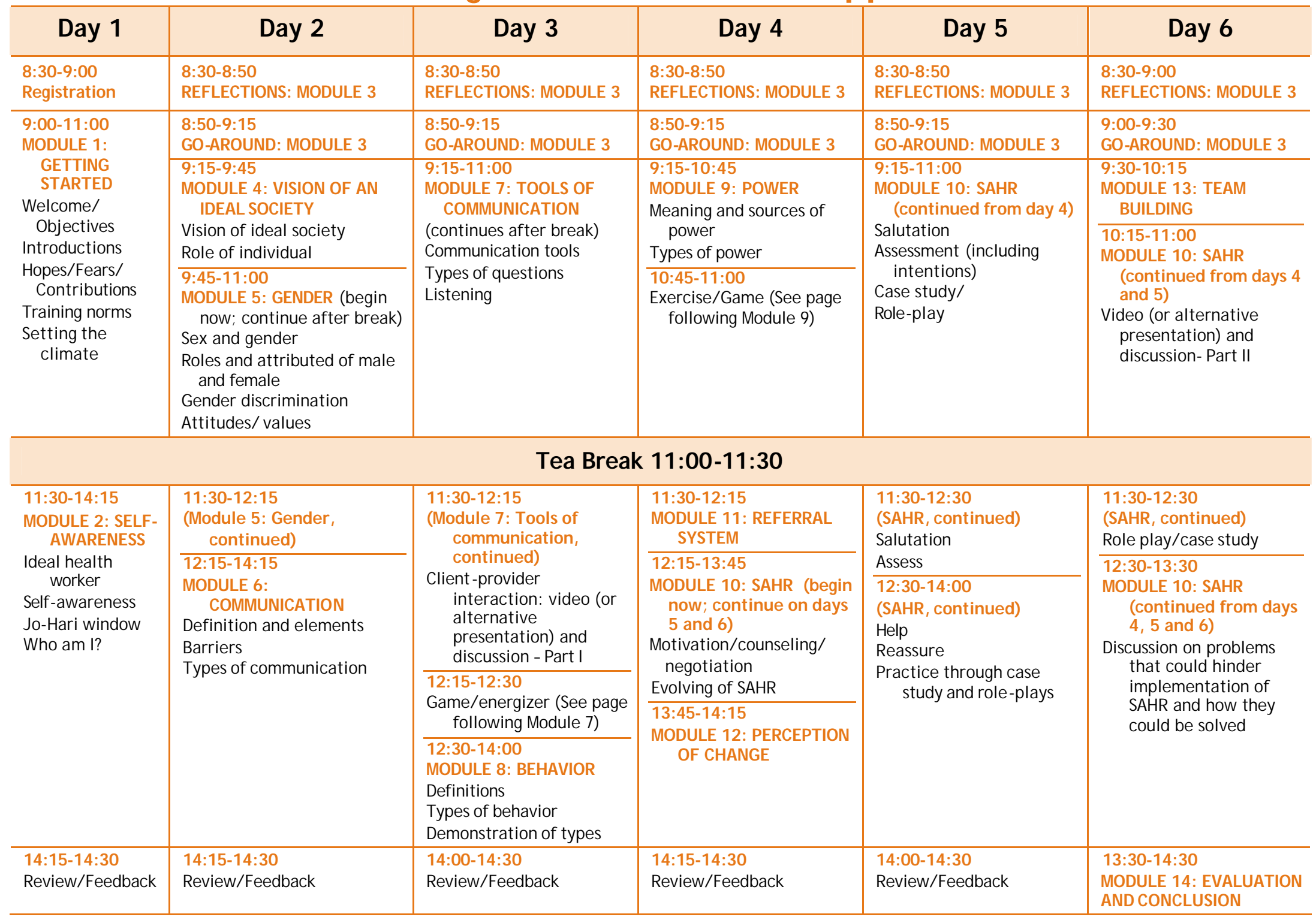




\section{Section II Trainer's guide}





\section{Module 1: Getting started}





\section{GETTING STARTED}

\section{SCHEDULE FOR MODULE 1}

\begin{tabular}{llll}
\hline Content & Methodology & Duration \\
\hline Activity 1 & $\begin{array}{c}\text { Welcome / Training } \\
\text { objectives }\end{array}$ & Briefing & 15 minutes \\
\hline Activity 2 & $\begin{array}{c}\text { Ice breaking / } \\
\text { Introductions }\end{array}$ & Game & 30 minutes \\
\hline Activity 3 & $\begin{array}{c}\text { Hopes / Fears / } \\
\text { Contribution } \\
\text { (Expectations) }\end{array}$ & Group work & 30 minutes \\
\hline Activity 4 & Training norms & Discussion & 30 minutes \\
\hline Activity 5 & Setting the climate & Game & 15 minutes \\
\hline Total duration & & & $\mathbf{2}$ hours
\end{tabular}

\section{OVERVIEW}

This module presents an overview of the training objectives, expectations of the participants and norm setting. It also helps the participants to become familiar with each other.

\section{MATERIALS}

Writing board, newsprint, colored markers (chalk) for newsprint and writing board, Plastercine, envelopes, slips of paper (half page sheets), pens and pencils

\section{LEARNING OBJ ECTIVES}

At the end of the module, the participants will be able to:

- GET more acquainted with each other. 
- DEFINE the scope, objectives, expectations and norms of the training.

- SET the climate for active participation.

\section{KEY LEARNING POINTS}

- A comfortable and relaxed atmosphere facilitates learning.

- It is not possible to meet all expectations. 


\section{ACTIVITY 1: OBJ ECTIVES OF TRAINING}

\section{TRAINER'S NOTE}

- Prepare charts with the following information:

$\rightarrow$ The objectives of the training (TM 1.1)

$\rightarrow$ A definition of the client-centered approach (TM 1.2)

$\rightarrow$ A definition of reproductive health (TM 1.3)

\section{INSTRUCTIONS}

1. WELCOME the trainees.

2. EXPLAIN the training objectives and duration (TM 1.1).

3. DEFINE the client-centered approach and reproductive health (TM 1.2, TM 1.3).

4. PASTE pre-prepared explanatory charts on the board while reviewing objectives, client-centered approach and reproductive health.

5. ASK if there are any questions and discuss them if there are. 


\section{ACTIVITY 2: INTRODUCTIONS}

\section{TRAINER'S NOTE}

- There are several ways to introduce participants but whichever one is used the idea is to create a congenial atmosphere.

- Prepare a chart with the following headings:

$\rightarrow$ Name

$\rightarrow$ Designation

$\rightarrow$ Organization

$\rightarrow$ Length of service

$\rightarrow$ One thing you like about your job

$\rightarrow$ One thing you do not like about your job

- Have enough envelopes and slips of papers (half pages of regular paper) for each participant.

\section{INSTRUCTIONS}

1. TELL the participants how important it is to become better acquainted with each other. A relaxed atmosphere encourages participation in the training.

2. TELL the participants that they will not introduce themselves, but will introduce the participant next to them.

3. PLACE the pre-prepared chart on the board. 
4. ASK the participants to interview the person next to them in order to fill in the information given in the chart.

\section{ALLOW 10 minutes.}

5. INVITE each participant to introduce his or her partner.

REMINDER: Setting the stage involves using tools that foster equality and an atmosphere that is good for learning.

6. TELL the participants that we will now conduct an

\section{$\rightarrow$ EXERCISE $\leftarrow$.}

7. ASK the co-trainer to give one envelope and one slip of paper to each participant.

8. ASK the participants to write their degrees, qualifications and designations on their piece of paper and then put the paper in the envelope and write their name on the envelope.

\section{ALLOW 3 minutes.}

9. ASK one participant or co-trainer to collect the envelopes.

10. SAY to the participants:

$\rightarrow$ Now that you have handed over your degrees, qualifications and designations, everyone is equal. There is no hierarchy.

11. TELL participants that there will now be another $\rightarrow$ EXERCISE $\leftarrow$. 
12. INVITE one volunteer to move forward toward the center along with the cushion that he or she is sitting on. (Note: if a chair is available in the room, or if, under special circumstances the participants are seated on chairs, the volunteer could be asked to use the chair instead of their cushion.)

13. TELL him or her to go back with the cushion.

14. ASK him or her to again come forward to the center but without the cushion.

15. ASK which was easier, moving with or without the cushion.

16. TELL the participants that the cushion represents our baggage; when we are carrying baggage it is difficult to move forward. Similarly in this training our degrees, qualifications and designations are our baggage that could hinder our learning.

17. ASK the participants to leave this baggage aside and free themselves of this burden. During this training there is no hierarchy.

18. CONCLUDE by saying that this exercise is only the beginning of getting to know each other and there will be more opportunities. Ask them to try to be more observant and perceptive of other people. 


\section{ACTIVITY 3: HOPES, FEARS AND CONTRIBUTIONS}

\section{TRAINER'S NOTE}

- Have enough newsprint and markers for each group (of 4-5 participants each).

\section{INSTRUCTIONS}

1. INFORM the participants that this module is about discussing various topics that will clarify the purpose of the training. It is important that everyone knows what to expect from the training.

2. TELL them that as adults coming to a training program after a gap of some years, they may have some apprehensions or fears. But they also have diverse experiences that they can contribute in facilitating the learning process.

3. DIVIDE the participants into groups of 4-5 each and ask them to discuss what they expect from the training (hopes), what apprehensions (fears) they have about the training, and how they can contribute to the learning process. Each group should write down their responses on newsprint (with everyone in the group contributing) under the three headings: hopes, fears, and contributions.

\section{ALLOW 15 minutes.}

4. ASK one member of each group to come to the center and present their group's work. Paste up the charts as they are presented. 
5. CIRCLE all of those items on each group's chart that this workshop will address. Explain that this training cannot address all of the issues and try to reach an understanding and agreement as to which expectations will be addressed.

6. NOW address the participants' fears. Allay any fears that participants might have mentioned: reassure them that they will not be tested, that the material is easy to understand, that no one will be punished, etc. Point out that past participants report having enjoyed the training.

\section{FEARS MIGHT INCLUDE:}

$\checkmark$ I will be asked to take a test at the end.

$\checkmark$ I will be asked about topics studied in a previous course.

$\checkmark$ I might not understand what is being taught.

$\checkmark$ I will be penalized for coming late.

$\checkmark$ My weaknesses will be exposed.

7. ASK participants to look at the list of ways in which they have said they might contribute to the training. Ask them to think about their own commitment to achieving the training objectives and to make a commitment to themselves and to each other to fully participate and to work to achieve the objectives.

8. CONCLUDE by reminding participants about the training objectives from Activity 1 and how important it is for them to review their own commitment to the training and to contribute to the best of their abilities so that the objectives can be achieved. 


\section{ACTIVITY 4: TRAINING NORMS}

2 TRAINER'S NOTE

- When the norms of training are developed, paste them on the wall and display them throughout the training period.

\section{INSTRUCTIONS}

1. TELL the participants that the learning process starts in their mother's lap. We are all taught informally by life experiences and formally in school, college or technical institutions.

2. ASK them to think of a time when they learned best and to define why.

ALLOW 2 minutes. 
3. INVITE them to give the reasons why they learned best in the situations they thought about; record their responses on newsprint/ board.

\section{ANSWERS COULD REFLECT (there will probably be many reasons):}

$\checkmark$ The atmosphere was friendly and relaxed

$\checkmark$ There was no fear

$\checkmark$ There was equality

$\checkmark$ There were fun elements

$\checkmark$ No one felt snubbed

$\checkmark$ There was respect for each other's views $\checkmark$ They had opportunities to practice concepts

$\checkmark$ There was no hierarchy

$\checkmark$ Feedback was given

$\checkmark$ Discussion and sharing was encouraged

$\checkmark$ The trainer was competent

$\checkmark$ Punctuality was observed

4. ASK participants if there are any other norms they would like to see followed in order to provide the best learning environment.

\section{ANSWERS COULD REFLECT:}

$\checkmark$ Raising their hands before speaking

$\checkmark$ Talking one at a time

$\checkmark$ Listening to others patiently

5. DISCUSS with the participants the following logistical details:

$\rightarrow$ Starting and ending times for each day

$\rightarrow$ Lunch / tea breaks

$\rightarrow$ Financial matters

$\rightarrow$ Any other problems (transport, accommodation, etc.)

6. SUMMARIZE important points and the logistical details without repeating details. 


\section{ACTIVITY 5: \\ SeTtING THE TRAINING CLIMATE}

\section{TRAINER'S NOTE}

- It is important to emphasize to the participants that this training will require active participation from everyone.

- Each session is connected to the others, so it is very important to attend all the sessions to understand the objectives of the training.

- Put the picture of the "old/ young woman" up on a big chart (TM 1.4); increase the size of the picture so that everyone can see it clearly.

\section{INSTRUCTIONS}

1. TELL the participants there will now be an $\rightarrow$ EXERCISE $\leftarrow$.

2. PASTE the picture of the old/ young woman on the board (TM 1.4).

3. ASK participants to look at the picture and think about what they see.

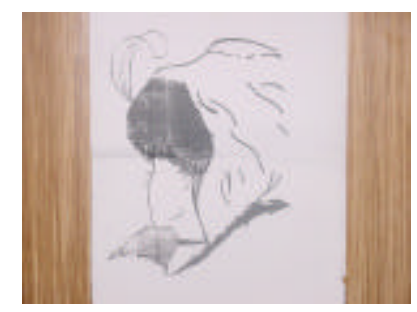

\section{ALLOW 1 minute.}

4. ASK the participants to share what they see.

REMINDER: Participants may see a young woman, an old woman or both ... or something else. 
5. RAISE these questions and discuss them:

$\rightarrow$ Why did they see different things?

$\rightarrow$ What is the message of this exercise?

DISCUSSION ASSISTANCE: What they experienced is known as selective perception and it depends on our personality and experience. We see, hear and read the same things, but we may understand and remember differently because we see what we want to see and recall what we want to recall.

6. SYNTHESIZE the answers.

ANSWERS SHOULD REFLECT: As individuals we need to respect other people's points of view and opinions, even when we think ours are right, because the perceptions of others may differ from ours because of their personality and experience. Opinions and points of views of others are not necessarily wrong, just different.

7. CONCLUDE by emphasizing that from this game we learn that appearances can be deceptive. Therefore we must inculcate the habit of looking at the problem in a wider context and must not be restricted by what we see or hear. By being open and accepting the views and ideas of other people we are increasing our own knowledge and experience. Therefore to make the teaching and learning more effective we will share and participate in each other's experiences. 


\section{Module 2: Self-awareness}





\section{Self-awareness}

\section{SCHEDULE FOR MODULE 2}

\begin{tabular}{cclc}
\hline Content & Methodology & Duration \\
\hline Activity 1 & Ideal health worker & $\begin{array}{l}\text { Use of Zopp cards } \\
\text { Discussion }\end{array}$ & 30 minutes \\
\hline Activity 2 & $\begin{array}{c}\text { Self-awareness and } \\
\text { its relationship } \\
\text { with health and } \\
\text { development }\end{array}$ & $\begin{array}{l}\text { Briefing } \\
\text { Discussion (group and } \\
\text { general) } \\
\text { Working in pairs }\end{array}$ & 45 minutes \\
\hline Activity 3 & J 0-Hari window & Lecture & 45 minutes \\
& Discussion & \\
\hline Activity 4 & Who am I? & $\begin{array}{l}\text { Briefing } \\
\text { Individual exercise }\end{array}$ & \\
& & Discussion & $\mathbf{2}$ minutes \\
\hline Total duration & & $\mathbf{4 5}$ minutes \\
\hline
\end{tabular}

\section{OVERVIEW}

This module deals with the concept of self-awareness and its relationship to health and overall development.

It also includes viewing oneself using the concept of the J o-Hari window, which divides human personality into four windows or components.

The concept of self-awareness is further elaborated under Who am I, which will help participants look at the attributes they have, the roles they perform and whether or not they have control over them. 


\section{MATERIALS}

Writing board, newsprint, colored markers (chalk) for newsprint and writing board, Plastercine, Zopp cards, sticky tape, and a bowl or a small box (for slips of paper)

\section{LEARNING OBJ ECTIVES}

At the end of the module the participants will be able to:

- LIST the attributes of an ideal health worker.

- DEFINE self-awareness, health and development and discuss the ways in which they interact.

- EXPLAIN the J 0-Hari window and discuss its role in dealing with clients.

- IDENTIFY the attributes we possess and the roles we perform, and discuss how these are related and how much control we have over them.

\section{KEY LEARNING POINTS}

- Self-awareness helps us to develop a positive and healthy appreciation of our strengths and limitations leading to control over ourselves.

- It helps us to accept others as they are with their strengths and limitations.

- To become self-aware is a difficult process. 


\section{ACTIVITY 1: IDEAL HEALTH WORKER}

\section{TRAINER'S NOTE}

- Have enough Zopp cards for each participant to have three or four.

\section{INSTRUCTIONS}

1. DISTRIBUTE three to four Zopp cards to each participant.

2. EXPLAIN that the participants should write down one quality or trait of an ideal health worker on each of the cards they were given. Give examples: helpful, skillful, etc.

\section{ALLOW 5 minutes.}

3. COLLECT all of the cards.

4. GROUP the cards together under the following categories (ask two to three volunteers to help):

$\rightarrow$ Attitude

$\rightarrow$ Knowledge and skill

$\rightarrow$ Practice (dealing with clients in a friendly manner, maintaining privacy, etc.)

5. TAPE the cards on the wall with scotch tape, grouping them by the three categories. 
6. ASK the participants to check the qualities and conduct a selfassessment to see how many of these attributes they have and how many more they can develop.

\section{ALLOW 5 minutes.}

7. ASK whether they use all the attributes they have and if not, why not?

8. CONCLUDE by emphasizing that to be an ideal worker all three qualities are necessary, because a person cannot be an ideal health worker if he or she does not have the knowledge and skill, does not put it into practice and if his or her behavior with clients is not positive. Skills are not enough to fully meet the needs of the client. There must be positive behavior as well. 


\section{ACTIVITY 2: SELF-AWARENESS}

\section{TRAINER'S NOTE}

- Prepare small slips of paper according to the number of participants. Write one of these words on each piece of paper: self-awareness, health, and development. Distribute the words equally (e.g., if there are 24 participants there should be 8 slips of each word; if there are 25 participants there will be 8 slips for 2 of the words and 9 slips for one of the words).

- Fold the slips of paper and put them in a bowl or box.

\section{INSTRUCTIONS}

1. ASK each participant to take one slip of paper from the bowl or box.

2. ASK them to look at the word on their slip of paper and, without speaking or showing their word to anyone else, pick out the participants who have the same word. Remember: they cannot show their slip to others or speak; they must enact the word written on the slip.

3. TELL the participants that they have now formed three groups according to the words they had on their slips of paper (health, development and self-awareness).

4. TELL each group to discuss their word and find a definition of it that they all agree on.

\section{ALLOW 5 - 10 minutes.}


5. INVITE each group to define the word they have for the others.

6. ASK other groups to comment.

7. FINALIZE the definitions with the consensus of all three groups.

8. ASK the participants to work in pairs and analyze the relationship between the three words (self-awareness, health and development) and demonstrate the relationship through words or a diagram or equation.

\section{ALLOW 10 minutes.}

9. ASK each pair to present and discuss.

10. PROCESS and come to the conclusion that all three are interdependent.

11. DISCUSS and clarify the concept of self-awareness (TM 2.1).

12. SYNTHESIZE by asking the group the following questions:

$\rightarrow$ Is it helpful to be self-aware and why?

$\rightarrow$ How can one become self-aware?

$\rightarrow$ How can self-awareness help the service provider in his or her personal and professional life?

13. CONCLUDE by emphasizing that:

$\rightarrow$ Becoming self-aware is a difficult process requiring patience because when someone points out our weaknesses we do not like it.

$\rightarrow$ Identifying one's own weaknesses is difficult; removing them or changing them is also difficult. The process requires a person to persevere. 


\section{ACTIVITY 3: \\ J 0-HARI WINDOW}

\section{TRAINER'S NOTE}

- Prepare a chart with the following incomplete personal statements:

$\rightarrow$ The members of my family are

$\rightarrow$ As a person my qualities are

$\rightarrow$ The thing that I cannot tolerate is

$\rightarrow$ The thing that I like best is

$\rightarrow$ I do not want others to

$\rightarrow$ I feel very upset if

$\rightarrow$ The best advice that I have received up to now is

\section{INSTRUCTIONS}

1. INFORM the participants that part of self-awareness includes viewing oneself according to the J0-Hari window model, which divides the human personality into four windows.

2. GIVE a briefing on the J 0-Hari window model, explaining each window (TM 2.2).

3. SYNTHESIZE by asking the participants the following questions (then discuss):

$\rightarrow$ Which window is better?

$\rightarrow$ How do we widen our open window?

4. DISCUSS these points in terms of the role of the service provider in widening the open window of clients in assessing their needs and status within their homes. 
5. TELL the participants that there will now be an

\section{$\rightarrow$ EXERCISE $\leftarrow$.}

6. PUT UP the pre-prepared chart with the incomplete statements so everyone can see it.

7. ASK the participants to read the statements and try to complete them, writing in their notebooks. Then also ask the participants to share this information with anyone in the group or with the trainer/ co-trainer.

\section{ALLOW 5 minutes.}

8. ASK the participants to share this information with another participant or with the trainer/ co-trainer; each should go in turn to share with the other.

\section{ALLOW 15 minutes.}

9. DISCUSS with the participants how they felt while sharing their personal information and listening to the experiences of others.

10. ASK whether sharing helps in building trust with others and in building one's own confidence. Did this exercise make them feel closer to each other?

11. CONCLUDE by emphasizing that an open window is better because it leads to greater self-awareness and confidence and helps in gaining the respect, confidence and trust of others. 


\section{ACTIVITY 4: WHO AM I?}

\section{INSTRUCTIONS}

1. TELL the participants that there will be an $\rightarrow$ EXERCISE $\leftarrow$.

2. INFORM the participants that this exercise is part of the theme of creating greater self-awareness. Tell them the exercise is called "Who am I?" and that it is an individual exercise; they do not have to share the information with anybody.

3. ASK them to divide a page of their notebook in two by drawing a vertical line down the middle of the page.

4. ASK them to write at least ten attributes or qualities that they have, both positive and negative, on one side of the page. Give examples: softhearted, aggressive, etc.

\section{ALLOW 5 minutes.}

5. DISCUSS with the participants how they felt about writing the list. Was it easy?

6. NOW ask them to write on the other half of the page the different roles they perform. Give examples: officer, father, daughter, etc.

\section{ALLOW 5 minutes.}


7. TELL them to match their roles with their attributes. Give an example - as a father you may be kind and softhearted but as an officer you may be rude and aggressive.

\section{ALLOW 5 - 6 minutes.}

8. NOW tell the participants to write down how much time they allot to each of their roles; they can do this by either prioritizing or giving a percentage.

\section{ALLOW 10 minutes.}

9. SYNTHESIZE by asking the following questions:

$\rightarrow$ Do we give time to ourselves? Should we and why?

$\rightarrow$ Do we have control over our emotions?

$\rightarrow$ Do we have control over our time and can we make adjustments by prioritizing?

$\rightarrow$ If we have control can we change and adapt?

10. CONCLUDE by asking the following questions:

$\rightarrow$ Have you ever had an opportunity to think about yourself in this manner?

$\rightarrow$ Is this something you should do in the future and what advantages would such an exercise have on your lifestyle? 


\section{Module 3: Reflections and go-around}





\section{RefLeCtiONS AND GO-AROUND}

\section{SCHEDULE FOR MODULE 3}

\begin{tabular}{|c|c|c|c|}
\hline \multicolumn{2}{|l|}{ Content } & \multirow{2}{*}{$\begin{array}{l}\text { Methodology } \\
\text { Discussion }\end{array}$} & \multirow{2}{*}{$\begin{array}{l}\text { Duration } \\
20 \text { minutes } \\
\text { each day }\end{array}$} \\
\hline Activity 1 & Reflections & & \\
\hline \multirow[t]{6}{*}{ Activity 2} & $\begin{array}{l}\text { Sharing experiences (different for } \\
\text { each day): }\end{array}$ & \multirow[t]{6}{*}{$\begin{array}{l}\text { Go-around } \\
\text { Discussion }\end{array}$} & \multirow[t]{6}{*}{$\begin{array}{l}25 \text { minutes } \\
\text { each day }\end{array}$} \\
\hline & $\begin{array}{l}\text { Day } 2 \\
\text { An incident when you supported } \\
\text { someone and felt pride in doing } \\
\text { so }\end{array}$ & & \\
\hline & $\begin{array}{l}\text { Day } 3 \\
\text { An incident when you felt } \\
\text { supported in time of need }\end{array}$ & & \\
\hline & $\begin{array}{l}\text { Day } 4 \\
\text { Gender discrimination you may } \\
\quad \text { have witnessed }\end{array}$ & & \\
\hline & $\begin{array}{l}\text { Day } \mathbf{5} \\
\text { Any situation where you saw } \\
\text { power dynamics/ decision- } \\
\text { making }\end{array}$ & & \\
\hline & $\begin{array}{l}\text { Day } 6 \\
\text { Any situation when you tried to } \\
\text { use SAHR }\end{array}$ & & \\
\hline \multicolumn{2}{|c|}{ Total duration } & & 45 minutes \\
\hline
\end{tabular}

\section{OVERVIEW}

Every day there will be a review of the previous day's sessions using a goaround during which participants are asked to describe a personal experience according to the topic for that day (see under activity 2 in the schedule above). 


\section{LEARNING OBJ ECTIVES}

At the end of the module, the participants will be able to:

- REVIEW/RECOLLECT what they learned on the previous day.

- COMMUNICATE more freely and be relaxed.

- PARTICIPATE actively and improve their communication skills.

REMINDER: Activities 1 and 2 in this module are to be repeated every day! 


\section{ACTIVITY 1: REFLECTIONS}

\section{TRAINER'S NOTE}

- Every day each participant is asked to describe one thing they learned on the previous day. The aim is to review the previous day's sessions.

\section{INSTRUCTIONS}

1. ASK each participant to describe something they learned on the previous day and discuss. Make sure each participant talks on a different topic, to the extent possible.

REMINDER: A lesson learned is different from repeating what was taught or discussed the day before.

EXAMPLE: In the session, the discussion may be about the definition of self-awareness, the advantage, how to become more self-aware, etc., but the lesson learned could be "to know our strengths and weaknesses makes us more confident."

\section{ALLOW 1 minute for each participant.}

REMINDER: Activity 1 is to be repeated every day, keeping in mind the sessions conducted on the previous day. 


\section{ACTIVITY 2: SHARING EXPERIENCES}

\section{TRAINER' S NOTE}

- When it is time to share information, start by going around the circle asking each person to describe a personal achievement. If any participant is not ready to share, continue on around the circle. Come back at the end to each person who did not share earlier; however, do not force anyone to share.

\section{INSTRUCTIONS}

1. ASK the participants to think about an incident when they felt proud to have made a difference to an individual or society. (The trainer can share an incident of his/ her own as an example, if that seems useful.)

\section{ALLOW 2 - 3 minutes.}

2. ASK each participant to share his or her incident in a go-around.

3. ASK the participants the following questions when the go-around is finished:

$\rightarrow$ How did you feel after sharing?

$\rightarrow$ What effect did the sharing have on you?

$\rightarrow$ Is sharing a good thing to do?

REMINDER: Activity 2 is to be repeated every day, sharing experiences according to the list in the schedule on the first page of this module. 


\section{Module 4: Vision of an ideal society}





\section{VISION OF AN IDEAL SOCIETY}

\section{SCHEDULE FOR MODULE 4}

\begin{tabular}{llll}
\hline Content & Methodology & Duration \\
\hline Activity 1 & Vision of an ideal society & $\begin{array}{l}\text { Group work } \\
\text { Discussion }\end{array}$ & 15 minutes \\
\hline Activity 2 & $\begin{array}{l}\text { Role of an individual in } \\
\text { contributing toward an } \\
\text { ideal society }\end{array}$ & Discussion & 15 minutes \\
\hline Total duration & $\mathbf{3 0}$ minutes
\end{tabular}

\section{OVERVIEW}

This module deals with sharing the vision of an ideal society and what roles we as individuals can play in achieving the desired vision.

\section{MATERIALS}

Newsprint, writing board, colored markers (chalk) for newsprint and writing board, Plastercine

\section{LEARNING OBJ ECTIVES}

At the end of the module, the participants will be able to:

- CONCEPTUALIZE and draw up a list of components of an ideal society.

- DISCUSS their role as an individual in contributing towards making an ideal society. 


\section{KEY LEARNING POINT}

- A common vision is an extremely powerful tool to bring people together. When motivated for common cause, minor differences do not matter and the power of an individual can become the power of the group. 


\section{ACTIVITY 1: VISION}

\section{TRAINER'S NOTE}

- Prepare for this activity by reviewing possible ways to describe an ideal society in order to help stimulate discussion, if needed.

\section{FACTORS THAT MIGHT BE USED TO DESCRIBE AN IDEAL SOCIETY:}

$\checkmark$ Respect for human beings

$\checkmark$ Based on religious beliefs

$\checkmark$ Free of corruption

$\checkmark$ No gender discrimination

$\checkmark$ Availability of the basic necessities of life (food, shelter, clothing, etc.)

$\checkmark$ Equal rights for rich and poor

$\checkmark$ Sense of responsibility and personal accountability

\section{INSTRUCTIONS}

1. DIVIDE the participants into two or three groups.

2. ASK the groups to designate one person to be the group leader/ rapporteur (to write and present).

3. TELL the groups to write down on newsprint their vision of an ideal society.

\section{ALLOW 10 minutes.}


4. INVITE all rapporteurs to present their work.

5. TELL the participants to decide on a joint vision of an ideal society through discussion.

6. WRITE the participants' vision on newsprint or a writing board as it is developed.

7. PUT the agreed upon vision up where everyone can see it. 


\section{ACTIVITY 2: ROLE OF AN INDIVIDUAL}

\section{TRAINER'S NOTE}

- The chart prepared in activity 1 showing the participants' joint vision of an ideal society should be pasted up where it is visible to all.

- Have envelopes and half-sheets of paper for all participants; distribute one envelope and one half-sheet of paper to each participant at the start of the activity.

\section{INSTRUCTIONS}

1. ASK the participants to think how they as individuals could contribute toward making an ideal society and discuss.

2. ASK the participants to look at the vision that was developed in the previous activity and think about, and then write down, two areas where they as an individual could contribute to an ideal society.

\section{ALLOW 10 minutes.}

3. COLLECT the papers and ask for their commitment to do what they have written down.

4. CONCLUDE by emphasizing that the majority of people want a just society where the basic rights and needs of individuals are met irrespective of their caste or creed. Often they do not realize how they as individuals can also play a role in improving society. 



\section{Module 5: Gender}





\section{GENDER}

\section{SCHEDULE FOR MODULE 5}

\begin{tabular}{llll}
\hline Content & Mythology & Duration \\
\hline Activity 1 & Sex and gender & $\begin{array}{l}\text { Story telling } \\
\text { Brainstorming } \\
\text { Discussion }\end{array}$ & \\
& & 20 minutes \\
\hline Activity 2 & $\begin{array}{c}\text { Roles and attributes of male } \\
\text { and female }\end{array}$ & $\begin{array}{l}\text { Group work } \\
\text { Discussion }\end{array}$ & 45 minutes \\
& & & \\
\hline Activity 3 & Gender discrimination & Working in pairs & 40 minutes \\
& & Discussion & \\
\hline Activity 4 & Attitudes and values & Exercise & 15 minutes \\
\hline Total duration & & $\mathbf{2}$ hours \\
\hline
\end{tabular}

\section{OVERVIEW}

This module includes an understanding of gender as separate from sex and the societal role assigned to males and females. Through the use of different exercises the factors contributing to gender discrimination and the means of mitigating these are discussed.

\section{MATERIALS}

Writing board, chalk, newsprint, colored markers (chalk) for newsprint and writing board, Zopp cards, Plastercine 


\section{LEARNING OBJ ECTIVES}

At the end of the module, the participants will be able to:

- DIFFERENTIATE between sex and gender.

- DISCUSS different attributes associated with male and female roles.

- EXPLAIN the contribution of society in determining roles and the consequent discrimination based on gender.

- DISCUSS the role of the service provider in mitigating gender discrimination.

\section{KEY LEARNING POINTS}

- Although they have biological differences, women and men are capable of performing the same roles and have similar attributes.

- It is society that determines different roles based on gender but these can and do change with time and effort.

- For a healthy society it is imperative to have no gender discrimination. Women should enjoy equal rights, including the right to live happily, learn, contribute and be acknowledged. 


\section{ACTIVITY 1: SEX AND GENDER}

\section{TRAINER'S NOTE}

- Prepare for briefing on gender (TM 5.1).

- Choose if you will tell the story or just brainstorm to differentiate between sex and gender.

\section{INSTRUCTIONS}

1. CHOOSE whether you want to tell the following story OR just brainstorm about sex and gender. If you choose to tell the story then read the following story; if you choose to brainstorm, go to instruction 4 and proceed.

\section{STORY}

A father and son were going from Islamabad to Peshawar by road. Unfortunately, on the way they were involved in an accident and taken to the nearest hospital. Both were seriously injured but the son had a head injury and it was decided to call a neurosurgeon to perform brain surgery. The neurosurgeon came and after seeing the boy said: "I cannot operate upon him because he is my son."

2. ASK what the relationship between the patient and the surgeon was.

ANSWER: The answer is mother and son. (Usually participants do not guess.) 
3. ASK, if appropriate, why they did not guess correctly. The usual answer is because neurosurgeons are mostly male.

4. BRAINSTORM, whether you told the story or not, to define what the words sex and gender mean.

5. SYNTHESIZE by saying that sex is a biological difference between women and men while gender is the role assigned to them by society.

6. ASK participants to imagine they see two people from afar, one wearing red and the other descending by a parachute. In each case which sex would they think the two people were?

7. DISCUSS the fact that roles of males and females are assigned at birth and even before if the sex of the child is known. Roles are defined by the color of the baby's clothes, style of stitching and the toys they are given. Small boys often accompany female relatives as a protector. A girl is told not to go out alone while for the boy there are no such inhibitions, etc. 


\section{ACTIVITY 2: ROLES AND ATTRIBUTES OF MEN AND WOMEN}

\section{TRAINER'S NOTE}

- This activity will deal specifically with the roles given by society; be prepared to discuss.

\section{INSTRUCTIONS}

1. EXPLAIN that we will now talk about the qualities and roles assigned to men and women that are given by society; roles and attributed assigned by society are changeable.

2. TELL the participants that there will be an $\rightarrow$ EXERCISE $\leftarrow$.

3. DIVIDE the participants into four groups and tell them to pick a rapporteur (to write and present).

4. $\quad$ ASK one group to write down the qualities of an ideal man; a second group to write the qualities of an ideal woman; a third group to list professions associated with men; and the fourth group to list professions associated with women.

\section{ALLOW 10-15 minutes.}

5. ASK the leader of group one to present that group's work; then ask the leader of group two to present.

6. PASTE both charts on the board or wall.

7. BRAINSTORM AND DISCUSS qualities that are different in the two charts; ask the participants whether those different qualities can be present in the opposite sex. 
8. ASK the leader of group three to present, followed by the leader of group four; then discuss, as before.

9. PROCESS by showing that there is little difference between the qualities and roles of men and women, except for biological and religious functions (reproduction and giving of azaan, etc.).

10. DISCUSS the factors that affect these qualities and roles.
ANSWERS SHOULD REFLECT THESE CONCEPTS:
$\checkmark$ Culture
$\checkmark$ Profession
$\checkmark$ Economic conditions
$\checkmark$ Religion
$\checkmark$ Age
$\checkmark$ Marital status (e.g., married, widowed, etc.)

11. ASK the participants if any of these factors can change and how.

12. CONCLUDE by emphasizing that except for biologically distinct functions, all of the roles given by society can and sometimes do change over time according to changing situations. 


\section{ACTIVITY 3: \\ GENDER DISCRIMINATION}

\section{TRAINER'S NOTE}

- Prepare Zopp cards using statements provided (one statement on one card). For each statement prepare three to four cards depending on the number of pairs of participants, so that every pair will have one of the statements (e.g., for: 24 participants $=12$ pairs $=3$ statements will be written 2 times and 2 statement will be written 3 times $=12$ statements). (Statements: TM 5.2.)

REMINDER: Feel free to develop other statements reflecting national or local aspects of gender discrimination.

\section{INSTRUCTIONS}

1. TELL the participants that there will now be an $\rightarrow$ EXERCISE $\leftarrow$.

2. ASK the participants to divide into pairs.

3. DISTRIBUTE the prepared Zopp cards, one to each pair.

4. ASK them to discuss the statement with their partner, and write down their main points:

$\rightarrow$ Do you agree with the statement?

$\rightarrow$ If yes, then why is the situation/ statement true?

$\rightarrow$ If not, then why do you disagree?

$\rightarrow$ What impact does the statement have on the health of women and the development of communities and the nation? 
$\rightarrow$ What can be done to improve the situation?

\section{ALLOW 10 minutes.}

5. ASK each pair to read out what they have written; group these presentations so that pairs with the same statement present one after the other before going onto the pairs with a different statement.

6. INVITE the participants to give comments and discuss.

7. $\quad$ ASK the participants if they have heard or seen people using domestic violence. Ask a few of the participants who have seen or heard such cases to discuss the possible causes.

8. INFORM the participants that women are at a disadvantage by being deprived of food (and in particular calcium), education and health facilities.

9. BRAINSTORM about the role participants can play in minimizing gender discrimination.

\section{BRAINSTORMING SHOULD REFLECT:}

$\checkmark$ Listening to problems.

$\checkmark$ Sharing knowledge and information (woman in developing countries are often ignorant of their rights; providers should inform them). 


\section{ACTIVITY 4: ATTITUDES AND VALUES}

\section{TRAINER'S NOTE}

- Prepare a chart with the following statements:

$\rightarrow$ Family planning goes against this country's traditions.

$\rightarrow$ The status of women has little to do with their overall health.

$\rightarrow$ A good healthcare provider has to be an activist.

- Plan what places in the room you will designate for the participants when they separate to indicate agreement, disagreement and undecided/ not sure during the exercise.

- Be prepared to participate in the discussion defending or challenging a position if no participant, or only one, takes a particular position during the exercise.

\section{INSTRUCTIONS}

1. TELL the participants that there will be an $\rightarrow$ EXERCISE $\leftarrow$.

2. ASK the participants to stand up.

3. DRAW a pretend line in the middle of the hall or identify two points in the hall about 10 feet apart. Identify a third point (between the other two if possible).

4. TELL the participants that the two ends are extremes: one point is 100 percent agree ("yes") and the other point is 100 percent disagree ("no"). The middle point is for those who are not sure or undecided. They may use the space anywhere between the endpoints to indicate degree of agreement/ disagreement. 
5. INFORM them that they will be shown a statement for which they will be asked to take positions along the line. Their position will depend on whether they agree or disagree and to what extent, or are undecided.

6. PASTE the chart you prepared beforehand on the board.

7. READ and point to one of the statements; ask the participants to go to the position that indicates whether they agree or disagree with the statement (or aren't sure, or agree somewhat, etc.).

8. ASK them, after they have taken their positions, to defend their decision to the other participants.

9. PARTICIPATE in the discussion if no one agreed or disagreed or if there is only one person taking any position so that you can present arguments either defending or challenging that position.

10. TELL the participants that, if they want, they can change their position after the discussion.

NOTE: Usually there will be many who change their position after the discussion.

\section{ALLOW 3-4 minutes.}

11. REASSEMBLE the participants.

12. ASK what happened and why people changed their position.

ANSWER SHOULD REFLECT: People changed their position after they were convinced by the arguments and reasoning. 
13. REPEAT the activity in the same manner for the other two statements if there is enough time (i.e., you may do one, two or three statements in this manner, as you choose).

14. CONCLUDE the exercise by reiterating that people may have certain attitudes and values; however, they can change their opinions given additional knowledge and reasoning.

15. ASK the participants to join you in holding hands. Say that by joining hands we can feel each other's warmth and power. Make the point that we are few but when we are a team we are powerful. Ask participants to pledge that they will try to help in any way they can, large or small, to remove gender discrimination starting at home (e.g., to welcome the birth of a girl as much as a boy, not to deprive girls of proper nutrition, education and health facilities, etc.). 



\section{Module 6: Communication}





\section{COMMUNICATION}

\section{SCHEDULE FOR MODULE 6}

\begin{tabular}{llll}
\hline Content & & Method & Duration \\
\hline Activity 1 & Definition of communication & $\begin{array}{l}\text { Brainstorming } \\
\text { Discussion }\end{array}$ & 15 minutes \\
& & Brainstorming \\
& Elements of communication & \multirow{2}{*}{$\begin{array}{l}\text { Briefing } \\
\text { Role-play }\end{array}$} & \\
& & Discussion & \\
& & Brainstorming & 30 minutes \\
Activity 2 & Barriers to communication & Discussion & \\
& & Exercises & \\
& & Briefing & 45 minutes \\
& & Exercises/ Role- \\
Activity 3 & Types of communication & \\
& & & $\mathbf{2}$ hours \\
\hline Total duration & &
\end{tabular}

\section{OVERVIEW}

This module is an exercise on interpersonal communication. Participants learn about the communication process, barriers, and verbal and nonverbal communication through games, group work, exercises and discussion. Roleplays and exercises will allow participants to practice the concepts.

\section{MATERIALS}

Writing board, newsprint, colored markers (chalk) for newsprint and writing board, a piece of wire, slips of paper, and profiles for role-play 


\section{LEARNING OBJ ECTIVES}

At the end of the module, the participants will be able to:

- DEFINE communication.

- EXPLAIN elements of communication.

- IDENTIFY barriers affecting communication process.

- DEMONSTRATE different types of communication (verbal and nonverbal).

\section{KEY LEARNING POINTS}

- Careful listening is the most important communication tool.

- Body language (nonverbal communication) can be much more effective than words.

- Feedback is a very important component of communicating, especially in client-provider interaction where it is essential to ensure the client has understood the instructions. 


\section{ACTIVITY 1: \\ DEFINITION AND ELEMENTS OF COMMUNICATION}

\section{TRAINER'S NOTE}

- Be prepared to define/ discuss communication and components of communication (TM 6.1).

- Be prepared to present a role-play with the co-trainer (TM 6.2).

\section{INSTRUCTIONS}

1. BRAINSTORM with the participants on what the word communication means (TM 6.1).

2. RECORD their answers on newsprint or writing board.

3. GROUP similar answers.

4. THROUGH discussion evolve a definition of communication.

\section{DEFINITION OF COMMUNICATION SHOULD REFLECT:}

$\checkmark$ The transfer of ideas, thoughts, feelings and images from one person to another.

$\checkmark$ Communication is shared meaning.

5. BRAINSTORM and discuss the components of communication (source, message, channel and receiver) (TM 6.1). 
6. ASK the participant whether the communication is complete when the message reaches the receiver.

\section{RESPONSE SHOULD INCLUDE THIS CONCEPT:}

Communication is complete only when there is feedback from the receiver that the message has been understood.

7. TELL the participants that you and a co-trainer will now perform a $\rightarrow$ ROLEPLAY $\leftarrow$.

8. PRESENT the role-play to the participants (TM 6.2); remember to stop and ask the questions as indicated in the role-play.

9. PROCESS the role-play at the end by asking the participants the following questions:

$\rightarrow$ What did you observe?

$\rightarrow$ What was wrong in the first part role-play?

ANSWER SHOULD REFLECT: No feedback was given to ensure that the message was understood.

10. INVITE participants to share with the group a similar experience in dealing with a client when no feedback was requested.

11. EMPHASIZE that communication is shared meaning.

REMINDER: If meanings are not shared, miscommunication can result. 
12. SYNTHESIZE the information, explaining that people listen and understand according to their personal experience and knowledge.

13. SUMMARIZE the activity and reiterate the importance of feedback during a client-provider interaction to ensure that the client has understood and will follow instructions correctly. 


\section{ACTIVITY 2: BARRIERS TO COMMUNICATION}

\section{TRAINER'S NOTE}

- Be prepared to brainstorm on barriers to communication; review list below.

- Be prepared to discuss the communication grid (TM 6.3).

- Note that you will use the exercise (TM 6.4) only if there is time and you think it would be useful.

\section{INSTRUCTIONS}

- BRAINSTORM with the participants about factors that can obstruct or create hurdles in the communication process especially during clientprovider interaction.

1. LIST their responses on newsprint or the writing board.

\section{SOME POSSIBLE BARRIERS TO GOOD COMMUNICATION:}

$\checkmark$ Language

$\checkmark$ Stress

$\checkmark$ Fear

$\checkmark$ Attitudes

$\checkmark$ Gender difference

$\checkmark$ Unclear messages

$\checkmark$ Culture

$\checkmark$ Lack of time

$\checkmark$ Confidentiality not maintained $\checkmark$ Differences in position/ power (no equality)

2. DISCUSS how these can be overcome. 
3. TELL participants that to enforce positive healthy behavior, the communication process has to pass through many steps and barriers.

4. DEMONSTRATE the communication grid to further clarify barriers in communication (TM 6.3).

5. BRAINSTORM ideas about communication issues by asking the trainees about the types of clients that come to them and list these on the board/newsprint. Then ask them what would happen when different types of providers work with these types of clients (e.g., aggressive client, passive client, or fearful client, etc., working with a provider who is aggressive, or in a hurry, etc.).

6. CONDUCT an exercise (only if there is time and you feel it would be useful) to clarify the concept of barriers to communication and to enable participants to appreciate the effect of communication barriers between client and provider and how they can be overcome. The exercise is included as TM 6.4.

7. CONCLUDE, whether or not you have used the exercise, by stressing that effective communication can only be considered complete when a person adopts the positive behavior and practices it continuously. This is a long process and passes through many steps and barriers. A service provider trying to inculcate a positive healthy behavior in his/ her clients should reinforce the messages whenever possible and appropriate. Remind participants that if there are barriers between the client and provider there will not be equality and without equality negotiation will be impossible.

Therefore, it is important to identify and understand these barriers and to overcome them in order to have a successful client-provider interaction. 


\section{ACTIVITY 3: \\ TYPES OF COMMUNICATION}

\section{TRAINER' S NOTE}

- Prepare four slips of paper with the phrase "what is the matter" and one emotion (e.g., anger, pride, criticism, secrecy, etc.) written on each. (In Urdu the phrase "what is the matter" would be "kiya baat hai.")

- Make copies of the different instruction sheets for the four groups in the role-plays demonstrating mixed messages (explained in detail in TM 6.5).

\section{INSTRUCTIONS}

1. ASK the participants about types of interpersonal communication; write their responses on the writing board or newsprint.

\section{RESPONSES SHOULD INCLUDE THESE TWO TYPES OF INTERPERSONAL COMMUNICATION:}

$\checkmark$ Verbal: expressed through words and tone of voice.

$\checkmark$ Nonverbal: expressed through actions and body language.

2. TELL the participants that the tone of voice is an important component in building rapport with a client.

3. TELL the participants that there will be an $\rightarrow$ EXERCISE $\leftarrow$,

4. DISTRIBUTE the four slips of paper, prepared beforehand, to four different participants. 
5. INSTRUCT the selected participants, without other participants overhearing, to read the phrase written on the slip of paper loudly and through tone of voice to demonstrate the feeling or emotion that is written on the paper without telling the participants what the feeling/ emotion is.

6. ASK the rest of the group to guess which emotion is being expressed and how the feeling is being shown.

7. WRAP up the exercise by explaining that the same words can be interpreted differently if the tone of voice is changed. The purpose of this exercise is to demonstrate how different emotions can be conveyed through voice tone. Ask the following questions:

$\rightarrow$ What tone of voice would you prefer to hear from a person you go to for help?

$\rightarrow$ What tone of voice should be avoided or is inappropriate during a client-provider interaction.

8. CONCLUDE the exercise by emphasizing that it is not so much what you say but how you say it.

9. TELL participants that there will be another $\rightarrow$ EXERCISE $\leftarrow$.

10. ASK them to form into pairs and stand back-to-back without touching each other. Ask if there is any communication? (The answer should be no.)

11. ASK them to stand side-by-side and look straight ahead.

12. ASK whether there is any communication. (The answer should be no.)

13. ASK them to face each other with one person looking down and the other looking up. Ask whether there is any communication. (The answer is no.)

14. ASK them to look at each other and decide whether there is any communication. (The answer should be yes because they are having eye contact.) 
15. EMPHASIZE that for good communication eye contact is an important factor.

16. TELL them to express to their partner through facial expressions each of these emotions: happiness, sadness and anger. The partner must guess which emotion is being shown each time.

17. DEMONSTRATE the importance of posture by asking some of the participants to sit back and then sit straight and then sit forward while talking to their partner. Ask at each step what the posture shows.

18. END the activity by asking which posture would be most suitable during a client-provider interaction and why?

ANSWER SHOULD REFLECT: Leaning forward is best; this posture gives the client the feeling that the listener is interested.

19. TELL the participants that the exercises they have just done should have helped to demonstrate some components of nonverbal communication.

20. ASK the participants to write in their notebooks which element is more important in communication: words, tone of voice or body language.

21. INVITE some participants to say what they have written. (Most of the participants will choose words over body language or tone.) 
22. SHARE with the participants the results of the following study that rates body language (e.g., eye-to-eye contact, posture, and facial expressions) and tone of voice as more important than words in effective communication:

\section{RESULTS OF A STUDY:}

What is most important in effective communication?

Body language

Tone of voice

Words
58 percent

35 percent

7 percent

23. SUMMARIZE the activity by emphasizing that we often underestimate the importance of body language and tone of voice, and the impact they have on the communication process.

24. TELL the participants that there will now be $\rightarrow$ ROLE-

\section{PLAYS $\leftarrow$.}

25. SELECT four groups with three participants in each group: the groups should choose who will play the part of the listener, the communicator and the observer. The rest of the participants will observe.

26. FOLLOW the instructions for the mixed messages role-plays (TM 6.5). Be sure to process each role-play when it ends by asking:

$\rightarrow$ The speaker: How did you feel?

$\rightarrow$ The listeners: How did you feel?

$\rightarrow$ The observer: What comments do you have about the process?

27. INVITE comments from the rest of the participants and discuss. 
28. SUMMARIZE the role-play by pointing out that the role-plays were designed to help clarify the concept of mixed messages (words giving one message while body language gives another). Remind the participants that for communication to be successful it is important that words and actions (body language) give the same message.

29. CONCLUDE the session by asking the participants what lessons they have learned about communication and how this affects the clientprovider interaction. 


\section{Module 7: Tools of communication}





\section{TOOLS OF COMMUNICATION}

\section{SCHEDULE FOR MODULE 7}

\begin{tabular}{llll}
\hline Content & & Method & Duration \\
\hline Activity 1 & Communication tools: & Briefing & 1 hour \\
& Reflective listening & Discussion & \\
& Stroking & Exercises & \\
& Ownership & Role-plays & \\
& I Statement & & \\
\hline Activity 2 & Type of questions & Brainstorming & 20 minutes \\
& & Briefing & \\
& & Discussion & \\
\hline Activity 3 & Listening & Exercise & 25 minutes \\
& & Briefing & \\
& & Discussion & \\
\hline Activity 4 & Client-provider interaction & Video (or & 45 minutes \\
& & alternative & \\
& & presentation) & \\
& & Discussion & \\
\hline \multirow{2}{*}{ Total duration } & & \multicolumn{2}{c}{ hours, } \\
& & & $\mathbf{3 0}$ minutes \\
\hline
\end{tabular}

\section{OVERVIEW}

In this module, some tools for effective communication will be learned through exercises, role-plays, use of video (or alternative presentation) and discussions.

\section{MATERIALS}

Writing board, newsprint, colored markers (chalk) for newsprint and writing board, Plastercine, TV, VCR 


\section{LEARNING OBJ ECTIVES}

At the end of the module, the participants will be able to:

- DESCRIBE the different communication tools.

- APPLY different types of tools appropriately.

- EXPLAIN the various types of questions and list their positive and negative aspects.

- IDENTIFY the strengths and weaknesses in a client-provider interaction and improve such interaction by using appropriate communication skills and tools.

\section{KEY LEARNING POINTS}

- Appropriate use of communication tools facilitates effective communication

- Active listening encourages others to speak freely and express their feelings without inhibitions.

- To understand the core problem, skill in asking questions is important. 


\section{ACTIVITY 1: COMMUNICATION TOOLS}

\section{TRAINER'S NOTE}

- Prepare for a briefing on four of the tools of communication: reflective listening, stroking, ownership and "I" statements (TM 7.1).

- Prepare about 20-25 statements that would require the use of different communication tools, writing each statement on a different Zopp card (TM 7.2).

- Ensure that a trainer or co-trainer is present with each group during the exercise to observe and give necessary guidance.

\section{INSTRUCTIONS}

1. BRIEF participants on communication using these concepts:

$\rightarrow$ Good communication is a difficult process to master; however, it is a skill that can be learned and learned well.

$\rightarrow$ For performing a skill some tools are used (e.g., a doctor has a stethoscope, an electrician and a gardener have their own special tools).

$\rightarrow$ In communication, there are also tools that are helpful for making interpersonal communication successful. 
2. INFORM the participants that we will discuss just a few of the many tools for communication.

\section{REMINDER: TOOLS OF COMMUNICATION}

$\checkmark$ Reflective listening

$\checkmark$ Stroking

$\checkmark$ Ownership

$\checkmark$ 'l' Statements

$\checkmark$ Types of questions

$\checkmark$ Active listening

3. GIVE a briefing on four of the tools of communication giving examples: reflective listening, stroking, ownership and ' $I$ ' statements (TM 7.1).

4. DISCUSS each tool and provide opportunities for practice.

5. TELL the participants that there will be an $\rightarrow$ EXERCISE $\leftarrow$.

6. DIVIDE all participants into groups of three.

7. TELL each group that they will need to decide who will play each of these rolls within their group: communicator, respondent, observer.

8. PROVIDE the statements written on the slips of paper/Zopp cards, which were prepared beforehand, to the groups.

9. ASK the communicator to make the statement and instruct the respondent to reply using the appropriate communication tool. The observer is to watch and give feedback. 
10. TELL each group to rotate the group members through the different roles (observer, respondent, communicator) so everyone gets to practice each role.

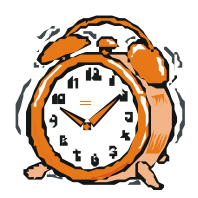

\section{ALLOW 40 minutes.}

11. REASSEMBLE the participants and ask them the following questions:

$\rightarrow$ How did you feel?

$\rightarrow$ Were you able to use the tools?

$\rightarrow$ Do you think the tools are helpful?

12. CONCLUDE the activity by acknowledging that the application of tools is difficult but useful for building rapport with clients and making the client-provider interaction more effective. 


\section{ACTIVITY 2: TYPES OF QUESTIONS}

\section{TRAINER' S NOTE}

- Prepare for briefing on types of questions (and examples) (TM 7.3).

\section{INSTRUCTIONS}

1. REMIND the participants that in the previous activity they learned about four of the tools of communication. Now tell them that another of the communication tools is asking appropriate questions.

2. ASK the participants why we ask questions and list their answers on the board/ newsprint.

3. DISCUSS their responses/ points and add any information that was missed.

4. ASK some volunteers to share a few common questions they ask during a typical client-provider interaction and list these on the board/ newsprint. 
5. BRIEF participants on the types of questions and their use.

\section{REMINDER: FOUR TYPES OF QUESTIONS}

$\checkmark$ Open-ended: used early in the interview

$\checkmark$ Closed:

$\checkmark$ Indirect: mostly used in taking medical history

$\checkmark$ Suggestive: the question itself suggests an answer; these should be avoided

6. ENSURE comprehension by going back to the list of questions the participants came up with (on the newsprint/ board) and ask them to identify what type of question each of their questions are: openended, closed, indirect or suggestive.

\section{EXAMPLES OF TYPES QUESTIONS:}

$\checkmark$ Open-ended: What is your husband's opinion of family planning? (Should be mostly used to help clients relax.)

$\checkmark$ Closed: What is your name [or age or marital status, etc. ]? (Mostly used when taking medical history in the early part of the interview.)

Indirect: How did you receive this injury? (Best for asking about sensitive issues.)

$\checkmark$ Suggestive: You will buy the medicines from the store? Did your husband beat you? (The question itself suggests an answer; these should be avoided.) 
Section II Trainer's Guide

7. CONCLUDE by reminding the participants which types of questions are best for certain situations, and which should be avoided. 


\section{ACTIVITY 3: LISTENING}

\section{TRAINER'S NOTE}

- Choose one of two exercises; one appears in this activity starting at instruction 2; the alternative appears in the training materials (TM 7.4).

- Prepare for a briefing on listening (TM 7.5).

\section{INSTRUCTIONS}

1. INFORM the participants that listening is an important component of interpersonal communication.

2. TELL the participants that there will be an $\rightarrow$ EXERCISE $\leftarrow$. Choose whether to do the following exercise or the one in the training materials (TM 7.4). If you choose to do the alternate exercise, proceed to instruction 7 below after conducting that exercise.

3. TELL the participants the following:

$\rightarrow$ I will be giving you a test. You will need to have a pencil or pen and a piece of paper. You will have two minutes to complete the test. The first person to finish will get a prize.

4. LOOK at your watch to give the impression that you are serious. 
5. GIVE the following instructions:

$\rightarrow$ First listen to all the directions before you do anything.

$\rightarrow$ Write today's date on the right hand corner of your page.

$\rightarrow$ Write your name.

$\rightarrow$ Multiply 3 and 4 .

$\rightarrow$ Solve $5+2-3$.

$\rightarrow$ Draw a square.

$\rightarrow$ Now that you have listened to all the directions, attempt only number 2 .

6. PROCESS the exercise by asking and discussing the following questions:

$\rightarrow$ Who wrote the correct answer?

$\rightarrow$ What helped you get the correct answer?

$\rightarrow$ Who missed the correct answer?

$\rightarrow$ What made you miss the correct answer?

7. SYNTHESIZE the responses and emphasize that active listening is important in order to collect correct information.

8. EMPHASIZE that listening is the key to effective communication but it is a skill that has to be developed.

9. GIVE a briefing on the definition of listening and active listening (why we listen, what we listen to, and how we listen actively) (refer to TM 7.5).

10. SUMMARIZE the whole session by emphasizing that communication is one of the most important tools the service provider can use to improve client-provider interaction. 


\section{ACTIVITY 4: CLIENT-PROVIDER INTERACTION}

\section{TRAINER'S NOTE}

- IF you do not have a copy of the video to show, then you will be asked to do an alternative presentation. The alternative activity is provided in TM 7.6. You and the co-trainer will be putting on this role-play and you will need to prepare in advance.

- IF you will be watching the video then prepare as follows:

- Watch the video for this activity beforehand and prepare notes on the important points.

- Arrange for a television, VCR and the prepared video for this activity; be sure that everything is in working order.

- Set the client-provider interaction according to the type of participants (i.e., community workers or based in static centers).

- Show the background first and then the client-provider interaction (first part).

- Have enough copies of the assessment sheet for everyone (TM 10.7).

\section{INSTRUCTIONS}

(NOTE: if you will be showing the video, then follow the instructions below. If you do not have the video to show, then you will be doing an alternative presentation provided in TM 7.6. If you are doing the alternative presentation then you will use the following instructions except that you will refer to the alternative presentation rather than the video; the basic steps will be the same for both the video and the alternative presentation.) 
1. TELL the participants that they will watch a $\rightarrow$ VIDE $O \leftarrow$ giving some background and then showing a client-provider interaction.

2. DISTRIBUTE the assessment sheets (TM 10.7). Tell them they will be given time to complete their assessment sheets at the end of the video.

3. ASK the participants to identify the strengths and weaknesses in the interaction in the video on the basis of communication skills/ tools, and note them on the assessment sheet.

4. SHOW the video (background and client-provider interaction, part $1)$.

5. ASK the participants to fill in the assessment sheet after the video.

\section{ALLOW 5 minutes.}

6. ASK each participant to point out the strengths and weaknesses in the interaction.

7. WRITE their responses on the board/ newsprint.

8. DISCUSS each point as to what should have been done and how.

9. CONCLUDE by emphasizing that for the client-provider interaction to lead to positive results, appropriate skills and tools of communication should be used. 


\section{Games/energizers/ exercises: to use after Module 7}

Note that in the six-day schedule for training in the client-centered approach, on page 17, there is a fifteen-minute period on Day 3, from 12:15 to 12:30 (after Module 7), and on Day 4, from 10:45 to 11:00 (after Module 9), for either games, exercises or energizers. Please see Games/ Exercises/ Energizers at the very end of the training materials for suggestions as to activities you could do in these time slots. These are suggestions for you to use to give participants a brief break and to relax and/ or reinvigorate them for the next session. You are welcome to use other similar activities of your own.

You may also use these or similar activities at any time that you feel the participants need a change of pace from the formal activities or if you find yourself with extra time. 



\section{Module 8: Behavior}





\section{BEHAVIOR}

\section{SCHEDULE FOR MODULE 8}

\begin{tabular}{llll}
\hline Content & & Method & Duration \\
\hline Activity 1 & Introduction & Briefing/ story & 10 minutes \\
\cline { 2 - 4 } & $\begin{array}{l}\text { Definition of: } \\
\text { - }\end{array}$ & Attitudes & 20 minutes \\
& - Beliefs & & \\
& - Values & & \\
& How behaviors are formed & & \\
\hline $\begin{array}{l}\text { Activities } \\
2 \text { and } 3\end{array}$ & $\begin{array}{c}\text { Types of behavior and } \\
\text { demonstration of types of }\end{array}$ & $\begin{array}{l}\text { Zopp cards } \\
\text { behavior }\end{array}$ & $\begin{array}{l}\text { Discussion } \\
\text { Rour }\end{array}$ \\
\hline Total duration & Role-play & \\
\hline
\end{tabular}

\section{OVERVIEW}

This module gives an insight into the different types of behavior exhibited by people (aggressive, assertive and passive), and the factors that form or affect them.

Through different role-plays and exercises we see how different types of behavior can influence the behavior of others. 


\section{MATERIALS}

Writing board, newsprint, colored markers (chalk) for newsprint and writing board, Zopp cards, tape, client profile for role-plays, Plastercine

\section{LEARNING OBJ ECTIVES}

At the end of the module, the participants will be able to:

- DEFINE behavior.

- DEFINE beliefs, values and attitudes and how these shape behavior.

- DESCRIBE three main types of behavior.

- DISCUSS reasons for these behaviors, their effect on others and ourselves and how they can be changed and why.

\section{KEY LEARNING POINTS}

- An individual can exhibit different types of behavior on different occasions.

- We have the ability to control and modify our behavior.

- Our behavior affects the behavior of others. 


\section{ACTIVITY 1: DEFINITIONS}

TRAINER'S NOTE

- Review the two stories that you will be telling.

- Prepare to brainstorm/ discuss the definitions of beliefs, values, attitudes, and behavior (refer to TM 8.1 to help stimulate discussion).

\section{INSTRUCTIONS}

1. TELL the story shown here:

\section{STORY}

A man was walking along the road when he saw someone breaking stones.

The man asked the person he saw: "What are you doing?"

"Can't you see I am breaking stones?" he replied.

He went further and saw another man sitting beside the road and breaking stones.

The man asked this person as well: "What are you doing?"

"I am breaking stones that will be used to build a road," was the reply.

When he saw a third person he asked a similar question. This time the person replied: "I am breaking stones that will be used to build a road that will lead to the school where the children from my community will study. This is my contribution to making that happen and to educating my community." 
2. ASK the following questions about this story:

$\rightarrow$ What happened?

$\rightarrow$ Why did this happen?

$\rightarrow$ What was the moral of the story?

$\rightarrow$ What have we learned from it?

LESSON LEARNED COULD REFLECT: Behavior depends on the attitude of the person, which derives from their background, knowledge, and life experiences.

3. SYNTHESIZE the impact of story one.

REMINDER: Behavior changes according to situations.

4. BRAINSTORM with the participants on the meaning of these words separately: belief, values, attitudes and behavior.

5. WRITE their responses on a board, and through discussion evolve their definitions and the affect they have on the behavior of an individual.

\section{DEFINITIONS SHOULD REFLECT:}

Belief: $\quad$ An idea thought to be true by an individual that may or may not be supported by facts.

Value: $\quad$ An opinion or standard that is important to an individual. Values are formed or influenced by religious, educational and cultural factors or grow from personal experiences.

Attitude: A view or opinion that is formed from a person's beliefs and values, which in turn shapes behavior.

Behavior: The way we act towards others. 
6. DISCUSS whether or not beliefs, values and attitudes can change.

7. DISCUSS how behavior is built from our attitudes and upbringing, and can change.

8. TELL the story shown here:

\section{STORY}

A woman was sitting in her house and there was a knock on the door. She saw that it was the milkman. She took the milk, paid him his money and went back into her house.

She boiled the milk and when her son came to ask for milk she gave him a glass.

There was another knock on the door. It was the milkman who had come back to say she had not paid him the right money. They argued until she gave him the extra money and went back into her house. When her other son came to ask her for milk she brushed him off and told him to away and not bother her. The child went away upset.

9. ASK the same questions that followed the first story.

10. DISCUSS how behavior is also built from our social circumstances, family background, religion, education, etc., and hence can change.

11. CONCLUDE by emphasizing that since behaviors stem from beliefs, values and attitudes, in order to change them we have to begin by changing beliefs and values. 


\section{ACTIVITY 2: TYPES OF BEHAVIOR}

\section{TRAINER' S NOTE}

- Review material on behavior to help stimulate discussion (TM 8.1).

- Have sufficient numbers of Zopp cards so that all participants have five to six.

\section{INSTRUCTIONS}

1. TELL the participants that to bring about a positive change in behavior, one should have an understanding of how we behave toward other people, what affect this has on us and others, and who benefits.

2. DISTRIBUTE 5 to 6 Zopp cards to each participant.

3. ASK them to write one behavior exhibited by different people on each card (e.g., rude, kindhearted, etc.).

\section{ALLOW 5- 6 minutes.}

4. COLLECT all cards.

5. INVITE volunteers to help organize the information by grouping the cards that describe similar behaviors together. Do this on the floor in the middle of the group. Once this is done, read the behaviors from one set of the grouped cards. Ask what sort of person is being described and summarize after the group's input by saying, "Can 
we call this person aggressive [or whatever is appropriate]. In the end, the people described by the behaviors should be labeled using one of these three labels: passive, aggressive or assertive. You should help the groups achieve this labeling.

6. DISCUSS some of the characteristics of each behavior further if need be.

7. DERIVE definitions of passive, aggressive and assertive behavior from the discussion.

\section{REMINDER: CATEGORIZING BEHAVIOR}

$\checkmark$ Passive/non-aggressive: A person tries to avoid conflict and unpleasant and risky situations, has low self-esteem, is apologetic and hesitant.

- Aggressive: A person shows a tendency to put others down, ignores the right of others, dominates, attacks, blames, and shows hostility and anger.

$\checkmark$ Assertive: A person is appropriately honest, is empathetic, respects the rights of others, listens to others, has positive feelings about him/ herself.

8. CONCLUDE by reviewing types and characteristics of behavior (using TM 8.1 as a guide). 


\section{ACTIVITY 3: \\ DEMONSTRATION OF TYPES OF BEHAVIOR}

\section{TRAINER'S NOTE}

- Prepare for role-plays. The behavior of the headmaster/ headmistress changes in each of the three role-plays; however, the basic scenario remains the same. Explain the scenario to the pairs individually so that others do not overhear (TM 8.2).

\section{INSTRUCTIONS}

1. TELL the participants there will now be three $\rightarrow$ ROLEPLAYS $\leftarrow$.

2. INVITE six volunteers, two for each role-play, to participate; assign each team one of the role-plays (TM 8.2).

3. INSTRUCT each pair individually, where others cannot overhear, as to how they are to perform their version of the role-play.

4. ASK the rest of the participants to be observers.

5. INVITE group one to perform their role-play in three to four minutes.

6. PROCESS after the role-play by asking those taking the different roles the following questions:

- The mother

$\rightarrow$ What were your feelings?

$\rightarrow$ How did you feel about the provider?

- The headmistress

$\rightarrow$ What were your feelings/ reactions? 


\section{- The observers}

$\rightarrow$ What characteristics did the provider show?

$\rightarrow$ What did you think was the reason for the behavior shown?

$\rightarrow$ How did you feel about the provider?

7. SYNTHESIZE by drawing out from the participants answers to the following questions:

$\rightarrow$ Reason for this behavior?

$\rightarrow$ Feelings about self?

$\rightarrow$ Feelings of others when engaged in this behavior?

8. CONDUCT the next two role-plays following the same process as for the first (steps 3-7).

9. DISCUSS the role-plays in light of client-provider interactions, highlighting that when a provider acts helpless or aggressive the client becomes irritated and, in many instances, their behavior changes to aggressive.

10. CONCLUDE by reminding the participants that one person can show different behavior in different situations. Emphasize that one should try to exhibit assertive behavior at all times. 



\section{Module 9: Power}





\section{POWER}

\section{SCHEDULE FOR MODULE 9}

\begin{tabular}{llll}
\hline Content & Methodology & Duration \\
\hline Activity 1 & Meaning and sources of power & Exercise & 45 minutes \\
& & Discussion & \\
\cline { 2 - 4 } & & Brainstorming \\
& Group work & \\
& & Discussion & \\
\hline Activity 2 & Types of power & Briefing & 45 minutes \\
& & Discussion & \\
& Role-play & \\
\hline \multirow{2}{*}{ Total duration } & & $\mathbf{1}$ hour, \\
& & $\mathbf{3 0}$ minutes \\
\hline
\end{tabular}

\section{OVERVIEW}

This is a crucial module that explains how through a process of empowering the service providers their clients can also be empowered. During this module, the concepts of sources and types of power and power dynamics are learned through exercises, role-plays and discussion.

\section{MATERIALS}

Writing board, newsprint, colored markers (chalk) for newsprint and writing board, Plastercine

\section{LEARNING OBJ ECTIVES}

At the end of the module, the participants will be able to:

- DEFINE power. 
- ENLIST and prioritize sources of power and how they influence decisionmaking.

- DESCRIBE the different types of power and how they can be dealt with.

S KEY LEARNING POINTS

- Power itself is neither good nor bad but it is the use of power that can be good or bad.

- Sharing of power does not in anyway diminish one's own power but instead enhances prestige and honor.

- A situation of powerlessness can be turned into powerfulness with effort and support; this is particularly true when working with others as a team. 


\section{ACTIVITY 1: MEANING AND SOURCES OF POWER}

S. TRAIner's NOTE

- Prepare for a discussion on power (TM 9).

\section{INSTRUCTIONS}

1. TELL the participants that we will now play a $\rightarrow$ GAME $\leftarrow$.

2. ASK the participants to work in pairs.

3. INSTRUCT one partner to close one fist firmly.

4. INSTRUCT the second partner to try to open their partner's fist using any technique they can think of.

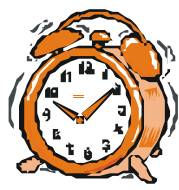

ALLOW 2 minutes.

5. REPEAT the game with the second partner closing the fist and the first partner trying to open the fist.

ALLOW 2 minutes. 
6. ASK each partner in the game the following questions:

$\rightarrow$ Were you able to open the fist?

$\rightarrow$ If so, how did you do it? (Write the responses on the board or newsprint.)

$\rightarrow$ What were your feelings when the fist was closed?

$\rightarrow$ How did you feel when it was opened?

$\rightarrow$ [NOTE: usually the term "power" comes out when participants are answering the preceding questions. Only if it does not, then reflect on how power is part of what just happened. Link, if possible, their responses, which you put on the board, to the second question.]

7. ASK the participants what power means?

ANSWER SHOULD REFLECT: Power is the ability to do something or have influence or control.

8. BRAINSTORM with the participants about sources of power and note them on the board or newsprint (refer to TM 9 for examples of sources of power).

9. TELL participants that there will now be an $\rightarrow$ EXERCISE $\leftarrow$.

10. DIVIDE the participants into three to four groups of seven to eight members. 
11. INSTRUCT each group to identify about six sources of power from the list just prepared and to put on newsprint their own list prioritizing these sources of power according to their level of importance.

\section{ALLOW 10 minutes.}

12. ASK each group to put up the newsprint with their prioritized list and present them to the participants.

13. COMPARE how different groups have rated the various sources of power.

14. CONCLUDE by emphasizing that knowledge and positive behavior are very strong sources of power (whether the group mentions them or not), which do not decrease by sharing with others. 


\section{ACTIVITY 2: TYPES OF POWER}

\section{TRAINER' S NOTE}

- Prepare for briefing on various types of power (TM 9.1).

- Prepare for a briefing on change in terms of power dynamics (TM 9.2).

- Prepare to explain the role-plays. Note that a still scenario requires the players to take positions that they believe shows the action requested; the players then freeze in those positions, not moving or speaking, until told to relax.

\section{INSTRUCTIONS}

1. BRIEF the participants on the various types of power (refer to TM 9.1).

\section{REMINDER: TYPES OF POWER}

$\checkmark$ Power over: ability to have control over others.

$\checkmark$ Power to: ability to transfer power from one person to another.

$\checkmark$ Power with: collective power of people united for a cause.

$\checkmark$ Power within: inner power that we all possess.

2. DISCUSS transfer of power in client-provider interactions; ask the following questions to stimulate discussion, if needed, or use example provided below:

$\rightarrow$ How can a transfer of power take place?

$\rightarrow$ What effect would a transfer of power have? 


\section{EXAMPLE}

(note: cite similar examples or ask participants to contribute examples from their own experience):

$\checkmark$ If a woman is given complete information on the danger signs during pregnancy and labor and has discussed her options should an emergency arise, then the family can decide for themselves about an appropriate solution if needed.

$\checkmark$ By providing relevant information (power to) to the client and discussing options according to their needs, the client is empowered (their power within is increased) to make decisions to address their own needs.

3. ASK the participants:

$\rightarrow$ Is it possible to be powerful and powerless at the same time?

ANSWER SHOULD REFLECT: Yes, a person can be powerful and powerless at the same time (e.g., powerless in front of the boss and powerful in front of subordinates).

$\rightarrow$ Can a situation of being powerless be changed into being powerful?

ANSWER SHOULD REFLECT: Yes, by improving performance and by networking with others.

4. TELL the participants that to demonstrate the concept of power there will be two versions of $\rightarrow$ ROLE-PLAYS $\leftarrow$.

5. FORM two groups of five to six volunteers.

6. INSTRUCT group one, without others overhearing, to prepare a roleplay of a situation relating to their job when they were powerless. The group must demonstrate using their power within and group 
together for the same cause (power with). As a group they can go to the person who has power over and get the problem solved.

7. INSTRUCT group two, so that others do not overhear, to create a still scenario (or sculpture) showing power over a number of people. The group can develop their still sculpture about a situation involving their job(s) or any other situation that suits them (e.g., landlord/ zamindari system, etc.). Explain the concept of a still scenario if necessary.

\section{ALLOW 5 - 6 minutes (for both groups to prepare).}

8. ASK the rest of the participants to observe and identify the types of power that are being portrayed but not to discuss these during the performance

9. INVITE group one to perform the role-play.

10. PROCESS the role-play by asking the following questions of the individuals playing the different roles:

- Observers

$\rightarrow$ What types of power were seen?

- Players

$\rightarrow$ The person with power over: How did it feel to be powerful and then powerless?

$\rightarrow$ The other players: How did it feel to be powerless and then powerful?

11. INVITE group two to perform their still scenario showing power over, giving the observers the same instructions as were given for group one's role-play.

12. AFTER a short time, instruct the performers to "change" using a firm voice. After a few seconds, ask them to become still again. 
13. PROCESS the scenario, asking the performers these questions:

- Observers

$\rightarrow$ What was shown initially?

$\rightarrow$ What occurred after the players were told to change?

\section{- Players}

$\rightarrow$ Boss/ Person with power: How did it feel to be powerful?

$\rightarrow$ Other performers: How did it feel to be powerless?

$\rightarrow$ Ask anyone who did not change position after the instruction was given why they did not change?

14. GIVE a short briefing on change in terms of power dynamics (TM 9.2).

15. DISCUSS the concepts of power in the context of the people in a community who do not want to change, even if they have the opportunity. Why does this happen?

16. SYNTHESIZE the role-plays by emphasizing the dynamics of power transition (i.e., how from being powerless one can become powerful).

17. CONCLUDE by reiterating that sharing of power does not in any way diminish one's own power but instead it enhances prestige and honor. 


\section{Games/exercises/ energizers: to use after Module 9}

Note that in the six-day schedule for training in the client-centered approach, on page 17, there is a fifteen-minute period on Day 3, from 12:15 to 12:30 (after Module 7), and on Day 4, from 10:45 to 11:00 (after Module 9), for either games, exercises or energizers. Please see Games/ Exercises/ Energizers at the very end of the training materials for suggestions as to activities you could do in these time slots. These are suggestions for you to use to give participants a brief break and to relax and/ or reinvigorate them for the next session. You are welcome to use other similar activities of your own.

You may also use these or similar activities at any time that you feel the participants need a change of pace from the formal activities or if you find yourself with extra time. 


\section{Module 10: SAHR}





\section{SAHR}

\section{SCHEDULE FOR MODULE 10}

\begin{tabular}{|c|c|c|c|}
\hline Content & & Methodology & Duration \\
\hline \multirow{5}{*}{$\begin{array}{l}\text { Activity } \\
1\end{array}$} & \multirow{3}{*}{$\begin{array}{l}\text { SAHR background: definition and } \\
\text { difference between motivation, } \\
\text { counseling and negotiation }\end{array}$} & Brainstorming & \multirow{3}{*}{$\begin{array}{l}20 \\
\text { minutes }\end{array}$} \\
\hline & & Briefing & \\
\hline & & Discussion & \\
\hline & \multirow{2}{*}{$\begin{array}{l}\text { Prerequisites and impediments in } \\
\text { good negotiation }\end{array}$} & Brainstorming & \multirow{2}{*}{$\begin{array}{l}10 \\
\text { minutes }\end{array}$} \\
\hline & & Discussion & \\
\hline \multirow{5}{*}{$\begin{array}{l}\text { Activity } \\
2\end{array}$} & SAHR- its components & Briefing & \multirow{5}{*}{$\begin{array}{l}30 \\
\text { minutes }\end{array}$} \\
\hline & - Salutation & Discussion & \\
\hline & - Assessment including intentions & & \\
\hline & - Help & & \\
\hline & - Reassurance & & \\
\hline \multirow{5}{*}{$\begin{array}{l}\text { Activity } \\
3\end{array}$} & \multirow{5}{*}{$\begin{array}{l}\text { Practical application of various } \\
\text { components of SAHR }\end{array}$} & Briefing & 4 hours, \\
\hline & & Case studies & \multirow{4}{*}{$\begin{array}{l}15 \\
\text { minutes }\end{array}$} \\
\hline & & Role-plays & \\
\hline & & Exercises & \\
\hline & & Discussions & \\
\hline $\begin{array}{l}\text { Activity } \\
4\end{array}$ & $\begin{array}{l}\text { SAHR in action: client-provider } \\
\text { interaction-identification of } \\
\text { strengths and weakness }\end{array}$ & $\begin{array}{l}\text { Video (or } \\
\text { alternative } \\
\text { presentation) } \\
\text { Discussions }\end{array}$ & $\begin{array}{l}45 \\
\text { minutes }\end{array}$ \\
\hline
\end{tabular}

Total duration

6 hours 


\section{OVERVIEW}

This module introduces SAHR (Salutation, Assessment, Help and Reassurance), which is a guideline for service providers to assess and meet the reproductive health $(\mathrm{RH})$ needs of clients.

The guideline includes developing a rapport with the client, identifying their reproductive health needs, addressing those needs through negotiation, empowering them by providing relevant information and finally reassuring them.

This is practiced through case studies, role-plays, use of video (or alternative presentation) and discussion.

\section{MATERIALS}

Writing board, newsprint, colored markers (chalk) for newsprint and writing board, assessment sheets, Plastercine

\section{LEARNING OBJ ECTIVES}

At the end of the module, the participants will be able to:

- DEFINE and differentiate between motivation, counseling and negotiation.

- DISCUSS prerequisites and barriers to good counseling and how to overcome these.

- UNDERSTAND and apply the principles of SAHR.

\section{KEY LEARNING POINTS}

- SAHR (Salutation, Assessment, Help and Reassurance) is a guideline for effectively meeting the reproductive health needs of the clients. 
- It involves giving respect to clients and their ideas and it is the key for carrying out any effective negotiation.

- Listening is more important than telling.

- By appropriately determining the needs of the clients, the help component becomes more focused and direct. 


\section{ACTIVITY 1: SAHR BACKGROUND: MOTIVATION, COUNSELING AND NEGOTIATION}

\section{TRAINER' S NOTE}

- Prepare for brainstorming/ discussion on the following aspects of communication: motivation, counseling and negotiation (TM 10.1).

\section{INSTRUCTIONS}

1. BRAINSTORM with the participants on the meaning of motivation (TM 10.1). Write their responses on the board or newsprint.

2. DISCUSS motivation, coming up with a definition and when it is used.

3. DISCUSS counseling, coming up with a definition (TM 10.1).

4. ASK the participants when they think good counseling takes place (TM 10.1). List these on the board/newsprint. Add if needed from the following list: 


\section{ANSWERS COULD REFLECT:}

$\checkmark$ An inviting climate

$\checkmark$ Open-ended questions

$\checkmark$ Enough time to respond to queries

$\checkmark$ Good listening skills

$\checkmark$ Appropriate body language

$\checkmark$ Respect for the client's opinions

$\checkmark$ Explored options

$\checkmark$ Shared knowledge

$\checkmark$ Assertiveness

5. INVITE one of the participants to read the list.

6. ASK what the impediments to good counseling might be.

7. WRITE their responses on the board.

8. DISCUSS how these can be overcome.

9. BRAINSTORM with the participants, developing a definition and a process for negotiation and discuss how negotiating is different from counseling (TM 10.1).

10. CONCLUDE by reviewing the definitions and distinctions between motivation, counseling and negotiation. 


\section{ACTIVITY 2: SAHR COMPONENTS}

\section{TRAINER'S NOTE}

- Prepare a chart by dividing the writing board or newsprint into four sections. Put a heading at the top of each section using roman numerals (I-IV). When participants are describing the routine process of dealing with clients, make brief notations under the appropriate headings. ONLY you should know that you are grouping the "steps" they describe as follows: (I) greeting or setting climate; (II) assessing needs; (III) providing treatment/referral; and (IV) reassuring clients. Participants will label the four headings later.

- Prepare for discussion on components of SAHR (TM 10.2; review also TM 10.3, 10.4a and 10.4b).

- Prepare for briefing on reproductive health intentions (see sections in TM 10.2, 10.3, 10.4a and 10.4b, where questions on RH intentions appear).

\section{INSTRUCTIONS}

1. EXPLAIN to the participants that there will be a discussion on the routine process of dealing with clients in order to meet their needs. Use the appropriate question to begin the discussion (whether participants are static center staff or community workers):

\section{- Static center staff}

$\rightarrow$ ASK volunteers to talk through the process of dealing with a client in a clinic situation from the moment he or she enters the room until they leave after treatment. 


\section{- Community workers}

$\rightarrow$ ASK volunteers to detail the process from the moment the community worker knocks on the door until she leaves.

2. RECORD the responses, grouping them appropriately under the column headings (IV) on the prepared chart.

3. FILL IN any points that might have been missed, discussing the reasons why that process should be carried out (refer to TM 10.3a or $\mathbf{1 0 . 3 b ) \text { . }}$

4. THROUGH discussion help the participants to give names to the four sections on the chart: (I) salutation (greeting or setting the climate); (II) assess (assessing needs); (III) help (providing treatment or referral); and (IV) reassure (providing reassurance). The highlighted terms make up the $\mathbf{S}-\mathbf{A}-\mathbf{H}-\mathbf{R}$ components. (TM 10.2).

5. BRIEF participants on the importance of asking clients about their reproductive health intentions (refer to sections in TM 10.2, 10.3, 10.4a and 10.4b).

DEFINITION OF REPRODUCTIVE HEALTH INTENTIONS: The client's reproductive health plans for the future.

6. CONDUCT a group discussion to develop questions for assessing RH intentions for family planning, safe motherhood and childcare.

7. ADD any questions that might have been left out that would help identify a client's RH intentions for family planning, safe motherhood and childcare. (Refer to sections in TM 10.2, 10.3, $\mathbf{1 0 . 4 a}$ and $\mathbf{1 0 . 4 b}$ where questions on RH intentions appear.) 


\section{EXAMPLES OF QUESTIONS TO HELP IDENTIFY A CLIENT'S RH INTENTIONS FOR FAMILY PLANNING, SAFE MOTHERHOOD AND CHILDCARE:}

\section{If woman is not pregnant:}

$\checkmark$ Do you want to have another child?

If yes: When?

If no: Are you doing something (using any contraceptive) to avoid another pregnancy?

$\checkmark$ What are your husband's thoughts about the number of children and when to have the next child?

\section{If woman is pregnant:}

$\checkmark$ Where will you deliver and with whom?

$\checkmark$ If danger signs appear, where will you go and how?

\section{Regarding childcare:}

$\checkmark$ Breastfeeding. Do you intend to breastfeed the baby? If no: Why not?

$\checkmark$ Immunization. Have you had your baby immunized? If no: Do you intend to immunize your baby? If no: Why not?

8. EMPHASIZE that if the intentions of a woman are clear (e.g., she wants family planning, wants another child, will not go to hospital whatever may happen, etc.) then the help component can be tailored according to her needs. This saves time for the client and the service provider who does not have to give unnecessary information. 


\section{ACTIVITY 3: APPLICATION OF SAHR}

\section{TRAINER'S NOTE}

- Review SAHR material, focusing on material for either community workers or static center staff depending on the participants (TM 10.2, $\mathbf{1 0 . 3}, \mathbf{1 0 . 4 a}$ or $\mathbf{1 0 . 4 b )}$. You may make a copy of the SAHR posters if you choose to display them.

- Prepare a checklist of each step of SAHR separately on chart/newsprint.

- Two scenarios are presented for each case study and role-play; pick which scenario you will use for practice in using SAHR components. Make enough copies of the appropriate case studies and role-plays for each group, depending on whether participants are static center staff or community workers (case studies TMs $\mathbf{1 0 . 5 a - d ; ~ r o l e - p l a y s ~} \mathbf{1 0 . 6 a - d ) . ~}$ Where time and interest permit you may choose to do a second scenario for any of the SAHR components.

- Make enough copies of the assessment sheet for all participants to use following role-plays (TM 10.7).

REMINDER: you may prepare other case studies and role-plays that draw on local conditions.

\section{INSTRUCTIONS}

1. REVIEW SAHR by asking the participants to explain the steps (TM 10-4a and 10.4b, depending on the participants).

2. TELL participants that they will now have an opportunity to practice the SAHR concepts of salutation and assessment by discussing one or two case studies and conducting one or two roleplays. 
3. TELL participants that there will be a $\rightarrow$ CASE STUDY $\leftarrow$,

4. PREPARE for the case study by dividing the participants into three to four groups of five to six people each.

5. DISTRIBUTE a case study to each group. (TM 10.5a or $\mathbf{1 0 . 5 b \text { , }}$ depending on whether participants are static center staff or community workers).

6. ASK each group to read the case study scenario and answer the questions given at the end of the case study. Tell them to select a rapporteur to record and present their group's work.

7. GO around and answer any questions as participants work on their presentations; remind them of the time limit if too much time is being spent on one question.

\section{ALLOW 20 minutes.}

8. INVITE each group to present.

9. DISCUSS each question by inviting comments from other participants.

10. REFER to TM $\mathbf{1 0 . 4 a}$ or $\mathbf{1 0 . 4 b}$ (depending on whether the trainees are static center staff or community workers) as a guide to stimulate thinking and to ensure that all points have been covered.

11. PUT up the pre-prepared checklist on salutation and assessment on the board and see whether all points have been covered.

12. DO a second $\rightarrow$ CASE STUDY $\leftarrow$ if time and interest allow, or if you feel that participants need additional practice (use the other scenario from TM 10.5a or $\mathbf{1 0 . 5 b}$ ).

13. SUMMARIZE the main points in the SAHR checklist having to do with salutation and assessment.

14. Tell participants there will now be $a \rightarrow$ ROLEPLAY $\leftarrow$. 
15. BRING the participants together again and prepare for the role-play by asking for two volunteers to play the roles of client and provider. Give the volunteers a copy of the scenario they will perform so that they can review it briefly.

16. DISTRIBUTE an assessment sheet to all participants for filling out weaknesses and strengths in the role-play(s) that they will observe.

17. ASK the volunteers to conduct the role-play following the instructions provided (TM $\mathbf{1 0 . 6 a}$ or $\mathbf{1 0 . 6}$, depending on whether participants are static center staff or community workers).

18. AFTER the role-play ask observers to fill in the assessment sheet.

\section{ALLOW 5 minutes.}

19. PROCESS the role-play by asking each participant about first the strengths and then weaknesses in the interaction.

20. WRITE their responses on board/newsprint under separate headings: strengths and weaknesses.

21. ASK the participants how the weaknesses they identified could be improved. Discuss.

22. DO a second $\rightarrow$ ROLE $-P L A Y \leftarrow$ if time and interest allow, or if you feel that participants need additional practice (use the other scenario from TM $\mathbf{1 0 . 6 a}$ or $\mathbf{1 0 . 6 b}$ ).

23. END the role-play(s) by reminding the participants how important it is to listen carefully and get accurate information about client needs.

REMINDER: Good assessment is an important step in meeting client needs. 
24. TELL participants there will now be another $\rightarrow$ CASE STUDY $\leftarrow$,

25. PREPARE for the case study on help and reassure (TM $10.5 \mathrm{c}$ or $\mathbf{1 0 . 5 d}$, depending on whether the trainees are static center staff or community workers) by again dividing the participants into groups of five to six.

26. FOLLOW the steps for the case study used for salutation and assess, including practicing a second scenario for help and reassure, if useful (use the second scenario in TM $\mathbf{1 0 . 5 c}$ or $\mathbf{1 0 . 5 d}$ ).

27. TELL participants there will now be another $\rightarrow$ ROLEPLAY $\leftarrow$.

28. PREPARE for the role-play by asking for two volunteers to perform the selected scenario (TM $\mathbf{1 0 . 6 c}$ or $\mathbf{1 0 . 6 d}$, depending on whether participants are static center staff or community workers).

29. FOLLOW the instructions used for the role-play for salutation and assess, including performing a second scenario for help and reassure, if useful (use the second scenario in TM 10.6c or $\mathbf{1 0 . 6 d}$ ).

30. CONCLUDE by restating the meaning and use of the SAHR components: salutation, assess, help and reassure.

REMINDER: Scenarios for case studies and role-plays provided in this module are examples. The trainer should prepare others that draw on local conditions if that seems appropriate. 


\section{ACTIVITY 4: SAHR IN ACTION}

\section{TRAINER'S NOTE}

- IF you do not have a copy of the video to show, then you will be asked to do an alternative presentation. The alternative activity is provided in TM 10.8. You and the co-trainer will need to be prepared if you will be doing this alternative presentation.

- IF you will be watching the video then prepare as follows: arrange TV and VCR for this session and set it at part II of interaction for community workers or static center staff, depending on the group.

- Make enough copies of the assessment sheets for all participants (TM 10.7).

\section{INSTRUCTIONS}

(NOTE: if you will be showing the video, then follow the instructions below. If you do not have the video to show, then you will be doing an alternative presentation provided in TM 10.8. If you are doing the alternative presentation then you will use the following instructions except that you will refer to the alternative presentation rather than to the video; the basic steps will be the same for both the video and the alternative presentation.)

1. EXPLAIN to the participants that they will see the VIDEO that has the same background as the one seen in the communication session.

2. DISTRIBUTE the assessment sheet (TM 10.7). Tell them that they will be given time at the end of the video to complete the assessment sheet. 
3. ASK them to watch the video and identify strengths and weaknesses keeping in mind all of the sessions that have been conducted during training.

4. SHOW the video (part II).

5. ASK participants to fill in their assessment sheets.

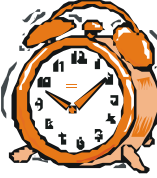

ALLOW 5 minutes.

6. DISCUSS first strengths and then weaknesses in the interaction and how they could be improved.

7. CONCLUDE by summarizing what participants have contributed. 


\section{Module 11: Referral system}





\section{RefERRAL SYSTEM}

\section{SCHEDULE FOR MODULE 11}

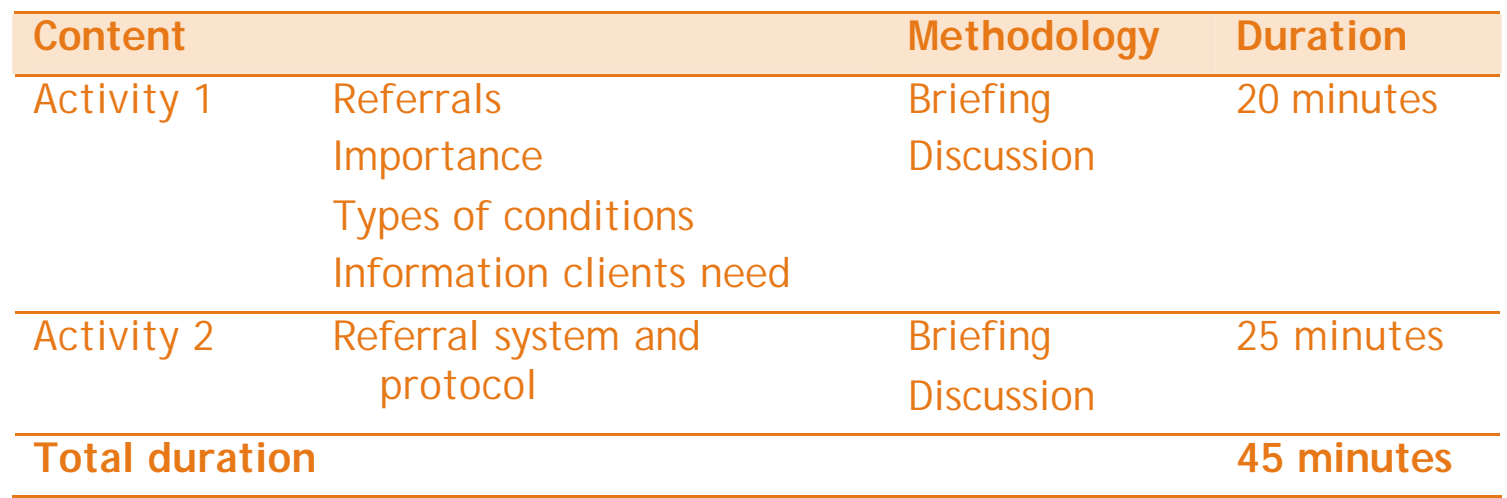

\section{OVERVIEW}

This module discusses the importance of timely referrals to the appropriate facilities. This could include referring up to a higher facility, down to a lower one or cross referrals to other public and private sector health facilities.

\section{MATERIALS}

Board, chalk, newsprint, markers (different colors), Plastercine

\section{LEARNING OBJ ECTIVES}

At the end of the module, the participants will be able to:

- DISCUSS the importance of timely referral.

- LIST the types of facilities and services needed for different reproductive health problems.

- EXPLAIN all of the possibilities within the referral chain. 
Section II Trainer's Guide

- GIVE appropriate information to clients while referring them to another facility.

\section{KEY LEARNING POINTS}

- Timely referral to the appropriate facility can save many lives and reduce reproductive health morbidity and mortality. 


\section{ACTIVITY 1: REFERRALS}

\section{TRAINER'S NOTE}

- Prepare for a general discussion on referrals: when they should occur and what information providers need to give their clients when the make referrals.

\section{INSTRUCTIONS}

1. ASK the participants to name the conditions for which they most commonly refer clients (e.g., family planning, safe motherhood, etc.) and list these on the board or newsprint. Participants may be asked to use their personal experiences to describe cases for which they made referrals. Add to this list if you think there are conditions that call for referrals that they did not mention.

2. DISCUSS the types of services needed for these conditions in terms of staff, equipment, etc. Write these on the newsprint as well.

3. ASK the participants what information should be given to clients when referring them to another facility or provider.

\section{RESPONSES SHOULD INCLUDE:}

$\checkmark$ Reason for referral

$\checkmark$ Where to go

$\checkmark$ When to go

$\checkmark$ Distance to be covered

Time it takes to reach the facility
Convenient mode of transport

$\checkmark$ Directions to the facility

$\checkmark$ Estimated cost 


\section{ACTIVITY 2: \\ REFERRAL SYSTEM AND PROTOCOL}

\section{TRAINER'S NOTE}

- Review the chart of the referral system (TM 11) in order to be prepared to give a briefing on the facilities/ providers to which clients can be referred; copy the chart onto newsprint so that everyone can see it. (Make your own chart if your local situation varies.)

- Use the chart made for activity 1 if it helps make the referral needs clear.

\section{INSTRUCTIONS}

1. INTRODUCE the topic by explaining to the participants that the referral system is a link between health facilities at varying levels to meet the needs of the community in an integrated manner. The referral protocol includes the procedures for making referrals.

2. ASK the participants what types of facilities clients can be referred to. You may refer to the chart made for activity 1 and ask them if they know what facilities in their area provide needed staff and equipment, etc., for the specific conditions and needs that they listed on the chart.

3. RECORD their responses on the board or newsprint making appropriate boxes. (Note: if any facilities have not been mentioned, use TM 11 as a guide to stimulate thinking)

4. PUT UP the prepared chart describing the local referral system (TM 11).

5. GIVE a briefing on the protocol to be followed for referring clients; emphasize that referrals can be made not only from lower to higher facilities but also the other way round. Referrals can be made to 
the LHWs for follow-up cases of diseases (e.g., diarrhea, ARI, etc.) and for the dispensing of contraceptives (i.e., condoms and pills).

TYPES OF FACILITIES CLIENTS CAN BE REFERRED TO: Health department and population welfare facilities, starting from community-based providers, and going on to include private sector facilities.

6. INFORM them that one of the most important factors when referring clients is knowing whether the facility/ provider is functioning or not. This would include knowing about staff availability and facility timings.

7. DISCUSS the issues of referrals and protocol to ensure that the resources and protocols are clearly understood.

8. CONCLUDE by stressing that timely referral to an appropriate facility can mean the difference between life and death and the service provider needs to be aware of all of the facilities and services (public and private) available for emergency treatment in the provider's area.

\section{REMINDERS:}

$\checkmark$ Timely referrals can make the difference between life and death.

$\checkmark$ Knowing what facilities are available and being fully informed about the details of their service provision is essential information for the service provider to have to make the best referral for their client.

REMINDER: If this training manual is used in a place that operates under a different referral system, the trainer should prepare a different chart, and alter other references accordingly. 



\section{Module 12: Perception of change}





\section{Perception of Change}

\section{SCHEDULE FOR MODULE 12}

\begin{tabular}{llll}
\hline Content & & Methodology & Duration \\
\hline Activity 1 & Change & Brainstorming & 30 minutes \\
& Definition & Discussion & \\
& Types & Exercise & \\
& Factors affecting change & & \\
& & &
\end{tabular}

Total duration

30 minutes

\section{OVERVIEW}

This module deals with factors that help or impede change.

\section{MATERIALS}

Writing board, newsprint, colored markers (chalk) for newsprint and writing board, Plastercine

\section{LEARNING OBJ ECTIVES}

At the end of the module, the participants will be able to:

- DEFINE change.

- DISCUSS factors that help or hinder change.

- UNDERSTAND changes that may be required in the health service delivery system from the perspective of the clients.

\section{KEY LEARNING POINT}

- Lasting change occurs only when people feel the need and accept change without force or pressure. 


\section{ACTIVITY 1: \\ CHANGE}

\section{TRAINER' S NOTE}

- Prepare for discussion on change (TM 12).

\section{INSTRUCTIONS}

1. BRAINSTORM with the participants on what the word change means.

2. WRITE the responses on the board or newsprint.

RESPONSES SHOULD REFLECT: Change means a shift from one status to another.

3. ASK the participants why people change and for what reasons?

4. NOTE their responses on the board and discuss.

5. ASK them if there are people who do not want to change?

6. DISCUSS reasons why people do not want to change and how barriers to change can be removed for them.

7. TELL the participants that we will now conduct an $\rightarrow$ EXERCISE $\leftarrow$.

8. ASK the participants to imagine they have a magic wand that would allow them to change three work-related activities (e.g., themselves, their supervisor, their job, their colleagues, etc.). 
9. ASK them to write the three things they would change in their notebooks.

\section{ALLOW 3 - 4 minutes.}

10. DISCUSS why they want these changes

11. ASK the participants to step into the shoes of their clients and think about what changes they would want in service delivery.

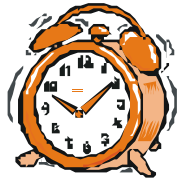

\section{ALLOW 3 - 4 minutes.}

12. ASK them to share their responses. Write their responses on newsprint/ board, and discuss what would be required to make these changes.

RESPONSES SHOULD INCLUDE: These activities help us learn about other people, their desires and frustrations.

13. CONCLUDE the activity by asking when lasting change can be brought about. Emphasize that to change others we have to change ourselves and act as role models.

RESPONSES SHOULD INCLUDE: Change will be lasting when need is felt and when change is accepted without pressure or fear. 



\section{Module 13: Team building}





\section{TEAM BUILDING}

\section{SCHEDULE FOR MODULE 13}

\begin{tabular}{llll}
\hline Content & Methodology & Duration \\
\hline Activity 1 & Importance of team work & Game & 25 minutes \\
\cline { 2 - 4 } & & $\begin{array}{l}\text { Exercise } \\
\text { Discussion }\end{array}$ \\
\hline Activity 2 & $\begin{array}{c}\text { Factors involved in team- } \\
\text { building }\end{array}$ & $\begin{array}{l}\text { Brainstorming } \\
\text { Discussion }\end{array}$ & 20 minutes \\
\hline Total duration & & $\mathbf{4 5}$ minutes \\
\hline
\end{tabular}

\section{OVERVIEW}

The importance of working as a team is learned through an exercise or game. Factors that help team building are also discussed in this module.

\section{MATERIALS}

Writing board, newsprint, colored markers (chalk) for newsprint and writing board, Plastercine, small table, broken square puzzle, envelopes (note the number and differing sizes of envelopes required)

\section{LEARNING OBJ ECTIVES}

At the end of the module, the participants will be able to:

- EXPLAIN the importance of team building.

- DISCUSS factors affecting team spirit. 


\section{KEY LEARNING POINTS}

- TEAM = Together - Everyone - Achieves - More

- To develop a team sprit among the staff one has to be a role model and be ready to make sacrifices.

- Goals can be achieved if people work as a team. 


\section{ACTIVITY 1: IMPORTANCE OF TEAM WORK}

\section{TRAINER'S NOTE}

- Prepare enough sets of the broken square game and the instructions for each group (following the instructions in TM 13.1a). There will be five sets of pieces of the squares and one copy of the instructions (for the game and players) for the players (TM 13.1b) and one copy of the instructions for the rapporteur (TM 13.1c), for each group. [NOTE: be sure you have enough envelopes. ]

- Write on newsprint the instructions for the game and the instructions for the players (TM 13.1b).

- Review the broken squares game so that you know how it works and how to instruct the rapporteurs.

- Arrange one table in the classroom.

\section{INSTRUCTIONS}

1. PLACE the table in the middle of the circle or nearby where everyone can see.

2. ASK one volunteer to come forward and pick up the table using four fingers of one hand.

The person probably cannot pick up the table or at least cannot pick it up easily.

3. ASK four volunteers to pick up the table together with one finger each. They will see that the table is easily lifted. 
4. ASK why it was easy with four people? Point out that when four people worked together as a team, the task became easy.

5. TELL them that there will be $\mathrm{a} \rightarrow$ GAME $\leftarrow$.

6. DIVIDE the participants into groups of six each (number of groups depends on number of participants). Extra participants will be observers.

7. ASK each group to sit in a different area.

8. ASK each group to select five players and one rapporteur.

9. GIVE each group one of the large envelopes and explain that inside there are five big envelopes and two smaller ones. Ask each group to open the large envelope and give the small envelope marked "instructions for rapporteur" to the rapporteur.

10. TELL all of the rapporteurs to gather together in a separate area and to read the instructions in the envelope while waiting for you. While they are doing this, tell the groups to take out the small envelope that is marked "instructions for players" and read these instructions while you talk to the rapporteurs.

11. INSTRUCT the rapporteurs separately: explain that they are separate from the group. Brief them on their two jobs: (1) to make sure the rules are followed according to the instructions that they were given and (2) to record what happens.

12. PUT the prepared instructions for the game and for the players on the wall and read them out loud (TM 13.1b). Remind players that they must follow the rules while playing. [Note: do not post or read the instructions to the rapporteurs. ]

13. ASK the players to take out the five big envelopes and give one to each player; they should not open these until you say to begin. 
14. TELL them that they will have 15 minutes to complete the assignment. Tell them that they may now begin.

\section{ALLOW 15 minutes.}

15. BRING the participants together whether they are finished making their squares or not.

16. DISCUSS what happened during the game by inviting each of the rapporteurs to report on what they observed both as policemen and as rapporteur. Then invite players to talk about how they felt during the game. In the end, the discussion should highlight the following points:

\section{HIGHLIGHTS OF GAME:}

$\checkmark$ There should be a spirit of sharing.

$\checkmark$ Overall goals are more important than personal goals.

$\checkmark$ If one person is not working, then the whole organization suffers.

$\checkmark$ Goals can best be achieved when everyone works as a team.

$\checkmark$ Working within limitations is difficult. 


\section{ACTIVITY 2: FACTORS INVOLVED IN TEAM-BUILDING}

S. TRAINER'S NOTE

- To stimulate discussion a list of some factors that affect team-building are provided (TM 13.2). Review this list and be prepared to assist participants if needed.

\section{INSTRUCTIONS}

1. ASK participants to work in pairs and discuss factors that positively affect team building.

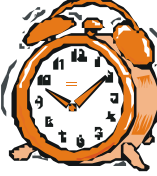

\section{ALLOW 5 - 6 minutes.}

2. ASK each pair to read out their points. Write their responses on the board or newsprint and discuss.

3. DISCUSS how the factors they have listed can be achieved; add to their lists if that seems appropriate (using TM 13.2).

4. CONCLUDE by emphasizing: Together Everyone Achieves More (TEAM). 


\section{Module 14: Evaluation and conclusion of training}





\section{EVALUATION AND CONCLUSION OF TRAINING}

\section{SCHEDULE FOR MODULE 14}

\begin{tabular}{llll}
\hline Content & & Methodology & Duration \\
\hline Activity 1 & Evaluation/ feedback & $\begin{array}{l}\text { Filling in forms and } \\
\text { discussion }\end{array}$ & 30 minutes \\
\hline Activity 2 & Conclusion & $\begin{array}{l}\text { Game } \\
\text { Poem }\end{array}$ & 30 minutes \\
& & & $\mathbf{1}$ hour \\
\hline Total duration &
\end{tabular}

\section{OVERVIEW}

This module deals with the evaluation of the training. The concluding session deals with making a commitment to work toward the betterment of the community and client satisfaction by using the client-centered approach.

\section{MATERIALS}

Evaluation forms, a ball of string

\section{LEARNING OBJ ECTIVES}

At the end of the module, the participants will be able to:

- EVALUATE objectively the content and methodology of training, the attitude of the trainers and logistic arrangements.

- PLAN for the future outcome of training.

\section{KEY LEARNING POINTS}

- Evaluation and feedback helps to remove weaknesses and improve future efforts. 


\section{ACTIVITY 1: EvaLUATION}

TRAINER'S NOTE

- Arrange for enough evaluation sheets for all participants (TM 14.1).

\section{INSTRUCTIONS}

1. DISTRIBUTE an evaluation sheet to all participants (TM 14.1).

2. TELL them not to write their names but to write sincerely what they felt about the training and how they think it could be improved.

\section{ALLOW 20 minutes.}

3. COLLECT all forms and keep these for later analysis.

NOTE: Review the forms at a later date; these may contain valuable ideas to be incorporated into future training. 


\section{ACTIVITY 2: CONCLUSION}

\section{TRAINER'S NOTE}

- Have a ball of string ready for the closing session.

- Be prepared to read the poem in TM 14.2a (and $\mathbf{1 4 . 2 b}$ ) or to select another poem with a similar inspirational message. [Note: this poem is provided in Urdu in TM 14.2a and in English in TM 14.2b)

\section{INSTRUCTIONS}

1. MAKE informal closing remarks about the training.

2. INVITE trainees to make whatever comments they would like to make about the training, etc.

3. TELL the participants that there will now be $\mathrm{a} \rightarrow \mathrm{GAME} \leftarrow$.

4. ASK all participants to sit in a circle.

5. GIVE the ball of string to one participant and ask him or her to keep holding the end of the string and to throw the ball to another participant across the circle after stating a positive point about that person's personality or participation in the training.

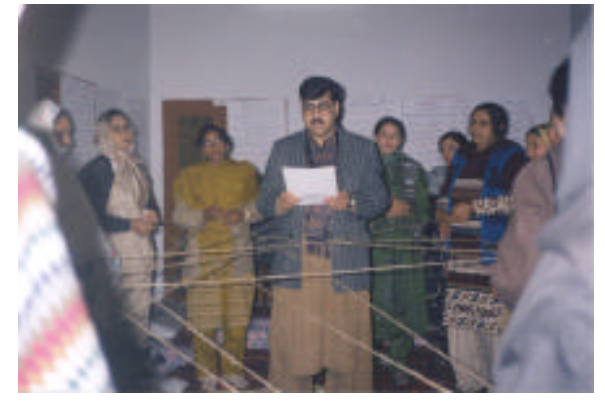

6. EXPLAIN that now each participant who receives the ball will toss it across the circle to another participant who has not yet been given the ball, making a similar positive statement first. Each participant must hold onto the string; the string will form a web. Do this until the ball has been tossed to all participants. 
7. ASK all participants to stand up keeping the string tight.

8. GOING into the center of the "web," the trainer says the following:

$\rightarrow$ Now we are joined together: if we move any part of the string, we will all feel the vibrations. Let us take a pledge that we will all try to promote healthy preventive practices through the implementation of SAHR, reducing our client's ignorance and empowering them to achieve better health care for themselves and their families. Let us pledge also that if any one of us has a problem, the rest of us will provide wholehearted help to that person.

9. READ the poem (TM 14.2a or $\mathbf{1 4 . 2 b}){ }^{1}$

\footnotetext{
${ }^{1}$ The poem was written in Urdu for use in this training in Pakistan. An English translation of the poem follows the Urdu version. Many partici pants in Pakistan have expressed their appreciation for this poem. However, if you feel this poem does not reflect the sentiments of your training, you are encouraged to choose another inspirational poem to conclude the training.
} 


\section{Section III Training material*}

*Note: Training materials are numbered by module and the order in which they appear within the module; they are not numbered sequentially in this section. 



\section{Training material 1.1: Objectives of the training}

\section{AT THE END OF TRAINING THE PARTICIPANTS SHOULD BE ABLE TO:}

- Clarify and explain the link between self-awareness, health and development.

- Identify their own attitudes, prejudices and behaviors so as to facilitate a positive change in them.

- Communicate more effectively.

- Increase their awareness regarding gender relations and it's link to health.

- Give respect and develop rapport with clients.

- Identify the reproductive health needs of clients beyond the immediate problem through a process of information exchange.

- Assess the client's domestic/ social background affecting those needs/ situations.

- Respect the identified needs of the client.

- Apply negotiation skills to meet the identified needs of the clients, and empower them through an equal information exchange. 


\section{Training material 1.2: What is a client-centered approach?}

- It is an approach that attempts to change the way that providers deal with their clients.

- It is ascertaining accurate information from the client in order to understand their needs.

- It is involving clients in the choice of solutions to their specific problems.

- It includes providing adequate information to clients to empower them to address their needs. 


\section{Training material 1.3: Reproductive health}

\section{DEFINITION}

- Reproductive health is a state of complete physical, mental, and social well-being in all matters related to the reproductive system and to its functions and processes. It is not merely the absence of disease and infirmity. Men and women have the right to be informed and to have access to safe, effective, affordable methods of family planning as well as access to health care for safe pregnancy and childbirth

\section{COMPONENTS}

- Safe motherhood

- Childcare (less than one year of age)

- Family planning

- RTIS / STDS

- Problems of the elderly

- Problems of adolescents

- Treatment of infertility

- Cancer detection

- Male involvement 
Section III Training material

\section{Training material 1.4: Young-old lady picture}

[See next page.] 
Training material

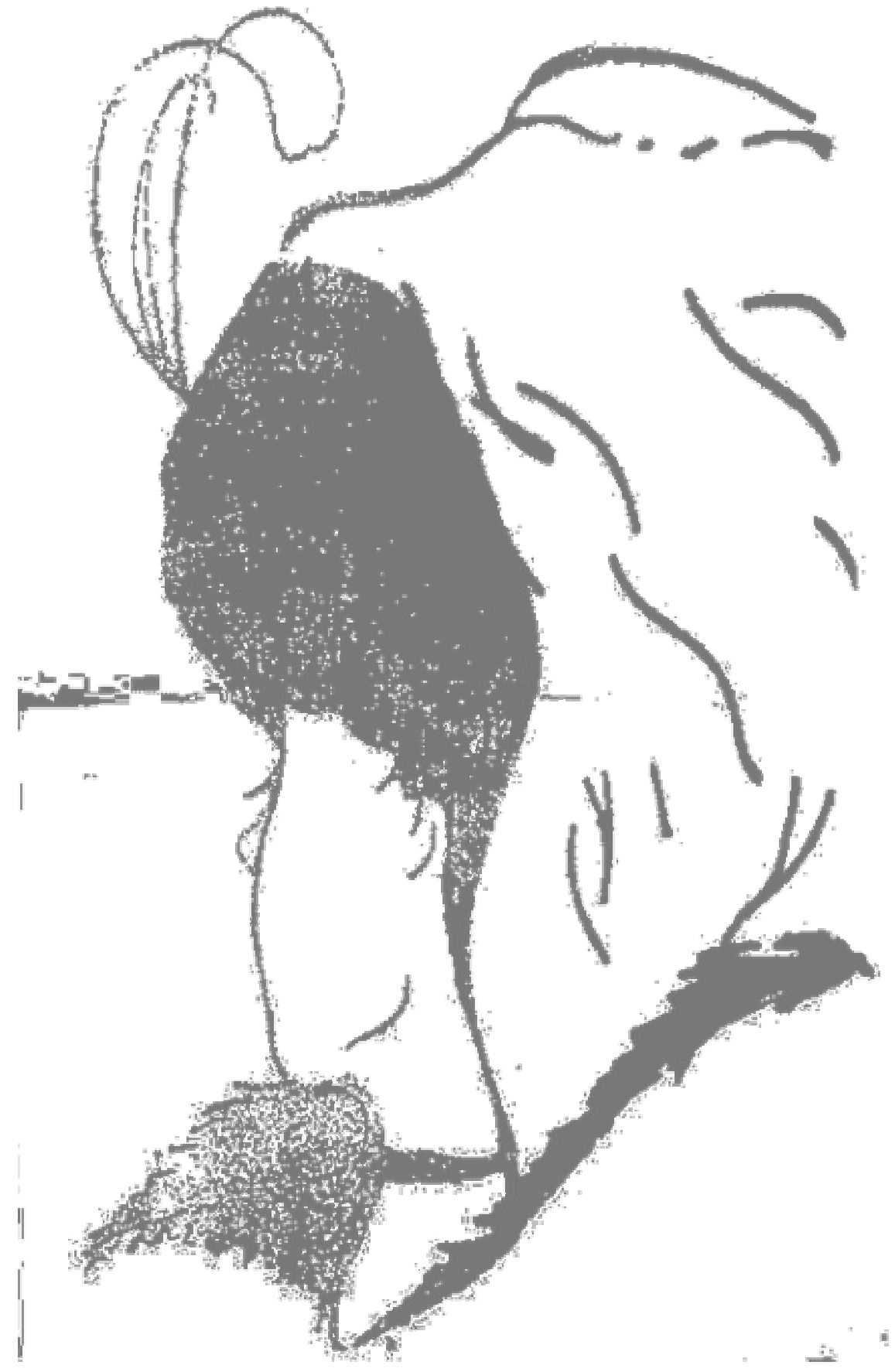




\section{Training material 2.1: Self-awareness}

- Extensive evidence shows that apart from our physical health, emotional well-being is extremely important in the development of a well-adjusted and stable personality.

- As defined by the World Health Organization, health is a state of complete mental, physical and social well-being and not merely the absence of disease and infirmity. This definition has been expanded to include spiritual and emotional well-being.

- Emotional well-being can be achieved by controlling our emotions and understanding how they affect our thinking and decision-making. It is enhanced by good relationships with friends and relatives and by inculcating a spirit of self-improvement.

- In order to improve social conditions in any country we must change our thinking and attitudes. To do this we have to first change ourselves. Knowing our own attributes, strengths and weaknesses is a step in this direction.

- Self-awareness helps in channeling our strengths and our energies in positive directions that bring maximum benefit to society.

- Developing self-awareness is a difficult process. The J 0-Hari window is one tool that can help us to understand and appreciate our abilities and personality. The concepts of self-awareness and self-development permeate this training. 


\section{Training material 2.2: J o-Hari window}

- Jo and Hari were two psychologists who believed that the human personality had four aspects. They developed a model known as the J oHari window, which is shown below. The text below the window explains the segments.

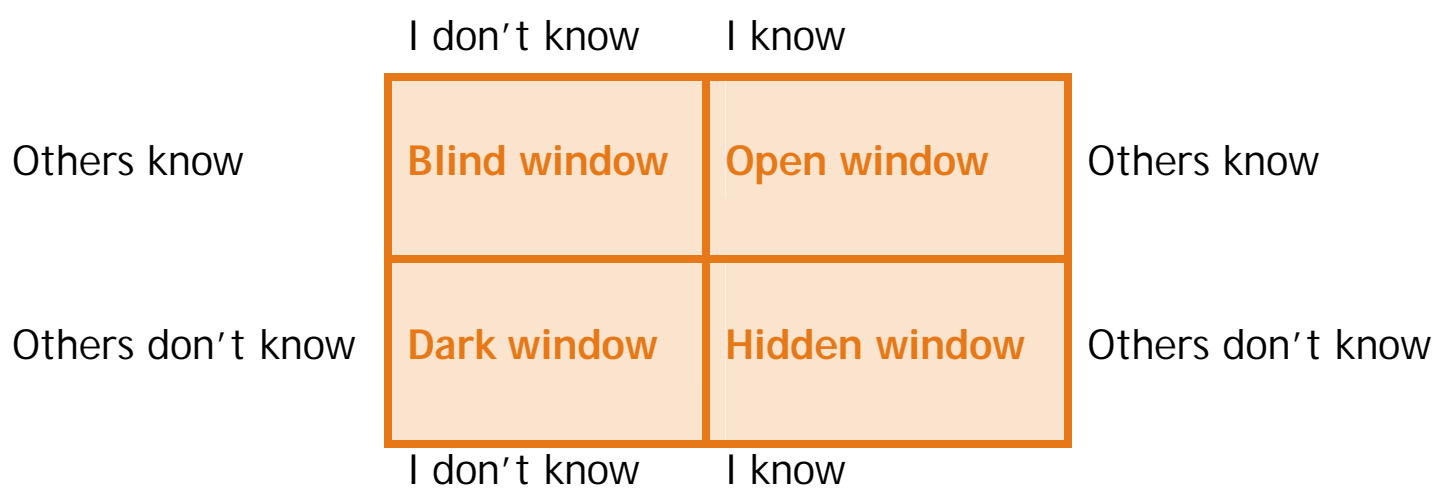

- Open window: This is the aspect of a person's personality that he or she knows about and others also know (e.g. name, qualifications, profession, physical characteristics, etc.).

- Blind window: This is the aspect of the personality that the person is not aware of but others are (e.g., mannerisms, attitudes, some strengths and weakness, etc. ).

- Hidden window: This is the aspect of the personality known to the person himself or herself but not to others (e.g., qualities-both strengths and weaknesses, fears and secrets, etc.).

- Dark window: This is the aspect of the personality that neither the person him/ herself nor others are aware of. These are the unknown 
capabilities that may become apparent in situations like emergencies. This could include our spiritual strengths.

- The open window of human personality should be wider than the other windows. The more open it is the more confident and self-aware the person is and he or she is more able to gain the respect, confidence and trust of others.

- This can be done only by reducing the blind and hidden windows.

- In order to have a balanced personality we should try to reduce our blind window. Being unaware of one's strengths and weaknesses makes one less confident and more insecure.

- Someone who is aware of their own strength is better able to use it to help others. Likewise if we know about our weaknesses we can try to overcome them.

- This wind ow can be reduced by taking feedback from others. This needs patience because it is often difficult to accept negative feedback and also to accept our weaknesses.

- The hidden window should also be reduced by sharing happiness and problems with others. It is said that a problem shared is a problem halved, but sharing cannot be done with everyone. It can only be done with a person you trust.

- Seen in the context of dealing with clients, providers should try to reduce their hidden window by developing a relationship of trust.

- When a client's trust is won he or she will then share their personal problems and fears. Once the need is properly identified, appropriate help and guidance can be given. 


\section{Training material 5.1: Gender}

- Sex is the biological distinction between women and men. It refers to the visible differences and the functions related to reproduction.

- Gender is how society assigns roles to men and women based on sociocultural norms.

\begin{tabular}{lc}
\hline Sex & Gender \\
\hline $\begin{array}{l}\text { (1) Biological and made by } \\
\text { nature }\end{array}$ & (1) Sociocultural and man made \\
\hline $\begin{array}{l}\text { (2) Constant and same } \\
\text { everywhere }\end{array}$ & (2) Variable and changes from time \\
to time and place to place \\
\hline (3) Cannot change & (3) Can change \\
\hline
\end{tabular}

- Sex is defined using the words male and female. Gender is defined using the words masculine and feminine.

- Differences in qualities, roles and responsibilities are usually said to be determined by nature but this is not the case. Gender is a matter of culture and society.

- This stereotyping begins from the moment the child is born or even before if the sex of the child is known. For example, boys are often dressed in plain blue clothes and girls are dressed in fancy pink clothes. Similarly, girls are given dolls to play with while boys are given cars or guns. When the child grows bigger he or she is given different advice on behavior. Girls are told to speak softly and act demurely. They are told not to go out alone. Boys are told to be brave and tough and to protect girls. As a result they develop differently.

- We can observe that in Western cultures, girls are often outgoing and independent and may dress similarly to boys. The body of a person 
develops according to how it is used (e.g., wrestlers and ballet dancers have very different shapes influenced by training and exercise). The physical differences between boys and girls can be altered.

- The roles and responsibilities of men and women change over time. In our parents' and grandparents' time our mothers stayed at home and were often uneducated. They were not mobile and they had little decision-making power whereas now things have changed.

- Factors that influence roles, responsibilities and attributes:

$\rightarrow$ Age

$\rightarrow$ Marital status

$\rightarrow$ Culture

$\rightarrow$ Country

$\rightarrow$ Education

$\rightarrow$ Development of society

$\rightarrow$ Economic condition

$\rightarrow$ Profession

- Despite their central role in the family, women have very little power over their own lives. They are dependent on their husbands and elders and do not make even small decisions.

- There is female discrimination in all spheres of life, both at the personal and public levels, that prevents women from enjoying healthy and meaningful lives.

- Nutritionally women are at a disadvantage right from childhood through motherhood when deficiencies can badly effect reproduction. For a society to be healthy it is imperative to remove gender discrimination. Women should have equal rights to live, learn, enjoy, contribute and be acknowledged. 


\section{Training material 5.2: \\ Statements to put on Zopp cards}

\section{STATEMENTS}

- Women perform two-thirds of the world's work, but earn one-tenth of the world's income.

- Women make up two-thirds of the world's illiterate people.

- Maternal mortality is 300-400 per 100,000 live births in Pakistan.

- In Pakistan, 32 per cent of women are literate of which only 33 per cent are rural.

- In most countries women are twice as likely to do unpaid work as men.

Note: statements that reflect information pertinent to the location/ country where the training is being given may be used in place of those provided here. 
Training material 6.1: Communication and components of communication

\section{DEFINITION}

Communication has many definitions and can mean different things to different people. Some people may define it as an exchange of ideas, information, thoughts, feelings or images between two or more individuals or groups. Others may go for a more academic definition, such as: the use of various theories and techniques for helping people gain full awareness of their situation, exploring the options available to them and empowering them to make free and informed choices as per their needs.

In the context of public health and family planning, communication is a tool through which the provider can help the client understand his/ her health situation and enable the client to make the most suitable choices. The most important element of communication is the ability to convey to the receiver the same meaning of a message as intended by the sender. Therefore, any communication that does not lead to a shared meaning of the message is not effective communication.

\section{COMPONENTS OF COMMUNICATION}

\section{Sender}

Also referred to as the source. The sender is the person, or group of people, who want to communicate or send a message/ direction/ information to another person or group. The sender could be anyone - health provider, teacher, client, etc. 


\section{Message}

The information, direction or feeling that the sender wants to convey to the receiver is called the message. Messages can be verbal as well as nonverbal. A typical message might be to wash hands before eating or brush teeth at least twice a day.

\section{Channel}

The channel is the medium through which the message is communicated.

The selection of the channel depends on the nature of the message and the intended receiver of the message. Depending on the situation, the channel could be face-to-face interaction, telephone, letter, email, TV, radio, etc.

\section{Receiver}

The receiver is the actual target audience of the sender, the person or group for whom the message was designed and sent. In a two-way conversation, the individuals or groups involved can become senders and receivers simultaneously. For example, if a health provider chooses to deliver a talk on basic health and hygiene to students of a local school, the provider would be the sender during the talk and the students would be the receivers of the health education messages. However, if in the same setting, a student asks the provider a question, then the student will become the sender and the provider will become the receiver.

\section{Feedlback}

The communication process is not complete without the feedback from the receiver that gives the receiver's reaction to the message that $s /$ he has received. Feedback helps the sender understand if the message has been received properly, that is, that it has been understood by the receiver or that there is a need to refine or reinforce the message. 


\section{Training material 6.2: Role-play on communication/ feedback (for trainer and co-trainer) ${ }^{1}$}

An employer sits in a chair pretending to do some work. Then the employer calls the servant and says: "Bring me my taar from downstairs." [Taar means wire or telegram in Urdu, as it does in English.]

The servant brings a piece of wire. The employer sees the wire and says: "What have you brought?"

The servant says: "You told me to bring a taar, so I have brought it."

1. ASK the participants why the employer became annoyed?

2. TELL the participants that you will now repeat the role-play with modifications:

An employer sits in a chair pretending to do some work. Then the employer calls the servant and says: "Bring me my taar from downstairs." [Taar means wire or telegram in Urdu, as it does in English.]

When the servant is leaving to go bring the taar, the employer asks: "Which taar will you bring?"

The servant says: "I will bring the one that is lying under the table."

The employer says: "No, not that one, I want you to go and bring my telegram."

\footnotetext{
${ }^{1}$ This role-play can be modified to suit local languages and situations, as needed.
} 


\section{Training material 6.3: Barriers to communication: clarification}

\section{GRID}

\section{How to get from}

\begin{tabular}{lll}
\hline Here & \multicolumn{1}{c}{ to } & Here \\
\hline 1. Say & $\begin{array}{l}\text { The voice should be loud and } \\
\text { clear. }\end{array}$ & 2. Hear \\
& $\begin{array}{l}\text { If you speak in a whisper your } \\
\text { voice will not reach the receiver. }\end{array}$ & \\
2. Hear & Use simple language. & 3. Understand \\
& $\begin{array}{l}\text { If you speak in a different } \\
\text { language or use difficult words, } \\
\text { the receiver will not understand. }\end{array}$ & \\
3. Understand & $\begin{array}{l}\text { Say something credible so the } \\
\text { receiver will believe. }\end{array}$ & 4. Believe \\
& $\begin{array}{l}\text { If you say something unbelievable, } \\
\text { the receiver will not believe. }\end{array}$ & \\
4. Believe & $\begin{array}{l}\text { Even if you believe, it does not } \\
\text { necessarily follow that you will } \\
\text { practice (e.g., we believe smoking } \\
\text { causes cancer but still people } \\
\text { smoke). There needs to be an } \\
\text { enabling "factor" to achieve } \\
\text { practice. }\end{array}$ & 5. Practice \\
\hline 5. Practice & $\begin{array}{l}\text { To maintain practice, } \\
\text { reinforcement is necessary }\end{array}$ & 6. Continuous \\
practice
\end{tabular}




\section{EXPLANATION}

Communication can be as complex as any other process having many elements and components and involving behavior patterns and individual characteristics. There are many barriers and difficulties that can hamper the communication between sender and receiver. Some of these barriers are discussed below. To understand the grid, follow the steps and barriers that the communication process passes through. Follow left to right across each row.

\section{Barrier 1 Difference between saying and hearing (from 1 to 2)}

As the goal of communication is shared meaning and ultimately to bring about a change in behavior, the most important element in this process is delivering the message in a way and through a channel that allows it to reach the receiver. Message delivery alone is not enough. Ensuring that the message has been delivered to the intended audience is important. It is not enough to say something; it is equally important that it be received.

\section{Barrier 2 Difference between hearing and understanding (from 2 to 3 )}

Sometimes the sender is able to send a message to the receiver and the message is received well. However, this does not automatically mean that the message has also been understood. The reasons for not understanding could be that the message is in a language or spoken in a way that that the receiver does not understand. Another problem could be that the sender has sent a message in a written form but the receiver is not literate. Therefore, it is very important to understand the receiver well enough to make sure that the message is in a form that the receiver can understand or decode. 


\section{Barrier 3 Difference between understanding and believing (from 3 to 4)}

All of the messages that are understood are not always believed. We get so much information every day and sometimes we do not necessarily believe it all. Therefore, it is important for the sender to ensure that his/ her message is believed as well as understood. One way to do this is to quote a credible source or give data that support the message. For example, one might say: spacing of 3-5 years between births enhances the chances of survival and better health for mother and child [message] according to the latest research published by J ohns Hopkins University [credible source].

\section{Barrier 4 Difference between believing and practicing (from 4 to 5)}

It is also important for a communicator to make sure that his/ her message is not only credible but also that it helps achieve the goal of initiating the required action from the receiver. This may require creating an enabling environment for the receiver to act in a certain way. For example:

convincing a woman to start using contraceptives is important; however, it is also important that she is able to access the contraceptives easily and also use them free of any fear or pressure. This means ensuring the supply as well as empowering the woman to convince her husband or family members if they object to the use of contraceptives that she should be able to use them.

\section{Barrier 5 Difference between practicing and continuing to practice (from 5-6)}

There are so many practices that people may start, such as daily exercises to shed extra pounds or avoiding junk food, etc., and do for some time, but later they relapse into old habits once the initial euphoria is over and they discover that it is too taxing on their time or involves other costs. The important transition across the barriers between practicing and continuing to practice needs to be understood and strategies need to be utilized that 
will help remove barriers. The receiver needs constant appreciation and help in continuing to utilize new/ better practices. For example: a woman may abandon the use of a contraceptive after experiencing some side effects. Using prior information, reassurance and follow up, a provider can help the woman continue using the method or switch to another method without risking an unplanned pregnancy. 


\section{Training Material 6.4:}

\section{Exercise on overcoming communication barriers}

\section{TRAINER'S NOTE}

- Use this exercise if there is time and you think it will be useful.

\section{INSTRUCTIONS}

1. TELL the participants that there will be an $\rightarrow$ EXERCISE $\leftarrow$.

2. DIVIDE the participants into four groups.

3. ASK two groups to write down the typical characteristics of a service provider (e.g., busy, educated, aggressive, etc.); ask the other two groups to write down the typical characteristics of a client (e.g., poor, nervous, shy, etc.).

4. INVITE each group to present their group's work. Paste each group's chart on the wall as they present.

5. IDENTIFY and compare different characteristics of a typical service provider when interacting with the typical client. (Refer to the following examples.) As each characteristic is named, ask the participants the following questions:

$\rightarrow$ Would this be a barrier? How?

$\rightarrow$ If this is a barrier, how could it be overcome?

$\rightarrow$ What should the role of service providers be in removing these barriers? 


\section{EXAMPLES:}

$\checkmark$ Educated service provider and illiterate client:

This could be a barrier because the service provider might use technical words that are difficult for the client to understand.

$\checkmark$ Aggressive, impatient service provider and nervous client: The client will not be able to explain her problem freely so proper assessment will not be possible.

6. CONCLUDE by emphasizing that if there are barriers, there will not be any equality and without that negotiations will be impossible. Reiterate that it is important to identify and understand these barriers and overcome them for a successful client-provider interaction. 


\section{Training material 6.5: Role-plays for mixed messages}

\section{TRAINER'S NOTE}

- Instructions for the observer and speaker are the same for all groups but different for the listener. Be sure that you give the observer, speaker and listener a copy of their instructions only (note: when you make the copies be sure that you copy the instructions on separate sheets of paper).

\section{INSTRUCTIONS}

1. BE sure you have prepared the participants for role-plays by dividing them into four groups with three participants in each group: one listener, one communicator and one observer.

2. TELL the rest of the participants that they will observe the roleplays.

3. DISTRIBUTE the instruction sheets (see below) to the four groups. Remember the instructions for observers and speakers are the same for each group; however, they are different for the listener in each group.

4. ASK the players to read the instructions and be sure they understand them. If necessary, explain them to anyone who does not understand.

\section{ALLOW 5 minutes,}

5. INVITE each group to perform a 3-4 minute role-play following these instructions as follows: 
- Observer"s instruction sheet (same instructions for all role-plays),

$\rightarrow$ Do not discuss or share these instructions at this time.

$\rightarrow$ Your task is to record what the communicator and listener are doing during their conversation. Do not concern yourself with the content of the conversation; just write down your observations about the processes they are using to communicate. Pay attention to what the listener and communicator do (e.g., eye-to-eye contact, gestures, body positions, and other nonverbal behavior).

$\rightarrow$ Describe what you observe as accurately as possible without judging it. Later you will be asked to give feedback to the communicator and listener.

- Communicator's instruction sheet (same instructions for all roleplays).

$\rightarrow$ Do not discuss or share these instructions at this time.

$\rightarrow$ You and your listener are to carry on any conversation that your trio has already started or can start now. Try your best to communicate your message to your partner. It is your responsibility to keep the conversation going!

- Listener's instruction sheets (there are four listener's instruction sheets, a different one for the listener in each role-play group; these appear on the next two pages): 


\section{Role-play, Group 1, Listener's instruction sheet: I DO NOT CARE}

\section{Do not discuss or share these instructions at this time.}

You and your communicator are to carry on a conversation. You are to listen carefully to what your partner is saying, but also are to send your partner nonverbal signals that indicate you are bored (i.e., look away, doodle, slump in your chair or sprawl on the floor, fidget, clean your fingernails, fiddle with your clothing, etc.). If your partner accuses you of being uninterested, insist that you are interested (you may even review what has been said) but continue to send nonverbal signs of boredom.

\section{Role-play, Group 2, Listener's instruction sheet: ANYT HING YOU CAN DO, I CAN DO BETTER}

\section{Do not discuss or share these instructions at this time.}

You and your communicator are to carry on a conversation. You are to appear attentive and to listen carefully, but you are to challenge everything your partner says. You may interrupt while he/ she is talking, anticipate what would have been said next and disagree or present your own point of view. You may point your finger, lean forward aggressively and engage in other nonverbal behaviors that highlight your verbal behavior. You are the critic. After making a criticism or statement, wait and allow your partner to begin the conversation again. Your task is not to take over the conversation but merely to interrupt, disagree, or challenge whatever is said. If your partner hesitates, remain silent until he or she begins to talk again, and then resume your role. 


\section{Role-play Group 3, Listener's instruction sheet: HOW SWEET IT IS}

\section{Do not discuss or share these instructions at this time.}

You and your communicator are to continue the conversation that your trio started a few minutes ago. You are to appear attentive, listen carefully, and agree with everything your partner says, regardless of your own opinion on the subject. When your real opinion is the opposite of what your partner is saying, smile as if you indicate agreement. You may make comments such as "That's a great way of putting that," "That's very insightful of you," "Oh, wow" and so on. Resist any invitation from your partner to share your ideas (say only, "Oh, I agree with you") or to criticize or evaluate the ideas being communicated.

\section{Role-play, Group 4, Listener's instruction sheet: THIS IS HOW IT OUGHT TO BE}

\section{Do not discuss or share these instructions at this time.}

You and your communicator are to carry on a conversation. You are to listen carefully to your partner and actively pursue the ideas your partner is sharing with you. Indicate that you understand his or her ideas by paraphrasing (restating) them. If you disagree, simply state your ideas calmly and logically. Ask for clarification or an example if this would be helpful. You can also indicate that you are interested in the conversation by using nonverbal cues (e.g., establishing eye contact or leaning toward the speaker). Do not attempt to lead the conversation or change its direction. Although your partner is the communicator, you are to play an active part in making the communication process as clear and mutual as possible. 


\section{Training material 7.1: Tools of communication}

\section{REFLECTIVE LISTENING}

The underlying theme of reflective listening is to understand the fact that when people talk they communicate more than words, they communicate their feelings also. A reflective response communicates to the speaker that the speaker has been heard and his or her feelings have also been understood. For example, a very worried looking woman brings her sick child in and says that her child is very ill. The provider should not only reflect back the woman's core message but also reflect back her core feelings (i.e., "I feel you are very upset because your child is very sick"). In another example, a woman comes to you crying that her child is suffering from severe diarrhea and vomiting and requests that you do something quickly otherwise her child may die. By using reflective listening, this woman might be calmed if she is reassured that not only her words have been understood but the provider also fully understands her feelings.

\section{STROKING}

A 'stroke' is any action that makes the receiver feel good and appreciated. This is different from flattery because in stroking the appreciation is genuine and honest. This can be done by words (e.g., good or excellent) and gestures (e.g., pat on the shoulder). For example, if a mother has completed her child's vaccination schedule, the provider should congratulate or commend her. The same is true if, during a client-provider interaction, a woman tells you that she has been having regular antenatal check-ups in the hospital or you go to a house and find that all of the edible items are properly covered. 


\section{OWNERSHIP}

Before dealing with any problem, the first step is to establish ownership, in other words establish whose problem it is. Owning a problem means having the right and responsibility to deal with it and to take the first step toward resolving it. For example it is the responsibility of the client to bring the child for immunizations while the responsibility of the provider is to administer the vaccine.

\section{" |" STATEMENT}

'I' statements mean honestly sharing our concerns thoughts and feelings, taking responsibility for a problem we have 'owned' and voicing that fact. It is speaking for oneself rather than generalizing or accusing others. For example, if the provider is at home and the client arrives with a non-urgent problem when the provider is busy the provider has the right to tell the client to come at another time (saying "I am not free to help you at this time...."). Another example: your family thinks you are not doing anything useful and they say that you should become a schoolteacher in the village but you do not want to do so because you like your job as a health worker and think that women in the community need you. Moreover you have been trained for this. In such a case it is evident that this is an issue for you to resolve, which you can do through effective use of ' $\mathrm{l}$ ' statements because you can deal with the issue without making others angry or creating conflict. This tool will help keep the focus on yourself rather than blaming others by saying: "You may consider this better for me but I feel...." In another example, 'I' statements would be useful when the husband of a pregnant woman, whose delivery is to be conducted in hospital, insists that you accompany them to the referral facility when it is not possible for you because of other patients in your health facility (you would say, "I am not able to leave my other patients at this time...." 


\section{Training material 7.2:}

\section{Statements for Zopp cards}

\section{(scenarios for practicing tools of communication)}

- An old woman from the village comes to you and says: "Children are given by God's blessing, you are working against the divine principle and that is a sin."

- A pregnant woman says to you: "I do not want to have children but it is not in my hands."

- A woman comes crying to you bringing her child, who is suffering from gastroenteritis and says: "Do something quickly otherwise my child will die."

- You go to a house that is very dirty with flies everywhere and you tell the residents about cleanliness. The woman of the house says: "How can we maintain cleanliness? We are poor people."

- A woman tells you: "I have completed the schedule of immunization for my child as you advised."

- What do you say to a woman who comes to you for a regular antenatal checkup?

- You go to a house where all the edible food is kept covered. What do you say?

- One pregnant woman with health complications that place her life at risk is worried and says to you: "My mother-in-law is against my going to the hospital." 
- A pregnant woman has to go to a local hospital for delivery and her husband insists that you go with her although this is not possible for you. What do you say?

- Women of the village come to your house all the time asking for help for very small and minor problems. What do you say?

- The house of one woman in the village is destroyed by fire and she says to you: "I do not think I will be able to recover from this."

- Your family members think that you are not doing any important work and want you instead to be a teacher in the local school. You do not want to do this because you believe that you are able to help women in your position as a health worker and you have been trained for this. What do you say?

- A woman comes and tells you that she has explained the advantages of family planning to her husband. What do you tell her?

REMINDER: The examples presented here are for your use; BUT you may choose to develop more examples. 


\section{Training material 7.3: Types and examples of questions}

\section{OPEN-ENDED QUESTIONS}

- Used in early part of the interview.

- Has many answers. Example: “What is your husband's opinion on family planning?"

- Used for learning about thoughts, feelings, knowledge and beliefs. Example: "How do you feel about family planning?"

- Helps clients to open up and say whatever they want to share. Example: "What are you thinking?" or "Is there anything else you want to tell me?"

\section{CLOSED QUESTIONS}

- Most useful in taking medical history.

- Answer is usually given in one or two words. Example: "How old are you?" or "How long have you had this fever?"

\section{INDIRECT QUESTIONS}

- Used when asking about sensitive issues (e.g., domestic violence, death of a child, etc. ).

- Example: When you suspect an injury is due to domestic violence, you would not ask the client if someone had beaten them. Instead, you would ask: "How did you get this bruise?" In the case of a child's death, you might ask: "You had another child?" The parent is free to answer as he/ she chooses. 


\section{SUGGESTIVE QUESTIONS}

- Used when the question itself suggests an answer.

- Suggestive questions should be avoided because they place the patient under pressure to agree to something that might not in fact be what they will do or would say if you asked an open-ended question. Example: "You will buy the medicines from the store?" [Urdu: Aap bazaar say dawai kareed laingi na?]. It would be better to ask like this: "Where will you buy the medicines?" 


\section{Training material 7.4: Alternate listening exercise}

(Use this exercise if you prefer it to the one in the module.)

\section{INSTRUCTIONS}

1. TELL the participants there will be an $\rightarrow$ EXERCISE $\leftarrow$.

2. ASK the participants to give their views in 2-3 sentences about why family planning has not been successful in Pakistan [or the trainer may choose another topic]. Tell the participants to start from one side and go around taking views from all the participants.

3. ASK, after the go-around, for each participant to say what the person sitting on his or her right said.

Most of the participants will not be able to remember.

4. PROCESS by asking the participants this question:

$\rightarrow$ Why did you not remember?

\section{THEIR ANSWERS COULD INCLUDE:}

$\checkmark$ Preoccupied

$\checkmark$ Not attentive

5. CONCLUDE this exercise by pointing out that one of the most important tools in communication is careful or active listening. 


\section{Training material 7.5: Listening}

\section{WHAT IS LISTENING?}

- Paying attention to sounds, perceiving with the ears.

\section{WHAT IS ACTIVE LISTENING?}

- It is more than just hearing. It involves:

$\rightarrow$ Observing (making use of other senses).

$\rightarrow$ Empathizing (putting oneself in the speaker's place).

$\rightarrow$ Communicating (understanding and showing interest).

\section{WHY DO HEALTH PROVIDERS LISTEN?}

- To obtain information to assess the needs of the client.

- To encourage the speaker to speak more frankly about their problems.

- To understand people's problems in order to better help them.

\section{WHAT DO WE LISTEN TO?}

- Facts.

- Feelings or opinions.

- A person's way of talking.

- A person's mood (sighing, hissing).

- The sound of silence (shyness, sorrow). 
- The hidden agenda (the unexpressed problem deep in the heart of the speaker).

\section{HOW DO WE LISTEN ACTIVELY?}

- We actively listen by being:

$\rightarrow$ Attentive: giving undivided attention to what the speaker is saying with eye contact and no distraction.

$\rightarrow$ Accepting: respecting what the speaker is saying without arguing or censoring even though their ideas may differ from ours.

$\rightarrow$ Alert: trying to listen not only to the words and facts but to the feelings and emotions as well.

$\rightarrow$ Respectful: treating the speaker as an equal and giving respect to his/ her feelings and attitudes.

$\rightarrow$ Encouraging: helping to bridge the gaps between the thoughts and feeling of the speaker in a supportive way. This is done to ensure that communication takes place smoothly (e.g., saying "yes," or "ok," or nodding, etc.).

REMINDER: Active listening means listening not only to the words but also to what underlies them (feelings), and what that tells us about the speaker. 


\section{Training material 7.6: Alternative presentation}

\section{THIS ROLE-PLAY IS TO BE PRESENTED IF THERE IS NO VIDEO AVAILABLE (OR IF THE EQUIPMENT YOU HAVE FOR SHOWING THE VIDEO IS NOT WORKING).}

\section{TRAINER'S NOTE}

- You and a co-trainer will need to prepare for this role-play in advance.

- Choose the scenario that is appropriate for the participants (static center staff or community workers).

- The key to this presentation is that the interaction between the provider and the client will NOT be the kind of interaction promoted by the client-centered approach. Therefore the provider must do things wrong so that the atmosphere is not positive, without being silly. For example, the provider may do things like not asking the client her name, not greeting other family members or asking about them, not following up by asking any questions about Zubaida's pregnancy, or not asking if she would be interested in birth control after the birth of the next child, and not telling Zubaida what to do if her son's problem persists. Any other actions that would lead Zubaida to not feel supported in this interaction would be acceptable, such as being impatient and not giving Zubaida the time she and her son need. "Zubaida" should feel free to respond to questions or express her fear, frustrations, etc., as the situation demands. The two scenarios follow: 


\section{Scenario for Static Center Staff}

\section{Players:}

1) Tasleem, a service provider in a static center

2) Zubaida, the client, is 30 years old and has three children, one daughter and two sons; the youngest child is a son who is four months old

When the role-play begins Zubaida has come to the static center and is being seen by the service provider. The provider has not seen Zubaida before this visit.

Zubaida tells the provider that her youngest son has chronic diarrhea and is not doing well; she is very worried. Zubaida also mentions that she has justlearned that she is probably pregnant and does not feel well herself. Zubaida's brother has accompanied her to the clinic but is not present in the examination room.

\section{Scenario for Community Worker}

\section{Players:}

1) Tasleem, is a community health worker

2) Zubaida, the client, is 30 years old and has three children, one daughter and two sons; the youngest child is a son who is four months old

When the role-play begins Tasleem has come to Zubaida's home. This is Tasleem's second visit to see Zubaida; the first visit was right after the birth of Zubaida's last child.

Zubaida tells the provider that her youngest son has chronic diarrhea and is not doing well; she is very worried. Zubaida also mentions that she believes that she might be pregnant again and did want another child so soon. Zubaida's mother and aunt are in the house but are not present while Tasleem is talking to Zubaida. 


\section{Training material 8.1:}

\section{Behavior}

\section{WHAT IS BEHAVIOR?}

- Behavior is how we act, react and perform in response to different stimuli under different situations, circumstances and conditions.

- Different people can behave differently under the same conditions. Our behavior depends on different factors that influence and modify our behavior.

- In general, behavior stems from the following three things:

$\rightarrow$ Beliefs: Beliefs are ideas that are thought to be true by an individual but which may or may not be supported by facts. For example: some women think that allopathic medicines, especially tablets, are very hot for the body. Some people think it is not good for a pregnant woman to go to a graveyard.

$\rightarrow$ Values: An opinion or standard that is important to an individual. Values are formed or influenced by religious, educational and cultural factors; they grow from our personal experiences. We display values, for example, in the way we greet each other, respect elders, obey parents, etc.

- Attitude: Our beliefs and values shape our points of view and attitudes that in turn shape our behavior. Attitude is what we think or intend to do. In other words it is our point of view about an issue or act. Our attitudes determine our behavior, what we actually do. So the attitude might be looked at as 'potential behavior.' Usually our attitude (our pre-existing point of view regarding a particular issue) is in accordance with our behavior. This is not always true and sometimes our behaviors are different from our attitude. This is called a gap between 
attitude and behavior. One example of this is in people's attitudes and behavior regarding cable/ satellite TV, etc.

- Therefore, there are different factors and reasons why people behave in particular ways. For example, a person from an urban society whose parents are well educated and economically sound will probably have received a quality education. His behavior will be different to that of a person with no education from a rural area.

- Upbringing, education, social circumstances, family situations, religion, etc., are important factors in the formation of our behavior.

\section{WHAT ARE THE THREE TYPES OF BEHAVIOR?}

\section{AggreSSIVE BEHAVIOR}

\section{Characteristics}

A person who behaves aggressively often displays one or more of these behaviors: is inappropriately honest, puts others down, ignores the rights of others, dominates, chooses for others, attacks and blames, overreacts in situations, uses loaded words, is sarcastic, loud, makes rigid demands and points his fingers at others.

\section{Reasons}

Aggressive behavior is adopted to express hostility and anger in order to achieve objectives (in the short run at least).

\section{Feelings about self}

A person who behaves aggressively has either high or low self-esteem. This person could be hostile, superior, righteous, alienated, defensive, frustrated, bitter or tense. 


\section{Feelings of others}

Other people can feel hurt, humiliated, defensive, vengeful and angry when a person engages in aggressive behavior.

\section{NON-ASSERTIVE (PASSIVE) BEHAVIOR}

\section{Characteristics}

A passive person usually lets others make decisions for him/ her and doesn't express feelings, ideas and wants. If in conflict, they may run away or give in easily. They use apologetic words and try to convey indirect messages hoping someone will guess what they want. They cry, plead, or hesitate.

\section{Reasons}

Such behavior is exhibited to avoid conflict and unpleasant, risky situations.

\section{Feelings about self}

Passive people have low self-confidence and self-esteem. They can appear hurt, helpless, anxious, powerless, possibly resentful and ultimately angry. They feel guilty and inhibited.

\section{Feelings of others}

When someone is being passive, the people interacting with him or her may feel guilty, angry, disrespectful, irritated, frustrated or superior. 


\section{Assertive behaVior}

\section{Characteristics}

An assertive person is appropriately honest and expresses wants and feelings directly. They are empathetic, spontaneous, able to make choices for themselves, exercise personal rights and respect the rights of others. They use objective words, make eye contact, listen, speak kindly and firmly and use ' $\mathrm{l}$ ' statements.

\section{Reasons}

A person exhibits assertive behavior to achieve objectives and to have positive feelings about him or herself.

\section{Feelings about self}

Such a person has self-respect, is confident and self-sufficient. He or she is powerful and relaxed.

\section{Feelings of other's}

Other people are respectful of an assertive person and feel respected by them. Occasionally some people feel threatened by assertive people.

Every individual has all of these behaviors but some exhibit a particular behavior in varying proportions in different circumstances. Positive and assertive behavior is the most desirable.

By understanding our own behavior, we can understand the behavior exhibited by other people around us. We can also analyze the reasons why someone behaves in a certain way. It is important to realize that the behavior of one person can affect the behavior of others. It is also important to realize we have the ability to modify and control our behavior. 


\section{QUOTES:}

$\checkmark$ Human beings are intrinsically good and friendly. (Carl Rogers)

$\checkmark$ Influence of the social environment and the culture forms the basis of human behavior. (Karen Horney)

$\checkmark$ Our behavior is affirmed by positive reinforcement. (B. F. Skinner)

$\checkmark$ The best way to find out what went wrong with wrong people is to study healthy people first. (Abraham Maslow)

$\checkmark$ Every person searches for a meaning to live, which gives a positive drive to Life. (Victor Frankl)

$\checkmark$ Often people expect stereotyped behavior.

$\checkmark$ People tend to behave like they are supposed to. 


\section{Training material 8.2:}

\section{Role-plays}

\section{Scenario for all three role-plays:}

A parent of a five-year-old boy goes to the head of a school to get admission for his/ her child. NOTE: In all three role-plays, the child does not get admission.

\section{Role-play 1}

The head of the school is rude and aggressive and says that the child is over age and that as the parent has come late for admission it is not possible to admit the child. In spite of the parent's pleas, the head is very rude and asks the parent to go away. In the end, the behavior of the parent becomes rude. The parent says: "When we don't educate our children people become angry with us; now when we are asking for admission it is denied."

\section{Role-play 2}

The head of the school is very passive and says she/ he cannot help the parent because it is not in her/ his hands. The government has set standards for the age and time of admission. In spite of the parent's pleas, the head of the school appears helpless. In the end, the parent of the child gets angry and says: "Then why are you sitting here when you cannot do anything?" 


\section{Role-play 3}

The head of the school is assertive and shows a positive attitude and tells the parent that the date of admission has passed and nothing can be done now. She realizes the problem of the parent but says there are government rules.

When the parent persists the head of the school is reassuring and says that the parent may give an application for the next session, which will start in six months' time, and the child might be admitted then.

REMINDER: Other role-plays can be developed showing client-provider interaction based on local situations. 


\section{Training material 9.1:}

\section{Power}

\section{DESCRIPTION OF POWER}

- Power is the ability to do something or have influence or control. Usually we think of power as physical strength but it has broader meaning and implications.

- Every living thing in this universe has been endowed with power no matter how minute.

- For human beings the power of the mind, of thinking and reasoning is the most unique and superior one.

\section{SOURCES OF POWER}

- In our daily life we draw power from different sources. For example, if someone is wealthy, his or her money might be a source of power for that person, giving them confidence.

- The same source of power could be positive or negative for different persons. So the exhibition of power drawn from a particular source may be negative for one person and positive for another. In the above example wealth or money can be used to help the poor and for charity. At the same time this source of power can be used to suppress other people.

\section{EXAMPLES Of SOME IMPORTANT SOURCES OF POWER:}

$\checkmark$ Physical strength

$\checkmark$ Knowledge or skill

$\checkmark$ Family background

$\checkmark$ Intelligence 
Beauty (physical appearance)

$\checkmark$ Love

$\checkmark$ Experience

$\checkmark$ Official status

$\checkmark$ Money

$\checkmark$ Criticism or discouragement

$\checkmark$ Education

$\checkmark$ Creativity

$\checkmark$ Health

$\checkmark$ Types of power

\section{TYPES OF POWER}

- There are four major types of power:

\section{Power over...}

This is the type of power that is used to repress others. We can imagine the typical picture of a boss sitting in his large chair with a stiff neck and a finger pointing at someone. We can easily see that person has power over others and shows it by shouting and ordering others about. Words like commanding, dictating, ordering are associated with having power over someone.

\section{Power to...}

This is the ability to transfer power from one person to another. For example, knowledge can be transferred from doctor to patient or from teacher to students. Transfer of knowledge and information leads to empowerment. Knowledge and information are sources of power and can be transferred. It is worth emphasizing that giving power to another person does not diminish the power of the giver. Power can be delegated to colleagues and subordinates in order for them to perform some work. Words 
like guiding, sharing, discussing, negotiating, helping and transferring are associated with giving power.

\section{Power with...}

This is the collective power of people united for a cause. For example, Pakistan was created by the collective power of Muslims. In many communities, people unite and use this type of power to construct a road or a well. When the power of more than one person is combined it is multiplied several times. This power has brought about revolutions (e.g., in France, Iran, Russia, China, etc.). Holding rallies, marches, etc., are another example of how people unite and use power to achieve their demands or goals.

This power can be used to achieve positive or negative purposes. Therefore it could be constructive or destructive.

\section{Power within....}

This is the inner power that we all possess; it may also be referred to be some as a spiritual power. It is possessed by all of us in varying proportion and it can be mobilized and utilized with effort and practice. Sometimes an incident provokes this power and one performs exceptionally well or does something extraordinary and unexpected. Some people feel challenged by difficulties and may decide to build a school or pass an exam and then work hard to achieve that objective. Inner power distinguishes human beings from other living things and it is because of it that humans landed on the moon, invented the airplane, conquered the highest mountains and made great scientific advances. Power within turns the impossible to possible.

\section{SYNTHESIS}

- Power comes in different forms and has different sources. Different people feel differently about a particular source of power. Hence power can be used positively or negatively. It is our intentions and goals that 
determine the correct use of power. One should try to think of any power source as positive and ultimately use power to, power with, and power within in a positive manner to improve ourselves and to empower those who are powerless. Those who are given power have an added responsibility to use it well to help others rather than to suppress and control them. 


\section{Training material 9.2: Change and power dynamics}

Nature always gives us a chance to change. Some of us do not understand the message, the call for change, and continue doing the same thing we have been doing. A few people are frightened by change because it disrupts the status quo; these people feel secure with the status quo and do not want to consider making changes. Some people see change as a threat to their current status and power so they resist change but do exhibit some change in their behavior in accordance with changing power dynamics. A few people really listen and understand when there is a call for change. These people look at change positively and strive to make the best use of the opportunity change brings to improve. Those individuals and nations that listen to the call for change and strive to respond to and utilize the positive aspects of change are the most successful. 


\section{Training material 10.1: Definitions of communication components}

\section{MOTIVATION}

Motivation is a one-way communication that helps influence the behavior of a person in a particular direction.

\section{COUNSELING}

Counseling is a process of face-to-face, two-way communication between a counselor and an individual or couple, or a counselor and a group. A counselor provides factual information and assists the individual, couple or group to make a decision about behavior change taking into account the feelings and concerns of the client.

\section{NEGOTIATION}

Negotiation is a two-way communication conducted in private; the two-way discussion and exchange of views with the client are designed to reach an agreement on how to solve a problem. While negotiating, it must be kept in mind that both provider and client are equally knowledgeable in their own ways (i.e., providers have technical information while clients possess information related to their specific circumstances/ conditions). 


\section{Training material 10.2: Introduction to the concept of SAHR}

\section{SAHR IS AN ACRONYM FOR SALUtATION, Ask/A Assess, HELP AND REAssurance}

SAHR is used to enable clients to meet their own needs. It can be put into action by using appropriate communication skills in an atmosphere of respect and cordiality influenced by the behavior of the provider.

\section{SALUTATION}

Salutation is about creating rapport with the client by using appropriate communication skills. The client must feel at ease and have confidence in the provider. Ensuring privacy, confidentiality and respecting client sensibilities are all part of salutation. Showing respect to any of the client's family members who might be present is also important. During salutation the providers should introduce themselves fully, and perhaps use some questions to help break the ice. For community workers, this means saying where you have come from and why you have come, asking permission to enter the home and inquiring whether it is a convenient time for the client. For static center workers, salutation includes asking the name of the client and where they are from.

\section{ASK/ASSESS}

This component deals with general observations of the client if the client comes to the center or of the household conditions if the provider visits the client's home. During the process, the client's reproductive health needs can be assessed through questions that are open-ended and asked one at a 
time. Ample time should be given to the client to fully explain her condition and the provider should listen patiently to what the client has to say. The provider should ask about the client's family situation and source of income, identify the decision-making source and past health record. If an examination is required, ask the client's permission and explain what is going on. After the examination the findings should be explained to the client and information sought on any other reproductive health needs. This also involves assessing the client's future intentions about reproductive health.

\section{HELP}

This part of the process involves discussing various ways of managing the client's needs, to provide the help they seek, while respecting their opinion. The solution must be negotiated and must be acceptable to the client. During the process of negotiations it is important to maintain an atmosphere of equality, avoiding judgmental remarks and laying of blame. Provide a wide range of options as a solution for the problem and let the client decide which one they would like. Try to ascertain who has the decision-making power in the household and volunteer to approach that person in order to help implement the solution. If need be refer the client to an appropriate facility where services are available. Inform the client about the distance, cost, mode of travel and necessary directions to reach the referred facility.

\section{REASSURE}

This stage aims to make the client feel they could visit the providers whenever necessary. It also ensures that the client is conversant with the solution that has been negotiated. If possible, ask the client to repeat the instructions. To alleviate the client's fears provide realistic reassurance that the chosen solution will serve their need. Also reassure him/ her that the chosen solution is not the only option and that if they are not satisfied they can always come again to explore another option. 
In the case of community worker and client interactions, the community worker could explain to the client that the worker will visit the client and, if the need arises, will accompany the client to the referred facility. 
Section III Training material

\section{Training material 10.3: Posters showing SAHR approach}

[See next two pages.] 


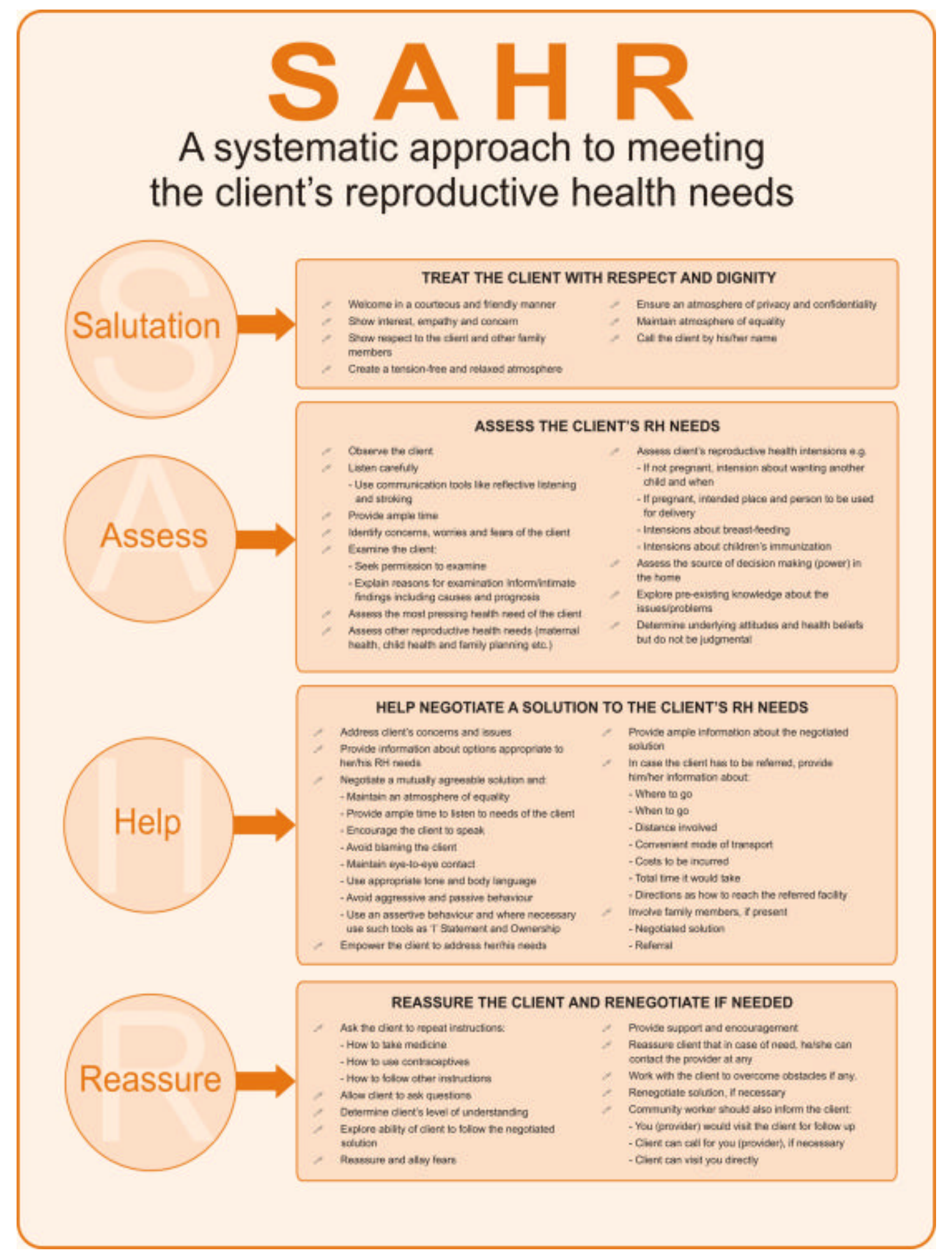




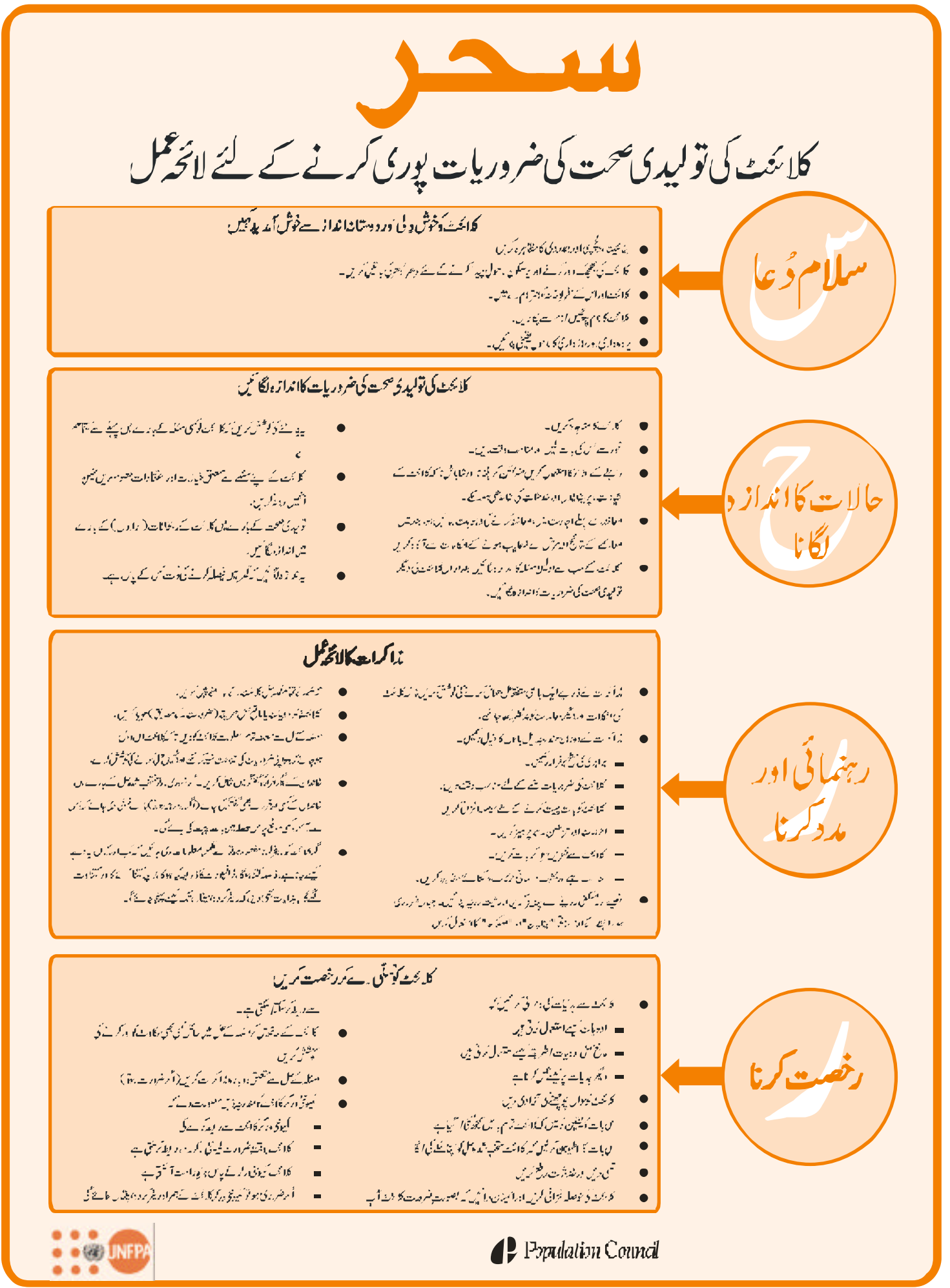




\section{Training material 10.4a: SAHR guidelines at work for static center workers}

\section{SALUTATION}

Treat the client with respect and dignity by following these procedures:

- Welcome client in a courteous and friendly manner.

- Create a tension free and relaxed atmosphere.

- Show interest, empathy and concern.

- Show respect to the client and other family members (if present).

- Ensure an atmosphere of privacy and confidentiality.

- Maintain an atmosphere of equality.

- Call the client by the client's name.

\section{ASSESS}

\section{Assess clients reproductive health needs by following these procedures:}

- Observe the client.

- Listen carefully and provide ample time.

- Use communication tools like reflective listening, stroking, ' $I$ ' statements and ownership (when useful).

- Ask appropriate questions (i.e., open-ended, indirect and nonsuggestive).

- Identify concerns, worries and fears of the client.

- Examine the client. 
$\rightarrow$ Seek permission from the client before conducting any examination of the client or accompanying child.

$\rightarrow$ Inform the client about the reasons for carrying out the examination.

$\rightarrow$ Inform the client of the results of the examination.

- Assess the most pressing reproductive health need(s) of the client.

- Assess other reproductive health needs of the client (e.g., maternal health, child health and family planning).

- Assess the reproductive health intentions of the client, for example:

$\rightarrow$ If not pregnant, intentions about wanting another child and when.

$\rightarrow$ If pregnant, intended place and person to be used for delivery.

$\rightarrow$ Intention about breastfeeding, immunization, etc.

- Assess the source of decision-making (power) in the home.

- Explore pre-existing knowledge about issues/problems.

- Determine underlying attitudes and health beliefs but do not be judgmental.

\section{HeLP}

\section{Help negotiate a solution to the reproductive health needs of the client by following these procedures:}

- Address client concerns or issues.

- Provide information about options appropriate to the client's reproductive health needs.

- Negotiate a mutually agreeable solution and:

$\rightarrow$ Maintain an atmosphere of equality.

$\rightarrow$ Provide ample time to listen to the needs of the client.

$\rightarrow$ Encourage the client to speak. 
$\rightarrow$ Avoid giving unsolicited advice.

$\rightarrow$ Avoid blaming the client.

$\rightarrow$ Maintain eye contact.

$\rightarrow$ Use an appropriate tone and body language.

$\rightarrow$ Avoid aggressive and passive behavior.

$\rightarrow$ Adopt assertive behavior.

$\rightarrow$ Use such communication tools as ownership and ' $\mathrm{l}$ ' statements when useful.

$\rightarrow$ Provide a wide range of options.

- Empower the client to address his/ her own needs.

- Provide method and medicine giving complete information about side effects, dose, etc.

- Provide ample information to the client about the negotiated solution.

- In case the client is to be referred, provide complete referral information, including the following:

$\rightarrow$ Where to go.

$\rightarrow$ When to go.

$\rightarrow$ Directions to referral facility.

$\rightarrow$ Distance involved.

$\rightarrow$ Convenient mode of transport.

$\rightarrow$ Total time trip will take.

$\rightarrow$ Cost to be incurred.

- Try to discuss the mutually agreed upon solution with other members of the client's family (if present and appropriate). 


\section{REASSURE}

Reassure the client and renegotiate, if needed, by following these procedures:

- Ask the client to repeat any instructions given, such as:

$\rightarrow$ How to take medicine.

$\rightarrow$ How to use contraceptive.

$\rightarrow$ How to follow other instructions.

- Allow client to ask questions.

- Determine client's level of understanding.

- Explore the ability of client to follow the negotiated solution.

- Reassure client and allay fears.

- Provide support and encouragement.

- Reassure the client that in case of need the client can contact the provider at any time.

- Work with the client to overcome obstacles.

- Renegotiate if necessary. 


\section{Training material $10.4 b$ : SAHR guidelines at work for community workers}

\section{SALUTATION}

Treat the client with respect and dignity by following these procedures:

- Introduce yourself.

- Seek permission to enter the home.

- Greet the client in a friendly manner.

- Greet any other family member present on the occasion.

- Show respect to the client and her family members.

- Ask the client if she is free at the moment and if it is convenient for her.

- Begin conversation by asking some ice-breaking questions.

- Ensure an atmosphere of privacy and confidentiality.

- Maintain an atmosphere of equality.

\section{ASSESS}

\section{Assess clients reproductive health needs by following these procedures:}

- Observe the general living conditions.

- Listen carefully and give ample time for interaction.

- Use the tools of communication (reflective listening and stroking), where needed.

- Use appropriate questions to assess the client's problem (i.e., open ended, indirect). 
- Identify concerns, worries and fears of the client.

- Examine the client (and/ or child, if needed), being sure to do the following:

$\rightarrow$ Seek permission to examine the client or her infant.

$\rightarrow$ Inform the client about the reasons for conducting the examination.

$\rightarrow$ Inform the client about the results of the examination.

- Assess the current and most pressing needs of the client.

- Assess other reproductive health needs of the client.

- Assess the reproductive health intentions of the client:

$\rightarrow$ If not pregnant, intention about wanting a/ another child and when.

$\rightarrow$ If pregnant, intended place for delivery.

$\rightarrow$ Intension about breastfeeding, immunization, etc.

- Assess the source of decision-making (power) in the home.

- Explore pre-existing knowledge about issues/ problems.

- Determine underlying attitudes and beliefs but not in a judgmental manner.

\section{HELP}

\section{Help negotiate a solution to the reproductive health needs of the client by following these procedures:}

- Try to negotiate with the client to find a solution to her problem.

- Provide sufficient information about options appropriate to her needs.

- Negotiate a mutually agreeable solution and:

$\rightarrow$ Maintain an atmosphere of equality.

$\rightarrow$ Provide ample time to listen to the needs of the client. 
$\rightarrow$ Encourage the client to speak.

$\rightarrow$ Ensure privacy and confidentiality.

$\rightarrow$ Avoid unsolicited advice.

$\rightarrow$ Avoid blaming the client.

$\rightarrow$ Maintain eye-to-eye contact.

$\rightarrow$ Use appropriate tone and body language.

$\rightarrow$ Avoid aggressive and passive behavior.

$\rightarrow$ Adopt assertive behavior and where necessary use communication tools such as ownership and ' $I$ ' statements.

$\rightarrow$ Provide a wide range of options.

- Empower the client to address the client's own needs.

- Provide the client with a method or medicine giving complete information about side effects, dose, etc.

- Provide ample information about the negotiated solution.

- Provide the following information in case the client has to be referred:

$\rightarrow$ Where to go.

$\rightarrow$ When to go.

$\rightarrow$ Distance involved.

$\rightarrow$ Convenient mode of transport.

$\rightarrow$ Cost to be incurred.

$\rightarrow$ Total time it would take.

$\rightarrow$ Directions to the referral facility.

- Try to discuss the mutually agreed upon solution with other members of the client's family (if present and appropriate). 


\section{REASSURE}

Reassure the client and renegotiate, if needed, by following these procedures:

- Ask the client to repeat the worker's instructions.

- Reassure and allay fears.

- Allow client to ask questions.

- Provide encouragement and support.

- Tell the client that in case of need the client could contact the worker at any time.

- Tell the client that the worker will be visiting her to inquire about her condition.

- Explain that if the client's condition does not improve, and it is necessary, the worker will accompany the client to the referral facility.

- Tell the client that other options can be discussed, if needed (renegotiate). 


\section{Training material 10.5a: Salutation and assess Case studies for static center workers}

\section{Scenario 1}

You are a service provider in a static center. A client called Zubaida comes to you. Zubaida is 20 years old with one child, a nine-month-old son. Zubaida tells you that her son has been suffering from a cough and fever for 5 days. He had had difficulty breathing since last night. Zubaida is four months pregnant.

\section{Questions:}

- How will you assess her current problem and its intensity?

- How will you assess her other reproductive health needs?

- How will you assess her family planning intentions?

\section{Scenario 2}

You are a service provider in a static center. A woman, Razia, comes to you. She has two daughters and one son; the son is eight months old. She has been taking oral pills for the last six months but is having some problems. She informs you that she has had irregular bleeding for 15 days and also feels that her weight has increased.

\section{Questions:}

- How will you assess her current problem and its intensity?

- How will you assess her reproductive health intentions and needs?

- How will you assess her other reproductive health needs? 


\section{Training material 10.5b: Salutation and assess Case studies for community workers}

\section{Scenario 1}

You are Naheed, a community health worker, and you visit Zubaida's house. Zubaida is 20 years old with one child, a nine-month-old son. Zubaida tells you that her child has suffered from a cough and fever for the last five days. He has had difficulty breathing since last night. Zubaida is four months pregnant.

\section{Questions:}

- How will you assess her current problem and its intensity?

- How will you assess her other reproductive health needs?

- How will you assess her family planning intentions?

\section{Scenario 2}

You are Tasleem, a community health worker, and today you go to Razia's house on a routine visit. Razia has two daughters and one son; the son is eight months old. She has been taking oral pills for the last six months but is having some problems. She informs you that she has had irregular bleeding for 15 days and also feels that her weight has increased.

\section{Questions:}

- How will you assess her current problem and its intensity?

- How will you assess her reproductive health intentions and needs?

- How will you assess her other reproductive health needs? 


\section{Training material $10.5 \mathrm{c}$ : Help and reassure Case studies for static center workers}

\section{Scenario 1}

You are a service provider in a static center. A woman, Zubaida, comes to you. Zubaida is 20 years old with one nine-month-old son. Zubaida tells you that her child has been suffering from a cough and fever for the last five days. He is having difficulty in breathing since last night. Zubaida is four months pregnant.

\section{On assessment you find the following:}

- The child has been suffering from a cough and fever for five days

- He is having difficulty in breathing since last night.

- The child is suffering from moderate pneumonia.

- The mother is not giving proper weaning food except milk and biscuits.

- The woman is four months pregnant.

- She wanted to wait three years before having another child therefore she is not happy with the present pregnancy.

- She has heartburn.

- She had TT injections during her last pregnancy.

- Previously she delivered at a Tehsil Headquarters Hospital.

- Now she wants her delivery to be conducted by the local dai [local midwife] because last time she did not receive proper care in the hospital.

- The child is not immunized at all.

\section{Question}

How will you help and reassure the client to enable her to meet her reproductive health needs? 


\section{Scenario 2}

You are service provider in a static clinic. A woman, Razia, comes to you. She has two daughters and one son; the son is eight months old. She has been taking oral pills for the last six months but is having some problems. She informs you that she has had irregular bleeding for the last 15 days and also feels that her weight has increased.

\section{On assessment you find the following:}

- Razia has had irregular bleeding for 15 days.

- Her weight has increased six kg in six months.

- She has been taking oral pills regularly and is satisfied with them.

- She has anemia.

- Razia and her family do not want more children.

- Her son is 8 months old and has received the BCG and 3 doses of DPT.

- She is still breastfeeding her child.

- She is not giving proper weaning food and her child is weak.

\section{Question:}

What help and reassurance can you provide Razia in enabling her to overcome her current problems? 


\section{Training material 10.5d: Help and reassure \\ Case studies for community workers}

\section{Scenario 1}

You are Naheed, a community health worker, and you visit Zubaida's house. Zubaida is 20 years old with one son who is 9 months old. Zubaida tells you that her child has been suffering from a cough and fever for five days. He is having difficulty in breathing since last night. Zubaida is four months pregnant.

\section{On assessment you find the following:}

- The child has been suffering from a cough and fever for five days

- He is having difficulty in breathing since last night.

- The child is suffering from moderate pneumonia.

- The mother is not giving proper weaning food except milk and biscuits.

- The woman is four months pregnant.

- She wanted to wait three years before having one more child and therefore she is not happy with the present pregnancy.

- She has heartburn.

- She had TT injection during her last pregnancy.

- Previously she delivered at a Tehsil Headquarters Hospital.

- Now she wants her delivery to be conducted by a local dai (local midwife) because last time she did not receive proper care in the hospital.

- The child is not immunized at all.

\section{Question:}

How will you help and reassure the client to enable her to meet her reproductive health needs? 


\section{Scenario 2}

You are Tasleem, a community health worker and today you go to Razia's house on a routine visit. Razia has two daughters and one son; the son is eight months old. She has been taking oral pills for the last six months but is having some problems. She informs you that she has had irregular bleeding for 15 days and also feels that her weight has increased.

\section{On assessment you find the following:}

- Razia has had irregular bleeding for 15 days.

- Her weight has increased six kg in six months.

- She has been taking oral pills regularly and is satisfied with this method.

- She has anemia.

- Razia and her family do not want more children.

- Her son is 8 months old and has received the BCG and 3 doses of DPT.

- She is still breastfeeding her child.

- She is not giving proper weaning food and her child is weak.

\section{Question:}

What help and reassurance can you provide Razia in enabling her to overcome her current problems? 


\section{Training material 10.6a: Salutation and assess Role-plays for static center workers}

\section{Scenario 1}

\section{Instructions for the client:}

You are Rubina, a 27-year-old married woman. You have three sons. Your mother-in-law wants you to have a girl but you want to wait 4 years before having any more children. Your youngest child is six month sold and has been suffering diarrhea for the last three days. He is passing 7-8 stools per day. You are giving your child breast milk and have given him a homemade ORS (boiled water with one handful of sugar and a pinch of salt) but have not given him any medicine.

You missed the last dose of immunization of your child, which was due two months ago.

You have a redness of the eye for the last four days. You visit the health facility of your village.

\section{Instructions for the service provider:}

You are a service provider in a static clinic. Today during clinic hours a client, Rubina, visits you along with her child and her mother-in-law. 


\section{Scenario 2}

\section{Instructions for the client:}

You are Shazia, a 23-year-old married woman. You have two daughters and one son. Your youngest son is seven months old. You had an IUCD inserted two months ago; since then you have had intermittent moderate bleeding. You are very worried. You feel tired and have pain in the lower abdomen. Your son has not been immunized.

Today you visit the health facility of your village or town.

\section{Instructions for the service provider:}

You are a service provider in a static clinic. Today during clinic hours, a client, Shazia, comes to visit you. Shazia is 23 years old and is married. She has two daughters and one son. Her youngest child, a boy, is seven months old.

She is a current IUCD user. 


\section{Training material $10.6 \mathrm{~b}$ : Salutation and assess Role-plays for community workers}

\section{Scenario 1}

\section{Instructions for client:}

You are Rubina, a 27-year-old married woman. You have three sons. Your mother-in-law wants you to have a girl but you want to wait four years before having any more children. Your youngest child is six months old and has had diarrhea for the last three days. He is passing stools seven to eight times per day. You are giving your child breast milk and have given him homemade ORS (boiled water with one handful of sugar and a pinch of salt) but have not given him any medicine.

You missed the last dose of immunization of your child, which was two months ago.

You have a redness of the eye for the last four days.

Today the community health worker for your village visits you.

\section{Instructions for the service provider:}

You are Samina, the community health worker. Today on your routine visit, you go to Rubina's house. Rubina is a 27-year-old married woman living with her mother-in- law. Rubina has three sons. 


\section{Scenario 2}

\section{Instructions for the client:}

You are Shazia, a 23-year-old married woman with two daughters and one son. Your youngest son is seven months old. You had an IUCD inserted two months ago; since then you have had intermittent moderate bleeding. You are very worried. You feel tired and have pain in the lower abdomen. Your son has not been immunized.

Today Nasreen, the community health worker, visits you.

\section{Instructions for the service provider:}

You are Nasreen, a community health worker. Today you visit Shazia at her home. She is 23 and married. She has two daughters and one son. Her youngest child, a boy, is seven months old. She is a current IUCD user. 


\section{Training material $10.6 \mathrm{c}$ : Help and reassure Role-plays for static center workers}

\section{Scenario 1}

Instructions for the service provider:

You are a service provider in a static clinic. Today during clinic hours a client, Rubina, visits you along with her child and mother-in-law.

\section{Findings of the assessment:}

- Rubina is 27 years old and married.

- She has three sons and the youngest child is six months old.

- Has missed the last $\left(3^{\text {rd }}\right)$ dose of immunization- date was two months ago.

- Child has had diarrhea (loose motions) for three days (7 - 8 times a day).

- Mother-in-law wants a girl child without any spacing.

- Rubina has had an eye problem for four days.

\section{Question:}

How will you help and reassure Rubina to meet her reproductive health needs? 


\section{Scenario 2}

\section{Instructions for the service provider:}

You are a service provider in a static clinic. Today during clinic hours a client, Shazia, visits you. Shazia is 23 years old and married with two daughters and one son. Her youngest child, a boy, is seven months old.

\section{Findings of the assessment:}

- Shazia is 23 years old and married.

- She has two daughters and one son.

- Her youngest son is seven months old.

- Her child is not immunized at all.

- Shazia wants four children; she wants one more son.

- Wants spacing of four years.

- Family planning- had IUCD inserted two months ago, since then having intermittent bleeding.

- She is breastfeeding her child but has not started proper weaning.

- Client is anemic.

\section{Question:}

How will you help and reassure Shazia to meet her reproductive health needs? 


\section{Training material 10.6d: Help and reassure Role-plays for community workers}

\section{Scenario 1}

Instructions for the service provider:

You are Samina, a community health worker. Today on your routine visit, you go to Rubina's house. Rubina is a 27 -year-old married woman living with her mother in law. Rubina has three sons.

\section{Findings of the assessment:}

- Rubina is 27 years old and married.

- She has three sons; the youngest child is 6 months old.

- Has missed last $\left(3^{\text {rd }}\right)$ dose of immunization - date was two months ago.

- Child has diarrhea (loose motions) for three days (7 - 8 times a day).

- Mother-in-law wants a girl child without any spacing but Rubina wants spacing of four years.

- Rubina has had an eye problem for four days.

\section{Question:}

How will you help and reassure Rubia meet her reproductive health needs? 


\section{Scenario 2}

Instructions for the service provider:

You are Nasreen, a community health worker. Today you visit Shazia at her home. Shazia is a 23-year-old married woman with two daughters and one son. Her youngest child, a boy, is seven months old. She is a current IUCD user.

\section{Findings of the assessment:}

- Shazia is 23 years old and married.

- She has two daughters and one son.

- Her youngest child, the boy, is seven months old.

- Her child is not immunized at all.

- Shazia wants four children (one more child).

- Wants spacing of four years.

- Family planning - had IUCD inserted two months ago, since then she has had intermittent bleeding.

- She is breastfeeding her child but has not started proper weaning.

- Client is anemic.

\section{Question:}

How will you help and reassure Shazia to meet her reproductive health needs? 


\section{Training material 10.7: Assessment sheet}

\begin{tabular}{l|l}
\hline Strengths & Weaknesses \\
\hline & \\
& \\
& \\
\hline
\end{tabular}




\section{Training material 10.8: Alternative presentation}

\section{THIS ROLE-PLAY IS TO BE PRESENTED IF THERE IS NO VIDEO AVAILABLE (OR IF THE EQUIPMENT YOU HAVE FOR SHOWING THE VIDEO IS NOT WORKING).}

\section{TRAINER'S NOTE}

- You and a co-trainer will need to prepare for this role-play in advance.

- Choose the scenario that is appropriate for the participants (static center staff or community workers).

- The scenarios presented here are the same as those you presented earlier in module 7 (TM 7.6). However, in this presentation make the interaction between the provider and the client the best you can, following the SAHR guidelines. Remember that it still won't be perfect and participants may yet notice things that could be improved. That is to be expected and means that they have understood the concepts. To improve on the last performance you would do things like introduce yourself and greet the client by name, greet or ask about other family members, ask about Zubaida's pregnancy, find out what she plans to do about the delivery, find out in what way she isn't feeling well, ask if she would be interested in information on birth control after the birth of the next child, either allay her fears or tell her what to do if her son's problem persists, ask if her children have been immunized, etc. Any other actions that would lead Zubaida to not feel supported in this interaction would be acceptable, such as being kind, patient and attentive to what Zubaida says. "Zubaida" should feel free to respond to questions or express her fear, frustrations, etc., as the situation demands. The two scenarios follow: 


\section{Scenario for Static Center Staff}

\section{Players:}

1) Tasleem, a service provider in a static center

2) Zubaida, the client, is 30 years old and has three children, one daughter and two sons; the youngest child is a son who is four months old

When the role-play begins Zubaida has come to the static center and is being seen by the service provider. The provider has not seen Zubaida before this visit.

Zubaida tells the provider that her youngest son has chronic diarrhea and is not doing well; she is very worried. Zubaida also mentions that she has just learned that she is probably pregnant and does not feel well herself. Zubaida's brother has accompanied her to the clinic but is not present in the examination room.

\section{Scenario for Community Workers}

\section{Players:}

Tasleem, is a community health worker

2) Zubaida, the client, is 30 years old and has three children, one daughter and two sons; the youngest child is a son who is four months old

When the role-play begins Tasleem has come to Zubaida's home. This is Tasleem's second visit to see Zubaida; the first visit was right after the birth of Zubaida's last child.

Zubaida tells the provider that her youngest son has chronic diarrhea and is not doing well; she is very worried. Zubaida also mentions that she believes that she might be pregnant again and did want another child so soon. Zubaida's mother and aunt are in the house but are not present while Tasleem is talking to Zubaida. 
Training material 11:

\section{New dimension of referral system}

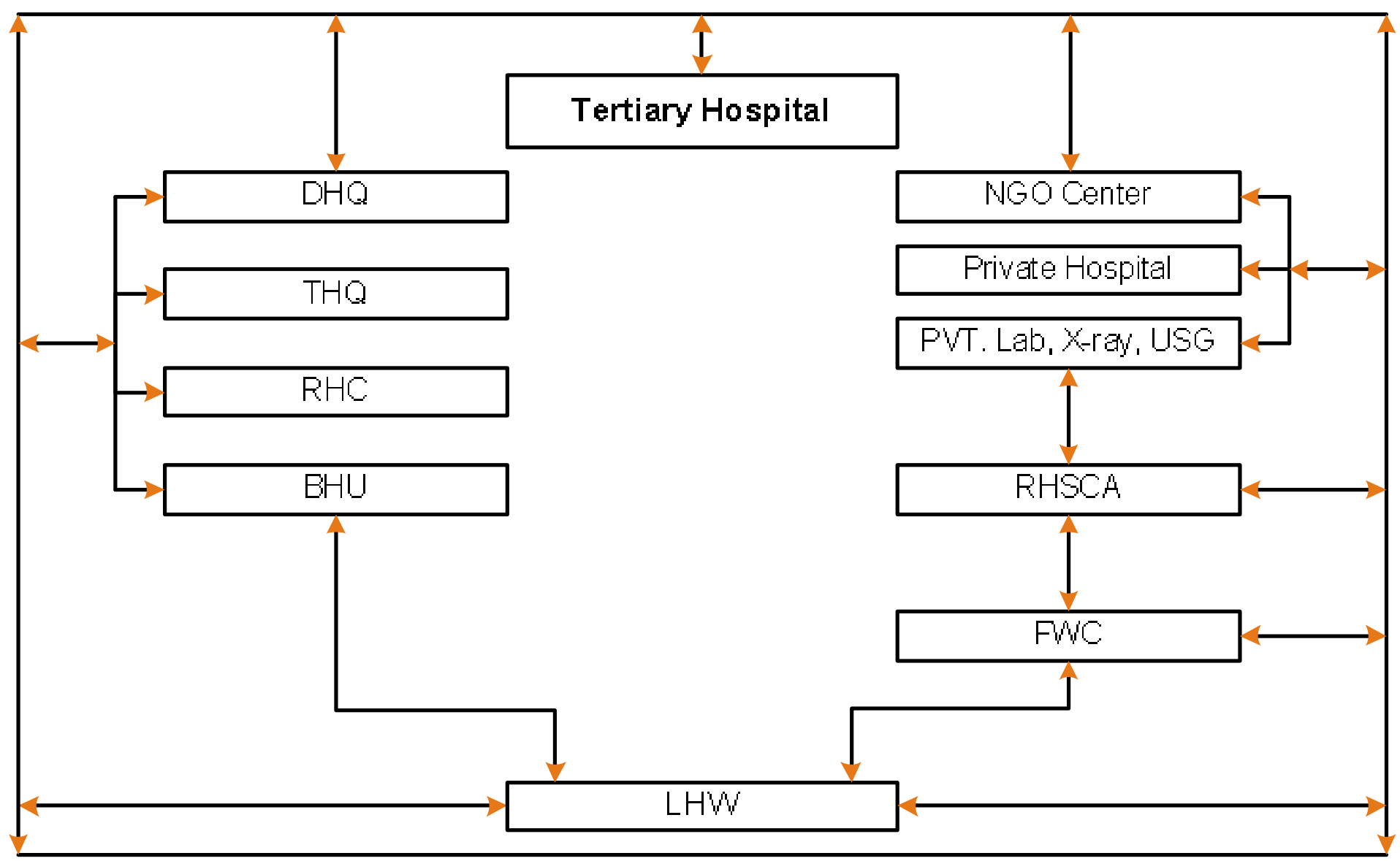




\section{Training material 12:}

\section{Perception of change}

Change is defined as a shift from one status to another. Change can be positive and constructive or negative and destructive/ catastrophic. There are many types of change (e.g., change of weather, residence, status, health, job, governments, designation, landscape, economy, behavior, etc.).

There are many factors that are responsible for the initiation of change. These could be necessity, pressure, obligation, competition, jealousy, boredom, fun, adventure, prize, incentive, atrocity, hate, love, etc. At the same time there are factors or barriers that prevent people from changing. There are those who prefer the status quo over change because of factors such as insecurity, ignorance and illiteracy, fear, hardship, challenges, ego, etc.

Sometimes change is transient and other times it may be long lasting. All people have the power to change their lives for the better. Ultimately, any lasting positive change and life-skill development must come from within - it cannot be forced upon or granted to an individual from the outside. Still, while the real work of change must be completed by each individual, research demonstrates that the likelihood of success can be enhanced through support, structure and guidance.

So for a change to happen, it must be positive and realistic. It should be needed and shared by the people. It cannot be forced upon individuals. One has to have a faith in the goodness of change from within.

The sustainability of any positive change is the ultimate goal of the process. A change is sustainable when it reveals its positive impact. Sustaining change 
requires will-power, continuous struggle (persuasiveness) and above all, a continuous desire for change.

\section{Quotes:}

- Tell you the truth, if you have faith as small as a mustard seed, you can say to this mountain, "Move from here to there" and it will move. Nothing will be impossible to you. (J esus [Matthew, 17:20b-21, NIV])

- What we see depends mainly on what we look for. (J ohn Lubbock)

- It takes a lot of courage to release the familiar and seemingly secure, to embrace the new. But there is no real security in what is no longer meaningful. There is more security in the adventurous and exciting, for in movement there is life, and in change there is power. (Alan Cohen)

- They say that time changes things, but you actually have to change them yourself. (Andy Warhol)

- Some men see things the way they are and ask, "Why?" I dream things that never were, and ask, "Why not?" (George Bernard Shaw)

- If the shoe doesn't fit, must we change the foot? (Gloria Steinem) 


\section{Training material 13.1a: Broken squares game: preparation}

\section{HOW TO PREPARE THE GAME}

Do all of the following steps for each game needed; you need one game for each group of six players:

1. Make five squares of 6 by 6 inches from cardboard. Cut each square into three pieces (see the example on the next page). Important: keep the three pieces of each square together at this stage! Mark each of the three pieces of each square alphabetically (as shown in the example; note that you should alphabetize the pieces of the squares differently, as shown).

2. Take five big envelopes and mark them $a, b, c, d$, and e. Put each piece, from all five squares into the envelope marked with the letter corresponding to the one on the piece of the square (e.g., all pieces marked "a" go into the envelope marked "a" and so on; note that there will not be an even number of pieces for each letter).

3. Make a copy of the page of instructions for the game and for the players (TM 13.2) and a copy of the instructions for the rapporteur (TM 13.3). Put the copies of each page in separate smaller envelopes and write on the outside what instructions are inside.

4. Put all five big envelopes, which contain the alphabetized pieces of the squares, and the two smaller envelopes containing the instructions for the players and the rapporteur, into one large envelope. One of the large envelopes you have prepared will be given to each group.

5. Write on newsprint the instructions for the game and for the players (TM 13.2); only do this once, as this will be posted for all groups to see. 

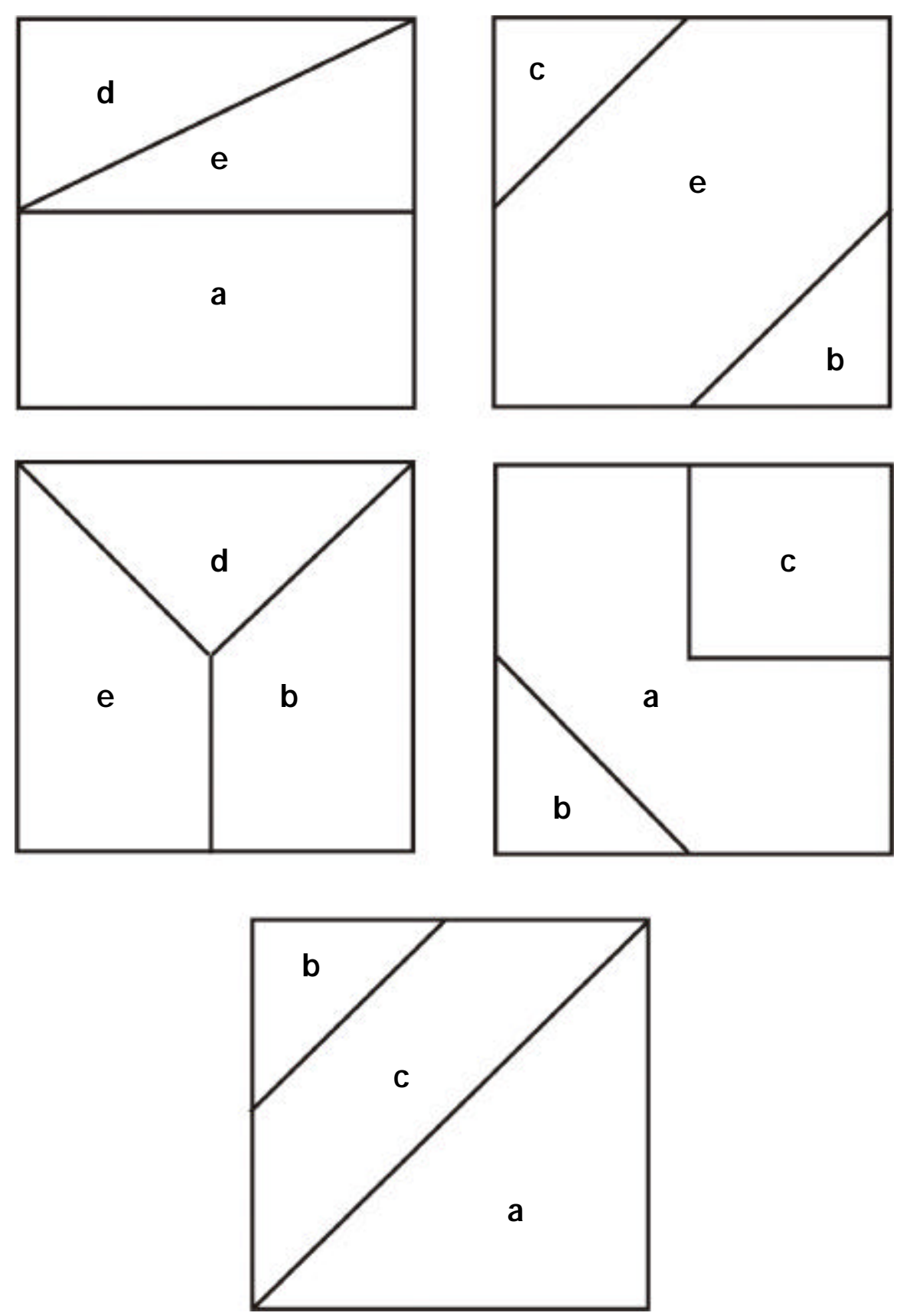


\section{Training material $13.1 \mathrm{~b}$ :}

\section{Broken squares game: Instructions for game and players}

\section{INSTRUCTIONS FOR GAME}

Each of the five big envelopes contains pieces of cardboard to be used to form squares. The task of each group is to form five squares of equal size. You must do this while following all of the instructions for players. The task will not be completed until each individual has before them a perfect square of the same size as that held by others.

\section{INSTRUCTION FOR PLAYERS}

The following specific limitations are imposed upon your group during this game:

- Talking, pointing or making any gesture for a card is not permissible

- You can give away cards to any member you wish but you are not permitted to throw the cards in the center.

- You may give away all of your cards to other members if you so desire, but you are not permitted to take cards from them. You may only take a card that has been offered to you 


\section{Training material 13.1c:}

\section{Broken squares game: Instructions for rapporteur}

\section{INSTRUCTIONS FOR RAPPORTEUR}

Your job is part observer but also part policeman to make sure participants follow the rules. Your two responsibilities are described below:

In your role as policeman it is your duty to see that:

- Members do not communicate at all either by talking or signaling.

- Members may give pieces to others but are not allowed to take pieces unless they are being offered.

- Members may not throw pieces in the center.

- Members may give away all of their pieces to other members even after they have formed the square.

In your role as rapporteur it is your duty to note:

- Which member is willing to give away the pieces.

- Any member who detaches him/ herself from the struggle of the rest of the group after completing the puzzle.

- Any member who continually struggles with the pieces yet is unwilling to give away any or all of the pieces to others.

- How many people are mentally engaged in putting the pieces together.

- The level of frustration/ anxiety in the group (check periodically).

- The critical point when the group starts to cooperate.

- Any violations of either talking or pointing as a means of helping others. 


\section{Training material 13.2: Factors involved in team building}

- Showing appreciation

- Providing training; helping to improve colleagues' knowledge/ skills

- Being empathetic; listening to problems and providing feedback

- Being unbiased

- Showing respect

- Sharing responsibility; giving responsibility/ importance

- Being sensitive to the feelings of others

- Not humiliating anyone because this develops antagonism

- Developing trust: acting sincerely and sharing information

- Making personal sacrifices to assist subordinates in a crisis

- Being a role model

- Creating a friendly atmosphere

- Involving subordinates in decision-making

- Giving equal/impartial treatment

- Giving freedom to work

- Giving praise and encouragement

- Making sacrifices to help

- Giving chance to improve (attitude should not be condemning)

- Providing counseling 


\section{Training material $\mathbf{1 4 . 1}$ Training evaluation form}

\begin{tabular}{|c|c|c|c|c|c|c|}
\hline \multicolumn{2}{|l|}{ CRITERIA } & \multicolumn{5}{|c|}{ RATING } \\
\hline & & POOR 1 & FAIR 2 & GOOD 3 & $\begin{array}{l}\text { VERY } \\
\text { GOOD } 4\end{array}$ & $\begin{array}{l}\text { EXCELLENT } \\
5\end{array}$ \\
\hline \multirow[t]{4}{*}{ OBJ ECTIVE } & Clarity & & & & & \\
\hline & $\begin{array}{l}\text { Appropriateness for } \\
\text { participants }\end{array}$ & & & & & \\
\hline & $\begin{array}{l}\text { Opportunity for application of } \\
\text { things you learned }\end{array}$ & & & & & \\
\hline & Attainment of objectives & & & & & \\
\hline \multirow[t]{5}{*}{ ORGANIZATION } & $\begin{array}{l}\text { Relevance/ Usefulness of } \\
\text { training content }\end{array}$ & & & & & \\
\hline & Coverage/ scope of modules & & & & & \\
\hline & Methods of presentation & & & & & \\
\hline & $\begin{array}{l}\text { Adequacy of time allotted to } \\
\text { modules }\end{array}$ & & & & & \\
\hline & Visual aids & & & & & \\
\hline \multirow[t]{3}{*}{ FACILITIES } & Rooms & & & & & \\
\hline & Session hall & & & & & \\
\hline & Food & & & & & \\
\hline $\begin{array}{l}\text { TRAINING } \\
\text { STAFF }\end{array}$ & $\begin{array}{l}\text { Responsiveness to participants } \\
\text { needs }\end{array}$ & & & & & \\
\hline $\begin{array}{l}\text { TRAINERS/ CO- } \\
\text { TRAINERS }\end{array}$ & (list any specifics below) & & & & & \\
\hline \multirow[t]{4}{*}{ Competence } & 1. & & & & & \\
\hline & 2. & & & & & \\
\hline & 3. & & & & & \\
\hline & 4. & & & & & \\
\hline \multirow[t]{4}{*}{ Effectiveness } & 1. & & & & & \\
\hline & 2. & & & & & \\
\hline & 3. & & & & & \\
\hline & 4. & & & & & \\
\hline \multirow[t]{4}{*}{ Attitude } & 1. & & & & & \\
\hline & 2. & & & & & \\
\hline & 3. & & & & & \\
\hline & 4. & & & & & \\
\hline
\end{tabular}


1) List the three most important things you learned in this course.

2) What did you like best about the training?

3) What did you like least about the training?

4) Given the limits of time, what recommendations could you give to improve this training?

5) List three words that best describe your feelings about the training, 


\section{Training material 14.2a: Poem (in Urdu)}

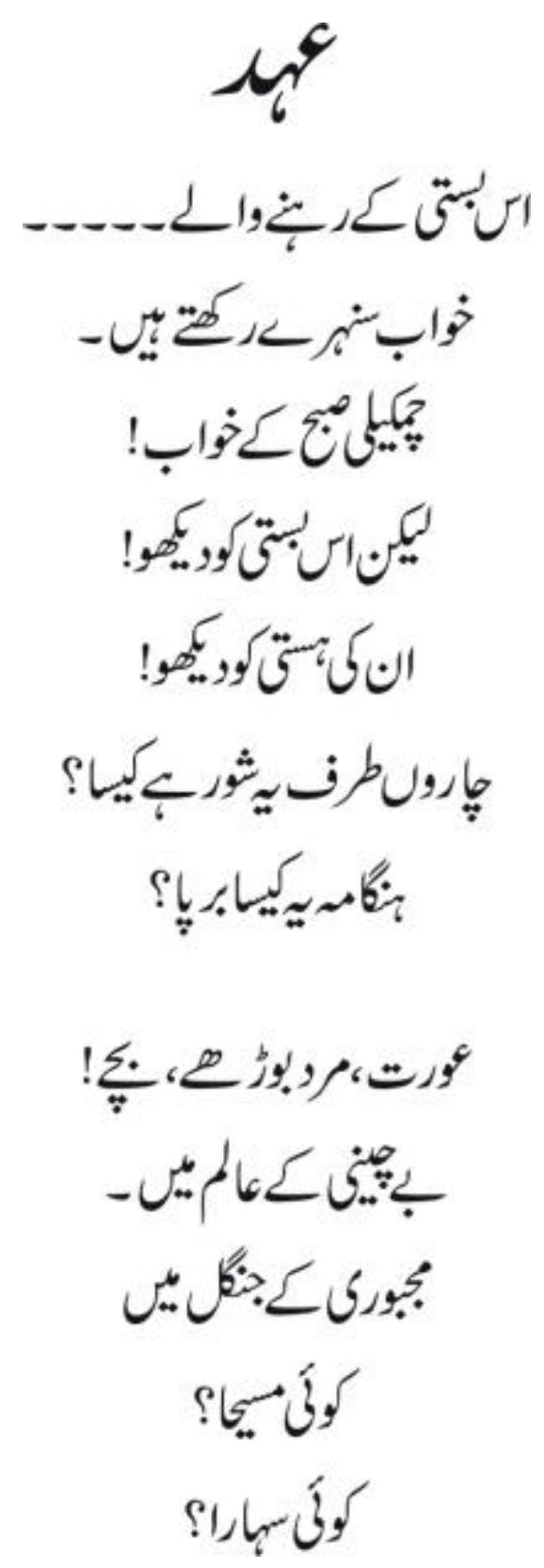




$$
\begin{aligned}
& \text { الكوآكرقام ــتوروات }
\end{aligned}
$$

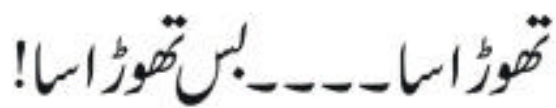

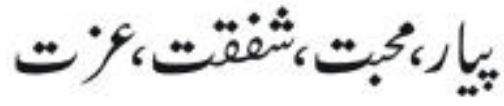

$$
\begin{aligned}
& \text { آكرانيلبانطو تقورًا- }
\end{aligned}
$$

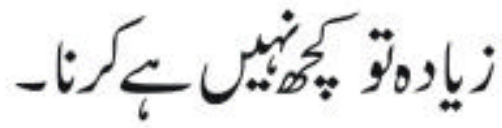

$$
\begin{aligned}
& \text { انسانكوبـ-_انسانكنا }
\end{aligned}
$$

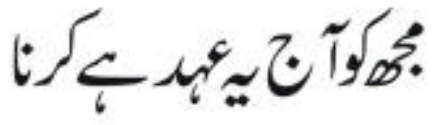

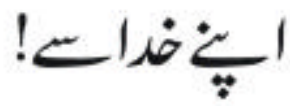

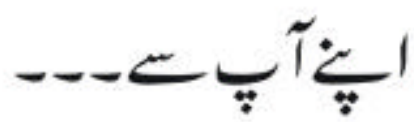

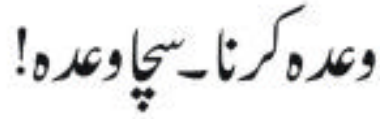

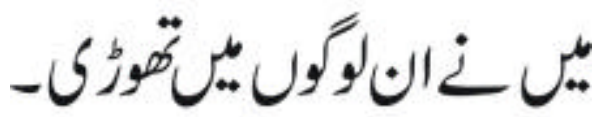

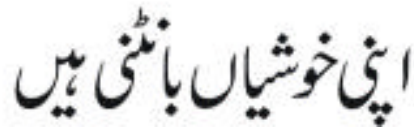




$$
\begin{aligned}
& \text { انكوة مكراسجنكل } \\
& \text { بتنتكسل اجاناب } \\
& \text { ير شثوركابيحرق }
\end{aligned}
$$

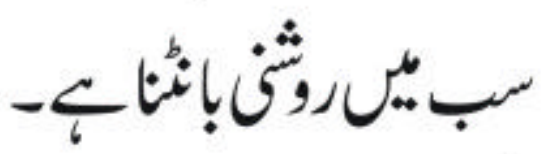

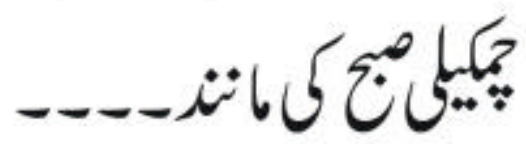

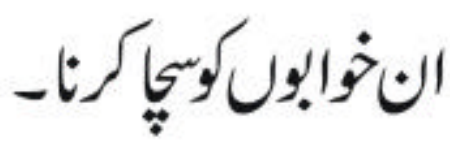

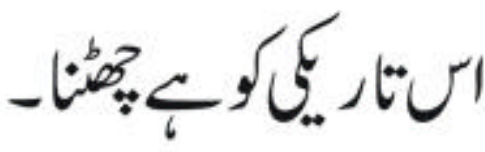

$$
\begin{aligned}
& \text { ثيرائبدب- ميراوعده- } \\
& \text { اسبتق كاندردينا، }
\end{aligned}
$$

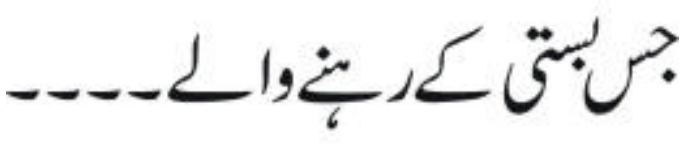

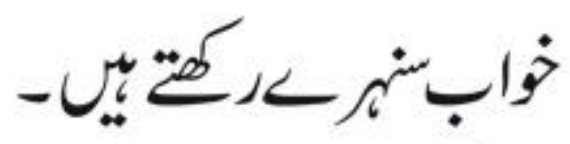

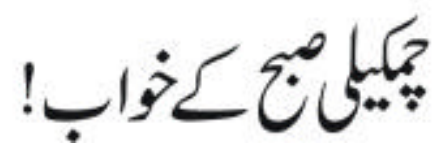




\title{
Training material 14.2b: Poem (in English) A Pledge
}

\author{
People of this land \\ Cherish beautiful dreams \\ Dreams of a bright morning! \\ But...... \\ Look at their fate... \\ Look at their faces... \\ Do you listen to the cries? \\ Men and Women, \\ Old and young... \\ In agony ... helpless \\ Waiting for a J esus? \\ Waiting for a helping hand? \\ Lest they don't fall \\ J ust a little helping hand \\ Someone to give..... \\ Only a tiny bit of ...... \\ Love, affection, care and respect..... \\ Nothing else.... \\ But their recognition as a 'Human being' \\ It's time for me to pledge... \\ To God Almighty \\ To myself \\ It's my promise...a sincere promise \\ From my happiness... \\ I will deliver happiness to them
}


I will have to take them...

From this valley of sorrow

To the land of peace and happiness

The light of wisdom and knowledge...

Demands me to distribute this light to others

This light is like a bright morning ...dawn

We have to make these dreams come true

Darkness is to vanish

Brightness is to prevail

It's my pledge...my promise

To live in the motherland...with my people

People who are oppressed and helpless

But they cherish beautiful dreams

Dreams of a bright morning

A fresh 'Dawn' 


\section{Training materials:}

\section{Games/Energizers/Exercises}

The following are suggestions for you to use after Module 7 and Module 9 or whenever you feel they would be useful for participants.

NOTE: for an excellent source of additional warm-ups/ energizers/ice breakers, check on the web at:

www. reproline.jhu. edu/ english/5tools/5icebreak/ icebreak3. htm and www. reproline. jhu. edu/ english/5tools/ 5icebreak/ icebreak2. htm.

The first energizer shown below is a slightly modified version of one from this source.

\section{BOOM!}

All participants should sit in a circle. They are instructed to count out loud around the circle. Each person whose number is a multiple of 3 (3-6-912 , etc.) must say BOOM instead of the number. The next person continues the normal sequence of numbers.

Example: The first person starts with 1 , the next one says 2 , and the person who should say 3 says BOOM instead, and the next person says 4 .

Anyone who fails to say BOOM or who makes a mistake with the number that follows BOOM is disqualified.

The numbers must be said rapidly (5 seconds maximum); if a participant takes too long to say her/ his number, s/ he is disqualified.

The last two participants left are the winners.

Note: You can have the participants clap their hands once instead of saying BOOM. You may also make this energizer more interesting by having the participants count backwards toward zero once they have reached 30. 


\section{CONNECT THE DOTS}

Draw nine dots on the newsprint or writing board, as shown below:

Ask the participants to copy the dots into their notebooks. Then ask them to join all nine dots using four straight lines without lifting their pen from the page.

Give them 3-5 minutes.

If anyone has achieved the objective, ask that person(s) to go to the board and show the others how they accomplished the task.

Solution: to complete the task, the lines must be drawn beyond the dots, as shown below:

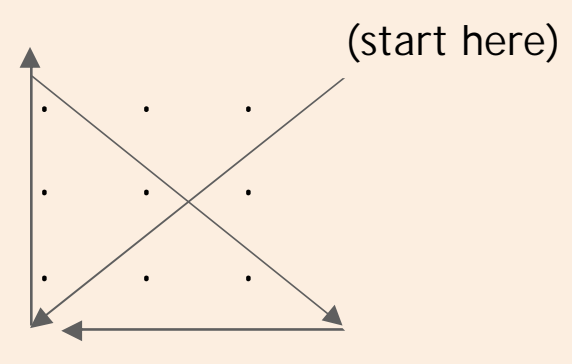

At the conclusion of the exercise, explain to the trainees that sometimes, even while following the rules, it is possible to use innovative measures to achieve your objective. Too often, we restrict ourselves within the system and within the boundaries that are either imposed or that we perceive to exist. It is a useful skill to learn to look at a situation or problem and to see the bigger picture, that is, to be able to "think outside of the box." By being able to free ourselves from the constraints of imposed or perceived restrictions/ rules, we can see new solutions to problems. 

The Population Council, an international, nonprofit, nongovernmental organization established in 1952, seeks to improve the well-being and reproductive health of current and future generations around the world and to help achieve a humane, equitable, and sustainable balance between people and resources.

The Council analyzes population issues and trends; conducts research in the reproductive sciences; develops new contraceptives; works with public and private agencies to improve the quality and outreach of family planning and reproductive health services; helps governments design and implement effective population policies; communicates the results of research in the population field to diverse audiences; and helps strengthen professional resources in developing countries through collaborative research and programs, technical exchanges, awards, and fellowships.

\section{Population Council}

\#7, St. 62, F-6/3

Islamabad, Pakistan

Ph: (92-51) 2277439

Fax: (92-51) 282140

Email: info@pcpak.org 